NBER WORKING PAPER SERIES

\title{
SOCIAL SECURITY AND RETIREMENT \\ IN ITALY
}

Agar Brugiavini

Working Paper 6155

http://www.nber.org/papers/w6155

\section{NATIONAL BUREAU OF ECONOMIC RESEARCH 1050 Massachusetts Avenue \\ Cambridge, MA 02138}

September 1997

This paper is part of the NBER Project on International Social Security Comparisons. I am in debt to Jonathan Gruber, David Wise and to the participants in the International Social Security Comparisons Project for their helpful comments. Thanks are due to Maria Cozzolino and Massimo Rostagno for many useful insights on the Italian SS system and to Luana Gava, Roberta Marcolin and Franco Mariuzzo for patiently setting up the data. I am grateful to the I.N.P.S. Administration and the Bank of Italy for providing me with individual level data and the C.N.R. for financial support (through grant number 96.01418.CT10). The usual disclaimer applies. This paper is part of NBER's research programs in Aging and Public Economics. Any opinions expressed are those of the author and not those of the National Bureau of Economic Research.

(C) 1997 by Agar Brugiavini. All rights reserved. Short sections of text, not to exceed two paragraphs, may be quoted without explicit permission provided that full credit, including $\odot$ notice, is given to the source. 
Social Security and Retirement in Italy

Agar Brugiavini

NBER Working Paper No. 6155

September 1997

Aging and Public Economics

\begin{abstract}
This paper analyzes the incentives provided by the Italian Social Security System (SS) to supply labor. Italy is an interesting example in this context as: (1) fertility rates are very low while life expectancy has improved dramatically over the past decades; (2) the SS Program is extremely generous to retirees by providing very high replacement rates; (3) virtually all retirement income is in the form of SS benefits; (4) the existence of an early retirement provision, which attracts no actuarial penalty, greatly distorts choices in favor of early retirement.

This paper addresses the above issue by first documenting the stylized facts of the labor market and the SS provisions. A simulation model is then developed to better understand the incentive effects of SS on current cohorts of retirees. This model proposes two measures for incentives: the accrual rate (i.e. the percentage change in Social Security Wealth) from postponing retirement and the implicit tax/subsidy (via SS entitlements) on potential earnings from working an additional year. The simulation results show that the Italian SS Program provides a strong incentive to retire early and the age-implicit tax profile fits very closely with the estimated hazards out of the labor force. Additional evidence of the existence of behavioral responses to SS policy changes lends further support to the view that old age insurance arrangements have an influence on labor supply decisions.
\end{abstract}

\title{
Agar Brugiavini \\ Department of Economics \\ University of Venice \\ 30124 Venice
}

ITALY

brugiavi@unive.it 


\section{Introduction.}

Italy is now experiencing one of the lowest fertility rates among developed countries while life expectancy has improved dramatically over the past few years ${ }^{1}$. This aging process is partly counterbalanced by a significant increase in the size and frequency of immigration flows into the country. However, even the most optimistic scenarios suggest that this inflow will not be enough to revert the demographic pattern shown by the data. In particular, Figures 1, 2 and 3 show a dramatic increase in the share of older people and in the dependency ratio over past decades ${ }^{2}$. Furthermore, the positive effects of the baby-boom generation were already fading by 1984 and the ratio of old people and very young people to the working age population stayed roughly constant after that year (Figure 3). Demographic projections suggest that by year 2030 each adult individual will support 0.4 elderly individuals and this rate may increase to 0.56 by 2050 (Figure 4$)^{3}$.

This demographic trend is coupled with a sizeable SS Program. In 1995 approximately $17 \%$ of GDP was devoted to old-age and other public assistance outlays ${ }^{4}$. Estimates of the size of the SS Administration liabilities for the payment of future benefit rights in terms of net SS wealth amount to $300 \%$ of GDP in $1993^{5}$. From the point of view of households this corresponds to a large share of their assets being in the form of Social Security wealth: estimates based on micro data suggest that, on average, SS wealth holdings are as large as private wealth holdings ${ }^{6}$. Not surprisingly, these stylized facts have prompted economists to investigate more closely both the financial viability of the Social Security System and the effects of the incentives provided by the SS program on households' behavior. As a result two major reforms have been implemented in very recent years aimed at reducing the level of benefits and restricting eligibility criteria for retirees.

One of the key elements both in evaluating future budget outlays and in assessing the impact of SS on households choices is the effect of the retirement decision on the labor market. In fact, 
understanding the link between SS-related incentives and labor supply can help to explain some features of the labor market structure (e.g. the increasing detachment of older people from the labor force). This in turn provides some idea of how the budget will be affected by a given labor market configuration, i.e. by the relationship between the number of SS tax payers versus benefit recipients Italy is a very interesting example in this context. First, because virtually all retirement income is provided to individuals by the SS as pension funds and private annuities play a negligible role. Second, replacement rates were (until 1995) very high (roughly $80 \%$ of last wage) and therefore the retirement decision involved a large fraction of the household's resources. In particular, when considering whether to work an additional year the individual sets against the earnings of one extra year almost the same amount of income not collected as SS benefits. Third, the existence of an early retirement provision, which attracts no actuarial penalty, greatly distorts choices in favor of early retirement. Finally, different groups in the population belong to different SS Funds characterized by different benefit payoffs and eligibility criteria. This causes redistribution between individuals and, given the variety of incentives provided across these groups, it generates different behavioral responses to policy changes (e.g. the recent reforms), which can be exploited for applied economic analysis.

This paper addresses the above issues by first documenting the stylized facts characterizing the labor market both over the recent past and over the life cycle of individuals (Part I). Part II describes the structure of the Italian SS Program and summarizes the relevant institutional details. Part III is devoted to a simulation model designed to better understand the incentive effects of SS on current cohorts of retirees. Part IV draws some conclusions.

Part I. Labor market behavior of older persons in Italy 
The Italian labor market has been characterized by a declining attachment to the labor force of older persons; but a different pattern is observed for men and women. After World War II the Italian SS system became increasingly more generous, particularly with regard to early retirement. There is now a consistent body of evidence that this increased generosity is closely related with a reduction in household savings (Rossi Visco, 1995; Attanasio-Brugiavini, 1996). This prompts the question of whether observed changes in labor supply behavior could be explained by the growth of the Italian SS program over those years. An interesting twist in the investigation of this issue in the Italian case is that, due to the lack of actuarial penalties on early retirement, the workers exhibiting these trends may still be relatively young.

The historical and contemporary facts presented in this section are drawn from a number of different data sources. These are summarized in Appendix I

Historical Trends

Figures 8 and 9 map out the labor force participation rates of men and women of different age groups since 1958. Four age groups are selected: $40-50,50-60,60-65$ and 65 plus $^{7}$.

From these aggregate figures a marked difference emerges between the labor market behavior of older men in the age groups 60 plus. Figure 8 indicates that for these groups, participation starts low (e.g. $60 \%$ in 1958 for the group 60-64) and declines sharply (to about $30 \%$ in 1994 for the group $60-64)$. These figures can be contrasted with the 50-60 group, which is characterized by a greater attachment (90\% share in 1958) and an almost comparable drop (to about $70 \%$ ) in recent years. 
The same distinction can be drawn for female labor force participation (Figure 9): for older women participation declines slightly but steadily, while for younger women higher and increasing participation i, observed. The decline in the LFP rate observed for older men in recent years is not so sharp for women because of an increase over time of participation in the LF which is more marked for younger cohorts ${ }^{8}$.

In order to explore possible correlations between the labor market evidence and the developments in the SS program a number of graphs are presented that document the increasing generosity of the SS system over time.

A first graph looks at the share of the population over age 30 receiving benefits (Figure 10$)^{9}$ These are distinguished in two time series: a first series shows the share of old-age SS benefits (inclusive of early retirement benefits) and benefits to survivors paid to the population in the age group 30-plus; the second series is based on the share of old age SS benefits, survivor benefits and disability benefits (DI) paid to the population of the same age group. It should be pointed out straight away that in this graph, and in all the following historical graphs, although the title reads "benefit recipients" it is actually the number of benefits which is recorded, as the number of recipients is not generally available. The two figures may differ significantly as each person may receive more than one type of benefit ${ }^{10}$. Both lines increase sharply from 1960 up to the first half of the 70 s, to follow a more moderate trend thereafter. What is striking is the incidence of DI benefits in this group of the population and how this feature evolves over time. However, the two series tend to converge for most recent years as screening for DI benefits eligibility gets tighter, e.g. in 1993 roughly $14 \%$ of DI benefits were paid out to this age group ${ }^{11}$. The number of all SS-related benefits for this age group was roughly $40 \%$ in 1975 and $50 \%$ in 1994 .

Figure 11 shows the change in generosity over time by plotting the aggregate replacement rate (for the Private Sector Employees fund only). This is available for years since 1970 and it is much lower than the "theoretical" replacement rate (roughly $80 \%$ ) because it is obtained as the 
average benefit level (all types of benefits) over the average of earnings computed on the basis of the payments made to the SS Administration. There is a clear pattern of increase over the last few decades, with a huge jump between 1980 and 1985

Labor Market Behavior in 1995

In order to explore more recent facts on the labor market and to analyze patterns of labor force attachment and benefit receipt over the life cycle, it may be useful to turn to micro evidence. 1 use the Bank of Italy Survey (SHIW) which is a nationally representative survey of Italian households based on questions about consumption, saving, demographic structure and labor supply asked to each member of the household (see Data Appendix I). The responses given by each adult member of the household concern current labor supply behavior as well as some retrospective information on employment. Unfortunately, the whole work history of each worker cannot be reconstructed as there are no questions about spells of unemployment or previous detachments from the labor force. I exploit the data both in its cross sectional component and its panel component for the years 1989-1991-1993 ${ }^{12}$. For the graphs contained in this section cross sectional data is better suited: I decided to work with the three cross sections, rather than just use the 1993 one, as the year 1993 is considered to have been affected by a brief, yet sharp, recession which could provide misleading results. The panel dimension is used to construct the hazard rate out of labor force to be discussed in Part III of the paper.

The age pattern of participation for men and women is given in Figure 12. There is a striking difference between the two curves. They both peter out after the age of 60 , but while for men we observe a participation close to unity at age 45 wich runs down to 0.44 by age 60 (normal retirement age under the pre-1992 legislation), women have a participation rate close to 
0.5 at age 45 which decreases steadily afterwards. The most precipitous drop for males seems to occur between age 55 and age 62 : early retirement seems a natural explanation of this finding.

Figure 13 shows how men allocate their time among different activities as they age. There are four categories of activity: employment, unemployment, disability and retirement. While disability insurance characterizes a non-negligible fraction of men at all ages, there is a downward trend in the numbers of the employed population which exactly parallels the labor force attachment profile $\mathrm{e}^{13}$ The age pattern of the share of the retired is most striking: retirement absorbs a huge share of men in a relatively short time, starting with approximately $1 \%$ at age 50 to reach $70 \%$ at age $66^{14}$. Figure 14 shows the results of the same split for women: the underlying trends are very different from the ones observed for men: while the share of employed women starts low and declines steadily over time, the share of retired women grows dramatically over time and reaches a peak at age 65 . E.g. at age 50 a negligible fraction have retired while at age 65 roughly $50 \%$ have quit work, mainly reflecting a different statutory retirement age for men and women. Disability insurance is claimed by a non-neglible fraction of women, starting at age 50 and continuing until advanced old age. It should be stressed that all graphs are much below the value of $100 \%$, as many women are not engaged in paid working activities during their life cycle ${ }^{15}$.

Income Sources of Older Persons

Figure 15 plots SS and DI recipiency for men and it shows a marked increase, over the life cycle, of SS benefits and, to a lesser extent, of other public assistance benefits. In Figure 16 this aspect is further investigated by looking at the percent of men and women receiving a SS benefit ${ }^{16}$. This share grows rapidly after age 55: between the ages 50 and 59 the percentage is higher for women (who are more likely to benefit from a survivor pension), after that age-interval there is a rather stable gender gap. The growing importance of SS over the life cycle is confirmed by Figure 
17, which shows how the share of family income coming from earnings declines rapidly after age 55 , the share of income from capital remains relatively stable, and there is a corresponding increase in SS benefits and public transfers ${ }^{17}$.

\section{Part II: Key Features of the Italian Social Security System}

\section{History of the SS System in Italy}

Old-age insurance originated in Italy in the public sector in the $19^{\text {th }}$ century for employees in the Army, while private sector blue collar workers had their first Fund set up in 1889 (it was fully funded and non mandatory). By 1960 the "National Institute for Social Security-INPS" was collecting mandatory SS payroll taxes from a large share of private sector employees (under the heading Private Sector Employees Fund-FPLD) as well as from an increasing number of the self-employed (workers in agriculture and commerce). Hence INPS, and particularly the Private Sector Employees Fund FPID, established itself as the main SS Fund Administration in the country, followed by the Public Sector Employees Fund ${ }^{18}$. However, many other groups of workers kept (or set up) their own independent Funds, each group taking the view that they should have their own special conditions. Hence, it was at a very early stage that the SS Program took the form of a patchwork of independent schemes, typically characterized by different rules concerning payroll taxes, benefit pay out and eligibility requirements.

While the introduction of a PAYG financing method had long been advocated, it is only in 1969 that the financial distress of the funded schemes caused by the events of World War II and the desire to set up a modern welfare state, finally led to a move toward a PAYG system for the major funds. Almost simultaneously three further important changes were introduced for the Private Sector 
Employees Fund: (1) benefit computation became of a "final salary" type (average of the last five years of employment, as explained below) in place of the previous career average measure; (2) a means-tested income maintenance scheme was introduced for each individual over 65 not covered by old-age insurance (the so called pensione sociale); (3) SS benefits became automatically linked to a price growth index. Finally the early retirement option was introduced for private sector employees: this would allow a retiree to claim old age benefits conditional upon having "completed" 35 years of SS tax payments, but with no constraint on age. It should be added that the early retirement option had been available to government employees since 1956: throughout the 60's and 70 's it was made even more generous for this group, as men could claim early retirement benefit having only made 20 years' SS tax payments, while married women needed to contribute to the Public Sector Employees Fund for as little as 15 years. The Public sector also received a preferential treatment in an other relevant respect: benefit computation was based on a "pure final salary" in place of an average of the last 5 years' earnings. More recently (1976) SS benefits for private sector employees were automatically linked to real wage growth as well as price growth.

These facts show that, after World War II, Acts of Parliament enacted piecemeal changes which went almost invariably in the direction of increasing generosity, with no concern about the long-term effects of these amendements. The Italian experience seems even more peculiar considering that for 40 years this trend continued uninterrupted and then two major reforms were passed by Parliament within a period of three years, both aimed at improving the SS budget. The first in 1992 (referred to as the Amato-Reform) and the second in 1995 (known as the Dini-Reform) 


\section{Current Features of the SS System}

In this section I describe in detail the legislation governing the SS system in 1992. In fact, the evidence illustrated in Part I concerns the features of the SS system before the reforms. I will then provide only a brief overview of the system after the reforms

The Italian SS system relies on three "pillars": (i) mandatory old age insurance, also providing insurance to survivors and disability benefits; (ii) pension funds and (iii) private annuities The first covers the majority of the working population (almost all private sector employees) and is financed through a PAYG (Pay-As-You-Go) ${ }^{19}$ method, while the remaining forms of insurance provide additional coverage outside (or, in a few cases, substitutes for) the public program. Pension funds are generally fully funded and non mandatory (unless they substitute the public program, as happens for employees in some banks and financial institutions)

In this study I consider the SS system to be a mandatory public insurance program collecting payroll taxes both from employers and employees to provide old-age benefits, benefits to survivors and disability insurance to its members ${ }^{20}$. I disregard pension funds and private annuities as they play a negligible role. The SS program is based on a number of Institutions administering public pensions. A vast majority of the population is insured with the National Institute for Social Security (INPS). This is itself responsible for a number of separate and independent funds, the most important one is the FPLD (Private Sector Employees Fund). Although a description of the INPSFPLD gives a fairly good idea of the system as a whole, it should be borne in mind that a wide variety of cases actually exists. Table Al summarizes some of the main indicators for the private sector employees fund (INPS-FPLD), the public sector employees funds, and the selfemployed INPS-managed fund ${ }^{2 !}$. 
Table Al shows clearly that INPS provides insurance to a large fraction of the working population; public sector employees account for only $15 \%$ of total INPS workers and $20 \%$ of the INPS-FPLD group.

Payroll SS taxes

The inflow of resources into the system comes from the employers' contributions and employees' contributions: when outlays exceed revenue the deficit is financed by the Central Government which has come under increasing pressure to pay for pensions. For example, it is estimated that the theoretical equilibrium payroll tax (i.e. the payroll tax which would balance the budget) was, in 1991, between $35 \%$ and $42 \%$ according to whether full imputation is made for administrative costs or not This is much higher than the actual payroll tax $(26.4 \%$ in 1991$)$ : the difference is an estimate of the tax levied on the entire population of income-tax payers in order to finance pensions ${ }^{22}$.

The payroll tax is unevenly shared between employer and employee. For the INPS-FPLD, the total payroll tax was $24.51 \%$ of gross earnings: $7.15 \%$ falling on the employee. In 1995 this grew to $27.17 \%$, of which $8.34 \%$ was paid by the worker ${ }^{23}$. In contrast, SS taxes for public sector employees and the self-employed have been (and still are) much lower. A further $7.41 \%$ should be added in the private sector for a "severance pay fund" referred to as T.F.R.. This is retained by the employer and builds up in a fund, directly managed by the employer, which provides a lump sum benefit at the time of retirement. I will discuss in more detail this provision in a separate section; however, it should be said that an additional $0,8 \%$ tax is related to the TFR provision in a complex fashion. This additional $0.8 \%$ SS tax is paid by the employer on a monthly basis and it relates mainly to health insurance provision for retirees (it goes to the National Health Service) hence it does not contribute in any way to the standard SS provisions nor does it accrue to the Severance Pay Fund. However, at the end of 
the year, the employer takes from his employees' TFR fund a rebate equivalent to the additional tax he paid, which is therefore effectively paid by the employees

The tax base is not capped: this is a point long debated in the literature, as SS benefits are capped. There is a limit to earnings under which the SS tax due stays constant: in 1995 SS tax had to be paid on at least 720 thousand Lit. of yearly earnings, (which is approximately $3 \%$ of mean individual earnings of that year and is below the value of the bottom $5 \%$ percent of the distribution of earnings) $)^{24}$. This limit is known as the "minimum amount subject to SS tax".

\section{Eligibility}

Eligibility requirements are met when a man reaches age 60 (a woman 55) and has contributed for at least 15 years ${ }^{25}$. However the early retirement option often makes the agerequirement irrelevant as a worker in the private sector can claim early retirement benefits at any age if 35 years' tax payments have been completed. For a male public sector employee 20 years of tax payments are required ( 15 years for a married woman ${ }^{26}$ ). In general, a year of work is completed if 52 weeks of SS tax payments have been recorded by the SS Administration. However, since 1984, only yearly earnings above a threshold (e.g. 13 million Lit. in 1995, approximately $37 \%$ of mean earnings) count as full: lower earnings lead to a proportional reduction in the recorded number of weeks $^{27}$. This limit is known as "minimum eligibility level". A relevant aspect in discussing incentives to labor supply provided by the SS program is the retirement earnings-test. In fact, in Italy workers can draw a pension and earn income at the same time. However, there are earnings-cutoffs which make this choice less attractive. The earnings cut-offs have changed over time and have been heavily affected by the Reforms: I focus attention solely on the rules applying to private sector employees prior to 1992: old-age SS benefits could be claimed while receiving earnings only if earnings did not exceed the minimum benefits. Early retirement benefits could not be claimed along with earnings 
From this brief description of eligibility criteria there emerges a SS System which is actuarially unfair and enacts, willingly or unwillingly, redistribution of resources across the population. In particular, there is an incentive to early retirement as no actuarial penalty applies to early retirees. For example, a private sector employee who started work at age 16 could retire at age 51 while the same worker could retire at age 36 in the public sector. This might explain why detachment from the labor force increases significantly over time in the age group 50-60 as well (Figure 1)

\section{Benefit C'omputation}

For a private sector employee (INPS-FPLD) benefits are computed by first averaging the last five years' earnings (prior to the retirement age): this gives the level of "pensionable earnings". Actual earnings of each year are taken before tax and converted to real amounts by means of a consumer price index ${ }^{28}$. Pensionable earnings are converted to SS benefit by applying a $2 \%$ factor (referred to as "rate of return") for each year of SS tax payment up to a maximum of 40 years. Hence a worker can get at most $80 \%$ of his pensionable earnings. If retirement is postponed, additional years of work beyond a total of 40 do not count for benefit computation; however, they are included in pensionable earnings as they replace earnings of earlier years. The system is highly progressive both because of capping on earnings and because of old-age minimum benefit levels. Earnings entering the benefit computation are capped. Between 1969 and 1988 pensionable earnings would be set against a given limit and the amount in excess of that limit would not contribute to the benefit formula E.g. in 1985, pensionable earnings in excess of 32 million Lit (1.6 times average earnings of that year) would not be included in benefit calculations. After 1988 the constraint was less stringent, as a lower "rate of return" was applied to pensionable earnings in excess of a given limit. In 1995 a $2 \%$ rate applied to the first 57 million Lit. (again 1.6 times average earnings), a $1.5 \%$ rate to pensionable earnings in excess of that figure but below 76 million Lit. (2.2 times mean earnings), and 
the returns fell to $1.25 \%$ for pensionable earnings between 76 and 95 million Lit. $(2.7$ mean earnings). Finally, the top earnings bracket attracted a $1 \%$ return.

The system is much more generous to low-income workers by providing a minimum benefit, i.e. a "floor" benefit level.

It is worth recalling that public-sector employees have their benefit level based on final salary rather than average earnings of the last five years. For all funds, benefits increase at regular intervals with nominal wages, i.e. consumer price growth plus real earnings growth. The former is measured by the consumer price index, but is implemented in a slightly staggered fashion (e.g. if the SS benefit amounts to more than three times the "minimum benefit", indexing is based on $75 \%$ of the price change.) Wage growth is measured by changes in real wages both in the private sector and public $\operatorname{sector}^{29}$

\section{Minimum benefit}

This is a relevant concept in the Italian SS system both because the number of retirees involved is non negligible, and because the minimum benefit is often used as a benchmark against which to set incomes for other provisions. In practice, if the benefit formula gives a retiree a benefit level below a given threshold the benefit itself is set in line with that threshold. Up to 1983 this provision could be applied to more than one pension for the same retiree, while it now affects only one pension for each retiree, leaving the other benefits at their computed level. This income transfer to low income retirees is conditional on means-testing: up to 1992 this test would involve only the claimant's income and exclude the income of the spouse. Hence, for example, in 1985 the means-test had a cutoff at twice the minimum level (roughly 4.7 million Lit.. of that year, which was $17 \%$ of mean household income of the same year). More recently, a similar limit applies to singles, but for married couples what 
matters is the sum of incomes of both spouses, which has to be below 4 times the minimum level (in 1995 approximately 8 million Lit, which was $18 \%$ of mean household income).

\section{Taxation}

While SS taxes are not subject to income taxes (as these are paid after the SS tax), SS benefits are taxed at current tax rates

Survivor Benefits

While survivor benefits to widows were part of the insurance contract at a very early stage, it was only in 1977 that several household members were entitled to claim such benefits: eligibility extending from widows and children below 18 to include widowers and children older than 18 in full-time education. More recently beneficiaries include: (i) the surviving spouse, (ii) children younger than 21 if in secondary school and younger than 26 if attending college for a degree or of any age if disabled, (iii) conditional on none of the above being alive, dependent parents or single dependent sisters and brothers can claim the benefit. In order to claim survivor benefit the worker should have had a full 15 years' tax payments. Survivor benefits can also originate from the DI benefit of the worker (described below): in this case only 5 years of SS tax payments are required. The actual benefit is a percentage of the old-age benefit that the deceased worker would receive at that age. This is $60 \%$ for lone surviving spouse, $20 \%$ to each child, if one of the spouses is alive, and $40 \%$ if orphan, up to a total amount not exceeding the initial old age benefit of the worker. Parents. brothers and sisters receive, if eligible, $15 \%$ of the old-age benefit each, up to grand total of $100 \%$ of the old-age benefit itself. The Italian SS system does not envisage a dependent wife benefit: the only advantages to married couples are for those drawing minimum level pensions (described above) 


\section{Other SS Programs}

In recent years the SS program has been under scrutiny as the financial distress within the system led to calls for a reduction both in benefits levels and eligibility. This also focused the attention of policy makers on a global SS reform in order to achieve a much needed realignment of treatment of different groups of workers. This process started with two important changes brought about in 1984 and in 1989; the former relating to DI provision and the latter trying to regulate those benefits aimed at the redistribution of income. One of the key elements in the debate which took place at the time was the insistence on clearly distinguishing between benefits relating to an income maintenance program (implementing redistributive policies, which would therefore be financed by the entire population) and benefits (which were more closely related to old-age insurance and therefore more properly financed by the working population).

A typical income maintenance provision, in which the role of Central Government predominated over that of the SS Administration was the means-tested "basic pension" (pensione sociale) granted to individuals over 65 (even if they had made no SS tax payments). To be eligible, a single person should not have an income above the level of the basic pension itself (the basic pension in 1995 was 4.6 million Lit., $13 \%$ of mean earnings) while a couple should not have an income above 19 million Lit. in 1995 (54\% of mean earnings). The benefit is granted with no penalty in the absence of other incomes and it is awarded only partially if some resources are available within the income cutoff. Another interesting example is unemployment benefit, paid in the form of early retirement benefit (pre-pensionamento), granted to workers of firms in specific industries going through a recession period. This benefit can be claimed by the worker five years earlier than the normal retirement age and could be regarded as a form of "involuntary" early retirement. However, not only does this apply to a limited number of occupational sectors in the economy but it is also becoming less frequent. 
The most striking feature in this debate is the role of Disability Insurance, which is still part of the SS Program. There are at present two possible DI benefits: (i) "DI Pension", provided under the legislation which applied up to 1984 and (ii) "DI Provision" (Assegno di Invalidità) which can be claimed under the post-1984 legislation. The former was granted to workers who proved they were physically unable to carry out their job (with their earnings ability reduced by $2 / 3$ ) and who had completed 5 years' tax payments. Earnings ability was, however, a rather loose concept involving the doctor's judgment of the general welfare level of the claimant, and not just his/her health quality. DI Pensions were computed by following the general rules of eligibility and of benefit calculation and by computing pensionable earnings as the average of actual earnings prior to date of the claim. After 1984 the existing DI Pensions were not terminated or modified, with the only exception for cases in which the beneficiary had an income exceeding three times the minimum benefit. Starting in 1984 , the "DI provision" was the new form of disability insurance benefit; it was granted under the same eligibility requirements as before, with the important difference that "Ioss of earnings ability" became a much tighter requirement. Furthermore, the DI provision was temporary and a new claim was required for renewal every three years, which entailed new medical examinations. Screening of health status is now carried out randomly on DI recipients. The DI provision is to be brought in line with the minimum benefit whenever the calculated benefit is below that level.

This brief description of the DI benefit and its evolution over time highlights the strong incentive provided to claim disability insurance in order to achieve early retirement in those cases where the early retirement option was not available. However, the 1984 Law had a major impact in reversing this trend: Figure 5 shows that the share of DI benefits over total benefits peaked in the years 1975-1980 and declined sharply thereafter. In Figure 6 the same pattern emerges from the ratio of DI benefits to insured workers: by relating DI benefits to the working population (insured with 
INPS-FPLD) it is possible to appreciate how the steepest decline came in 1987 , when the new DI legislation of 1984 had its full impact ${ }^{30}$. More interestingly, the age group for which DI benefits over total benefits dropped dramatically was the age group $50-59$, which is the age group immediately preceeding normal retirement age (Figure 7).

The Severance Pay Fund -T.F.R.

This provision applies both to private sector and public sector employees. In the private sector, a non-negligible fraction of annual earnings $(7.41 \%)$ are ear-marked by employers towards an end-ofjob one-off payment. This money does not contribute to any pension fund but is directly managed by the firm which uses it as internal funds. This appears as another key feature of the system in analyzing the incentives of S.S. with regard to retirement the prospect of cashing in a lump sum at retirement (which would otherwise earn a low rate of interest) may induce a worker to leave the labor force earlier than the normal retirement age.

The TFR was originally set up in the private sector and was regarded by workers as a form of unemployment benefit, while firms encouraged the growth of this fund in order to both reduce workers' mobility and create an extra source of internal financing. The legislation concerning the lump sum benefit computation differs from sector to sector and, prior to 1982 , from occupation to occupation within the private sector. In particular, prior to 1982 the lump sum would, for the vast majority of private sector employees, correspond to a share of $8.33 \%$ (i.e. $1 / 12$ ) of final wage adjusted according to the number of years in employment with the same firm. Hence the fund would effectively grow at the wage-growth rate for each year up to 1982 and the employer would each year retain $8.33 \%$ of the gross wage of his employees. After 1982, for all employees in the private sector the fund built up each year was capitalized at a rate given by the sum of two components: a fixed 
$1.5 \%$ plus $75 \%$ of the growth in prices recorded in the month of December of the previous year. In periods of high inflation this growth rate would be below the price growth rate and much below nominal wage growth. For this reason, it is often argued that workers would be better off if they could invest that money with a financial institution. While $7.41 \%$ of gross earnings is retained by the employer for the TFR fund in the way decribed above, a further $0.8 \%$ of the worker's gross earnings is paid by the employer to the INPS Administration, which does not contribute to the employee's SS benefit nor to his TFR ${ }^{31}$. The employer collects a full rebate on this additional payroll tax by reducing the TFR of his employees for an equivalent amount at the end of the year. Hence this additional tax is effectively paid by the employee with no corresponding benefit.

While the TFR payroll tax is not subject to any income tax, the worker pays on the TFR lump sum benefit separate income tax. I.e. the TFR lump sum received at retirement is not summed with other incomes but is itself subject to income tax at the current tax rates ${ }^{32}$.

Old Age Insurance Through Private Schemes.

Saving through Pension Funds is available for only a limited number of individuals in specific occupational sectors and is almost invariably a voluntary additional supplement to the basic pension. More recently, the need to alleviate part of the burden of pension provision that falls on Social Security has shifted attention to a system in which, in addition to the public pension scheme, there should exist a non-own-managed Pension Fund and possibly a private old-age insurance contract. The recent reforms intend to channel the enforced "low-return" savings of the TFR into Pension Funds for newly-hired employees, provided the firm/industry and the Fund itself abide by a number of requirements. It is still debated whether this change will increase or decrease workers' welfare, depending on a number of factors (including the behavior of firms in setting wages). 
<smiles>C=[IH]</smiles> 
window of pensionable ages with actuarially-based adjustment of pensions. These vary between age 57 and 65 with "actuarial adjustment factors" between $4.720 \%$ and $6.136 \%$ respectively. Contribution requirements changed from the initial 15 years, to just 5 years after 1995 . Payroll taxes jumped to $32.7 \%$ of gross earnings (to be split between employer and employee): the increase (from approximately $27 \%$ in 1995 ) was partly artificial as it was simply the result of relabeling under one SS tax rate several contribution items. The other provisions were basically unchanged, though following the new eligibility requirements and benefit formula, the rules governing "minimum benefits" became tighter. The Basic Pension (Pensione Sociale) was replaced by a Basic Provision (Assegno Sociale) which was to be financed by the Central Government and was granted under stricter means-testing.

Table A2 summarizes some of the key features of three regimes: the regime prevailing before the Amato-Reform (denoted as pre-1992 Regime), the one prevailing at the steady state after the Amato-Reform (post-1992 Regime) and the one prevailing after the Dini-Reform (post-1995Regime). However both reforms are characterized by a rather long transitional period affecting all the cohorts of post-1992-retirees: the provisions for the transitional periods involve a pro rata method of establishing eligibility and benefit computation criteria. This method allows the legislation of the old regime to apply to the share of years in employment under that regime, while the remaining share is regulated by the new rules. This meant that in practice during the transitional phase a retiree could have his eligibility and his SS benefits computed according to three different systems of legislation ${ }^{34}$.

\section{The hazard rate out of the labor force}


From the brief description of the SS System in place before 1993 it is clear there were many "holes in the net", which allowed workers to get away earlier than the normal retirement age. The early retirement option, which attracted no actuarial penalty, was the leading candidate in explaining some of the facts observed at the aggregate level. Other SS provisions have played a major role: e.g. DI benefits may have contributed to increasing detachment of young workers from the labor force, due to the poor screening methods implemented prior to 1984 . However, a more detailed description of the dynamic nature of the retirement choice could be gained by looking at hazard rates. These are costructed by using the panel dimension of the Bank of Italy data over three years of interviews 1989-1991-1993. Although the panel component is a rather small random sample (about 3000 households, roughly 8000 earner units per year) it is useful in controlling for compusitional effects (see Appendix 1 for a description of the data).

The hazard rate out of the labor force for men is depicted in Figure 18. There are several interesting spikes in this diagram: at age 60 at age 55 and age 66 . The first peak is easily explained by recalling that the normal retirement age prevailing before 1992 in the private sector is 60 for men. The spike occurring at age 55 is, however, of almost comparable size: this corresponds to recipients of either early retirement provisions or DI benefits. The huge spike at age 66 is partly due to a small denominator and partly to the fact that private sector employees are only a fraction of the labor force $\mathrm{e}^{35}$. From Figure 19 it is possible to gauge the different labor force attachment of women: the early spike at age 53-55 corresponds to normal retirement age in the private sector. By 65 , virtually all women in the sample are out of the labor force. However, a non-negligible fraction gradually exits the labor force by the age of 55 .

In order to get a sharper description of the relationship between institutional features and actual behavior I have computed hazards for the two sub-samples of private sector and public sector employees. The limited sample size did not allow me to distinguish between males and females There is a clear distinction between the behavior of the two groups: in Figure 18a the hazard for 
private sector employees shows that there is a progressive detachment from the labor force at three crucial ages: age 55 (presumably early retirement), age 60 (normal retirement age) and age 63 Public sector employees (Figure 18b) also show an early peak at age 55; however many seem to carry on working until normal retirement age (65)

These findings are confirmed by the frequency distribution of actual retirement ages presented in Figures 20,21 and 22. The pictures are based on actual retirement ages of retirees who answer a retrospective question on which was the year of their retirement. I use four cross sections of the Bank of Italy Survey (see Appendix I) for the years 1989,1991,1993 and 1995 and compute the frequency distribution of the various retirement ages relative to the total number of retirees. These figures show that institutional features greatly affected retirement decisions: two peaks occur for men at ages 60 and 65; while for women there are three peaks at ages 55, 60 and 65 .

Part III: Retirement Incentives

\section{Simulation Model}

The simulation model I use to assess the incentives of SS on retirement computes net SS wealth for a married individual who was born in January 1930 and turned 65 in January 1995. The simulation is carried out for a "base case" and for a number of alternative cases in which the sensitivity of the results to the parameter configuration is assessed. Retirement is analyzed between ages 55 and 69 and it is assumed that our median worker claims benefits under the pre-1992 legislation $^{36}$. In fact, two major reforms of the Italian SS system took place within this period, one in 1992 and one in 1995, both characterized by a long transitional period, as described in Part II On the one hand, the pre-1992 legislation seems the relevant regime on which to base the model in order to explain the features of the time series data on labor force attachment; on the other hand, 
from 1993 onwards, individuals have experienced a gradual move toward a different system which is not described in the simulation. However, since the transitional phase, starting in 1993 , has been characterized by a pro rata method of benefit computation, which only marginally affected individuals on the verge of retirement, the use of the pre-1992 legislation seems the appropriate one $^{37}$.

The simulation computes retirement old-age benefits, benefits to survivor (wife) if the worker has died, and net pension wealth for a married employee in the private sector (i.e. insured with the INPSFPLD). It should be stressed that, as shown in Part II, the private sector employees fund INPSFPLD is representative of the insured population both in terms of size and because of its historical relevance; however, the other Funds (particularly the Government Employees and INPS-Selfemployed funds) are of non-negligible size and of growing importance. I neglect DI benefits since the worker becomes eligible to claim benefits in 1985 , when the new screening rules were in place and DI benefits could no longer be a substitute for early retirement, as was the case prior to 1984 . I take into account the "severance pay fund" provision (TFR)

The basic assumption is that this individual worked continuously in a full-time job during his active life. In almost all cases, the worker is assumed to enter the labor force at age 20 , but in one case an incomplete earnings history is modelled.

It should be said immediately that Italy has experienced wild variations in wage growth and price growth rates over the past decades: it seemed reasonable to assume a constant earnings growth rate, constant inflation rate and tax brackets fixed in real terms throughout the simulation. I present only one case at the end of this section where I have adopted the actual earnings profile and actual tax brackets as a counterfactual. All these assumptions will be described in more detail below.

The simulation involves a number of steps: 
(a) Computation of the benefit level at the chosen retirement age.

This step requires computing a sort of "final salary" formula, which is obtained by averaging the last five years' gross earnings (inflation-indexed) - this average is referred to as pensionable earnings. The retiree will receive in his first year of retirement $2 \%$ on pensionable earnings, for each year of contributions, up to a maximum of 40 years contribution. Cappings apply to the computation of pensionable earnings, and benefit levels which do not reach a given minimum threshold are brought up to that level (see Part II and Appendix I for details). Net benefits are obtained by subtracting the income tax applying in that given year.

\section{(b) Computation of expected Social Security Wealth.}

Net Social Security Wealth is the present discounted value of future benefits up to age 100 . This is the weighted sum of projected benefits with weights given by male survival probability, and the individual discount rate. The pre-1992 legislation applies a "double-indexation" of benefits which grow both with inflation and real wages ${ }^{38}$. I compute a stream of future benefits in nominal terms. This allows me to set the nominal benefits against the actual level of the mimimum benefit in each year when considering the incentives for a low-earnings individual. In fact, although everything else grows with the economy, I use actual parameters as far as the SS features are concerned. In particular, the historical levels for capping of earnings, for the minimum benefit levels and for the SS tax rate are adopted. This also makes it easier to compute after-income-tax benefits on the basis of

the nominal benefit. In fact, income taxes apply to pension income as well as to earnings. ${ }^{39}$. Hence, all figures are then discounted back to age 55 at a nominal rate based on a $3 \%$ real discount rate plus a $3.5 \%$ inflation rate. The mortality prospect is given by the Italian sex/age specific life tables ${ }^{40}$. The life table is kept unchanged over the years, i.e. the perspective is taken of a 55-year-old-forward looking worker who plans for his retirement at each future age up to 69 . To compute net SSW 1 
take out, along with income taxes, SS payroll tax that the individual would pay during any continued work. Hence, if the worker evaluates the possibility of postponing retirement for one year, his SSW is net of the present value (at age 55) of SS payroll tax that he and his employer would pay in that year $^{41}$. Because income tax rates and SS tax rates (plus the severance pay fund tax rates) affect earnings and SSW calculation in a complex fashion, I provide below a sketch of the steps taken in the simulation to include these different tax rates.

(c) Pension Wealth to the surviving wife.

The Italian SS System provides a pension to survivors ( in this simulation, the surviving wife), though no benefit is provided to the dependent wife ${ }^{42}$. Hence a joint likelihood of death of the worker and survival of the wife is computed for each year beyond the chosen retirement age. In the base case the worker's wife is three years younger and has never worked

(d) Severance Pay Fund Benefit (TFR).

This involves computing the lump sum benefit at the age of retirement corresponding to the $7.41 \%$ fraction of gross earnings ear-marked by the employer for this fund. While the lump sum benefit is added to SSW, the TFR-tax from additional work reduces net SSW. I have made two simplifying assumptions throughout all the simulations in order to compute the TFR

(1) The relevant rules for benefit computation are those in place after 1982 (see Part II). This implies that the same rate is used to capitalize the TFR fund each year ( $1.5 \%$ plus $75 \%$ of the inflation rate), hence underestimating the value of the Fund accumulated up to 1982 . In fact, up to 1982 , the fund would basically grow at the nominal growth rate of the worker's wage ${ }^{43}$.

(2) I do not apply income tax to the TFR benefit: this omission overestimates the actual benefit. Since the average income-tax rate on the TFR benefit is approximately, for a median worker, 
between $10 \%$ and $15 \%$, this should be almost equivalent to the underestimation discussed above Hence the two biases should roughly cancel each other out ${ }^{44}$.

\section{Methodological issues}

The results of the simulation are the net of tax replacement rate, the accrual rate and the tax/subsidy rate from additional work. The net of tax replacement rate is the rate at which the net SS benefit replaces the worker's (after tax) earnings should he continue to work in that year. The other two measures of the incentives provided by the SS Program require the computation of net SSW. This is the present value of future pension benefits (after income tax) net of the present value of any additional contribution from continued work. Hence the accrual rate can be computed as the percentage change in net SSW from the previous year. Finally, the implicit tax/subsidy is the absolute change in net SSW over the potential earnings from working an additional year. The implicit tax/subsidy should be interpreted as an implicit tax, via SS entitlements, on an additional year of work. The numerator is the opposite of the numerator used in the accrual rate and it measures the change in SSW looking at one additional year of work. Hence a positive number indicates a disincentive to (a tax on) work through SSW which the worker foregoes.

Both the net replacement rate and the implicit tax/subsidy require a measure of earnings from additional work: since the income tax system and the SS tax system interact in a complex way it is best to provide some notation at this stage.

\section{Replacement Rate}

Both the SS benefit and the earnings of the additional year of work are subject to income taxes. In accordance with the Italian tax system the relevant measure of earnings is obtained by first subtracting SS taxes and then income taxes, as SS contributions are not subject to income tax. A further complication arises when considering the TFR-tax ${ }^{45}$. This is a fraction of gross earnings 
retained by the employer which is not recorded in the available gross earnings data (neither is the employer SS tax). Hence, under the assumption that the employer SS tax payment and the TFR tax are reflected in a lower wage, a grossing-up procedure is required in order to obtain the theoretical gross earnings figure.

Let' assume that the tax system can be described by one tax rate $\tau_{I}$ (in fact, there are several tax rates, tax exemptions and tax rebates). Let $\tau_{W}$ be the worker SS tax rate, $\tau_{E}$ be the employer SS tax rate and $\tau_{T F R}$ be the TFR tax rate, while $\mathrm{Y}$ represents earnings before income tax and employee SS tax but after the TFR tax and after SS taxes have been paid by the employer ${ }^{46}$. Hence $Y$ represents earnings as recorded by the available survey data.

The replacement rate is based on after-income-tax and after-SS-tax earnings on the one hand, and after-income-tax SS benefits on the other hand; hence, obviously, the lump sum TFR benefit (a stock value) should not appear in the numerator of the replacement rate As for net earnings, these are given by ${ }^{47}$ :

$$
\mathrm{YN}=\left(1-\tau_{W}-\tau_{I}\right) \mathrm{Y}
$$

\section{Implicit tax/subsidy}

In measuring earnings which appear in the denominator of the implicit tax/subsidy $\mathbf{I}$ add back to after-income-tax earnings both the employee and the employer contributions. In fact, these have already been taken out of net SSW. In other words, earnings (YTS) which appear in the denominator of the implicit tax/subsidy are obtained by grossing up as follows:

$$
\mathrm{YTS}=\mathrm{YN}+\tau_{W} \mathrm{Y}+\tau_{E} \mathrm{Y}+\tau_{T F R} \mathrm{Y}
$$




\section{Assumptions for the "hase case".}

In the "base case" simulation the worker is characterized by a "synthetic earnings history". This is obtained by projecting backward and forward the 1994 median earnings of a particular year-of-birth cohort of workers. Median earnings are computed on a panel of workers (private sector employees) in continuous employment, drawn from the Private Sector SS workers archive. The data available goes from 1974 to $1994^{48}$. Although it would seem appropriate to focus on the cohort which was born in exactly 1930, I have defined a cohort of a 10-year age band (from 1927 to 1936): this is in order to allow for both a reasonable sample size within each cell and comparability with other data sets $^{49}$

Because wages for all cohorts, and particularly for the cohort we are interested in, show marked changes over the sample period (mainly due to price changes) and since income taxes greatly affect net earnings in a non linear fashion over the years, the simulation results based on historical earning profiles and historical tax rates proved hard to interpret. It seemed approriate to turn to an economy where wages and taxes grow at constant rates. Hence $I$ used the 1994 median earnings figure and the 1994 tax system as a starting point. To project earnings both forward and backward I used the assumptions on inflation, wages and GDP growth adopted by the Italian Government in making their forecasts on future SS Government expenditure ${ }^{50}$. The choice of a cohort of full-time employees in continuous employment provides a misleading estimate of median earnings of that cohort: part-time work and, more importantly, incomplete earnings histories, are quite common in the Italian labor market. However, this characterization of the base case is then compared with an alternative case where an incomplete earnings history is modelled explicitly. Finally, I adopt the historical values for 
SS tax rates while the TFR retention rate is assumed constant throughout, for the reasons given above

\section{Base Case Results}

Table 1 shows the base case results. Each row represents the age of the worker in the last year that he works. Hence the first row presents results for a married man who has worked during the year 1984 and retired on his 55 th birthday (January 1, 1985). The first column is the net replacement rate described above. The row which is highlighted refers to the first year of eligibility. The next three columns show the evolution of net SSW over time. Finally, marginal retirement incentives are captured by the rates presented in the last two columns. It is worth recalling at this stage the aspects of the SS system which determine the figures in Table 1, in particular the tax implicit in postponing retirement by one year.

(a) The pre-1992 regime allowed a private sector employee to benefit from early retirement, with no age requirement, provided 35 years contributions had been completed. Hence, although the normal retirement age for a man in the private sector was 60 , the base-case individual could actually claim retirement as early as his 55 th birthday. Also it should be noted that, although retirement is nonmandatory, in practice very few can retire after age 65 (see Part II on this point)

(b) For each additional year of work, the worker must pay SS taxes: in Italy these have grown in discrete jumps. Hence net SSW is affected in a non-linear fashion over time.

(c) The additional year of earnings enters the benefit computation formula, both because pensionable earnings are an average taken over the last five years' earnings, and because, up to age 60 any such additional year increases the fraction of years of contributions accounted for in the computation itself $^{51}$. After age 60 the fraction of pensionable earnings which is converted into a pension stays constant at $80 \%$. The effect on SSW of adding one year to the benefit computation then depends on 
real earnings growth and inflation; in fact, past earnings are converted to current figures by means of price indexation.

(d) For an additional year of work there are fewer years over which benefits are claimed, lowering SSW. On the other hand, the TFR fund accumulates for one more year; but the rate of return on this funds is below nominal earnings growth and has no actuarial adjustment

(e) For each future year there is a chance that the worker will die, lowering his SSW.

The first result to notice in Table 1 is that the replacement ratios are very high at all ages. This is an important feature of the Italian system to be kept in mind in order to explain all subsequent results. Although the benefit computation formula suggests that SS benefit should replace at most $80 \%$ of pensionable earnings, the actual figures show replacement ratios which range from 0.735 to 0.803 . This is both because pensionable earnings differ from earnings coming from an additional year of work and because the tax system affects both the numerator and the denominator in a progressive fashion. The variation over time of the replacement ratio is totally explained by the SS tax figures: the same rate computed before SS tax earnings would give simply two levels, one before age 60 and one after age 60

Table 1 shows that a typical worker starts with a net pension wealth SSW (inclusive of the TFR benefit) of 285 million Lit. reaching 183 million Lit. at age 65 (going from approximately 15 times to 7 times his respective median earnings). There is a steady decline in SSW over the life cycle, however, a careful inspection of accrual rates reveals a significant fall between age 59 and age 60 . This means that there is no incentive to delay retirement - particularly at the normal retirement age (because in that year the individual completes 40 years' tax payments and reaches "full contribution history").

The final column shows the tax/subsidy rate. This is a very high number: the tax on working one additional year is roughly between $25 \%$ and $82 \%$ of after-income-tax earnings of that year. The main 
reason for such a remarkable result is the large replacement ratio implied by the pre-1992 SS system. Similarly to the accrual rate, the implicit tax shows a jump at age 60 and it then grows steadily for later ages (a graph is provided in Figure 23)

Finally, it should be noted that while the Severance Pay Fund Provision (TFR) affects the levels of SSW, it does not have significant effects on the marginal changes in SSW or on the shape of the implicit tax/subsidy profile ${ }^{52}$. Further simulations (not shown here) imply that the implicit tax is higher in the presence of the TFR provision than in its absence, providing one more reason to retire early. This is because the return on this fund is lower than earnings growth.

\section{Other cases}

In this section some sensitivity analysis is carried out by allowing for both permutations in the ageearnings profile and variations in the parameters.

Table 2 looks at a single man who considers retirement at different future ages, starting at age 55 . The results for the replacement rate differ only slightly from the base case scenario. In fact, under the assumption that the wife never worked, old-age-pension benefits for a couple are based on the man's earnings profile. However, the income tax system differs in the two cases and it entails a tax rebate for couples which could affect both SS benefits and earnings. The replacement rate is lower than for a married man (apart from the first figure at age 55), hence suggesting that the income tax rebate weighs more on the earnings of an additional year of work than on SS benefits. SSW is at a lower level than for a married man because there is no pension to the surviving spouse. Results for the accrual rate are simply a re-scaled version of the finding obtained for a married man at a slightly lower level (hence becoming more negative). The implicit tax is lower throughout for a single man (apart from the first figure) than for the married man, again because of the income tax system. A slight divergence between the implicit tax path for a couple and for a single worker occurs toward the end of the working life, due to the effect of the wife's survival probability becoming important in 
the net SSW calculation. This similarity across the two cases is explained by: (a) the lack of additional benefit for the dependent wife; (b) benefits to the surviving spouse are provided with no age limit (only means-testing).

Table 3 describes the results for a worker with an incomplete earnings history. Unlike the base case, he starts working at age 24 (in 1954); hence when considering retirement on his 55th birthday he would have completed only 31 years out of 40 of his SS tax history and would reach full eligibility only at age 64 (working at age 63). This variation on the base case has interesting implications for the incentive results. First, the replacement rate is lower than in the base case up to age 64 and it then coincides. The tax/subsidy path is shifted to the right at a much lower level for ages below 65 . This is because at that point full eligibility is reached in both cases, hence up to that age there is a higher incentive to work for someone who entered the labor force later. After age 65 the two paths do not overlap exactly because of the TFR provision, which stays constantly lower for the case of an incomplete earnings history.

Further variations to the base case are obtained by changing the age-earnings profile and the institutional set up. The results are summarized in Table 5, where findings across different simulations are shown for significant ages only, and in two graphs where the time series evolution of the tax/subsidy rate is considered.

The first permutation is in the earnings profile by including both ends of the distribution of earnings. In the Italian SS system there is both capping on pensionable earnings and topping up of low benefit levels, hence interesting cases may be explored when earnings reach the roof or the floor of SS benefits. Experimenting with the data revealed that the two interesting cases lie at the top $95 \%$ and bottom $5 \%$ of the distribution of earnings ${ }^{53}$. These two points of the distribution were obtained, for the year 1994, from the same panel data set used in constructing median earnings. In both cases, I 
then applied the same earnings growth rate (backward and forward) used for the median earnings profile. For the earnings capping level and the "minimum benefit" I take actual figures; however, for the years after 1995, they are calculated on the basis of economic growth.

These permutations show some inherent redistributional features of the Italian SS system and they explain how these provide incentives for intertemporal decisions by individuals. Obviously replacement rates are on average much higher for the 5th percentile and much lower for the 95 th percentile than in the base case: an example for age 61 can be found in the first column of Table 5 . Accrual rates and the tax/benefit of continued work look very different in the base case than they do for the low-earner and high-earner individual. Some interesting insights can be gained from the comparison. In fact, while capping on pensionable earnings applies to pensionable earnings, topping up of benefits applies directly to the benefit level. The tax/subsidy pattern for the bottom $5 \%$ of the distribution shows large fluctuations (Figure 23). This is because the minimum benefit grows roughly in line with actual historical earnings. The implicit tax levels are very high (reaching a peak of $180 \%$ of potential earnings at age 62). In fact, there is a large transfer component from the system to the individual which the individual foregoes if he postpones retirement. Opposite results are obtained for the top 95th percentile. The replacement rate is lower than for the base case and the implicit tax pattern is constantly lower than the base case. This is explained by a high level of potential earnings (in the denominator) which is not fully reflected in the benefit computation (in the numerator). Moreover, the 95th-percentile tax pattern is not as smooth as the age-tax profile obtained for the base case, again because actual earnings capping changes over time in discrete jumps.

A further set of results is based on the post-1995 legislation. The assumption is made that the 1995 reform of the Italian SS system has been completely phased in - and this naturally means that one should be extremely careful in interpreting the findings. In fact, as explained in Part II, the 
transitional period of the 1995 Reform is a very long one (ending 2035), while in my simulation the legislation is considered when implemented for a worker retiring between the years 1985 and 2000

At this stage, it is useful to give a brief recap of a few crucial features of the post-1995 (steady state) legislation, as they differ radically from those of the base case scenario.

(a) The post-1995 reform adopts an average-earnings based method of benefit calculation. First the present value (at retirement) of past payroll taxes is determined. This is obtained by taking a $33 \%$ share of past earnings for each year in which the worker and the employer paid payroll taxes and weighing each past wage by means of a 5-year-moving-average of the nominal GDP-growth-rate This stock measure is then converted into an annuity by applying an age-related actuarial adjustment factor given below.

(b) The 1995-Reform enacts a window of pensionable ages with an actuarially-based adjustment of pensions: the ages are between 57 and 65 with factors ranging between $4.72 \%$ and $6.136 \%$ respectively. Before age $57 \mathrm{I}$ have used a constant factor $4.72 \%$ and after age 65 a constant factor $6.136 \%$

(c) Future benefits then grow with prices only.

(d) The TFR provision abides by the same rules as in the old Regime.

It is obvious that the crucial features of this benefit calculation method are: (1) the difference between the (smoothed) GDP growth rate and the earnings growth experienced by each individual and (2) the actuarial adjustment factor. Because individuals cannot withdraw from the labor force before their 57 th birthday or after their 65 th birthday I have highlighted these two rows, however, as with the base case, 1 have carried out the simulation from age 54 (last year of work) to age 69

From Table 4 there immediately emerges a striking contrast with the pre-1992 regime with regard to the replacement rate figures (now ranging between 0.463 and 0.652 ) and the net SSW figure 
(roughly million Lit. 160 at age 54 , i.e. 10 times median earnings). This is because workers only gradually build up an increasing stock of SS taxes. Accrual rates are negative throughout; however, they do not follow the pattern observed for the base case. Perhaps the most interesting comparison with the base case is that concerning the implicit tax (Figure 25). While the implicit tax is much lower than in the base case, the new Regime does not particularly encourage work beyond age 57 (age of eligibility). Between age 64 and age 65 the implicit tax jumps because there is no further increase in the adjustment factor. After age 65 the implicit tax grows almost in line with that in the base case this is because in both cases all the relevant parameters remain constant. However, while in the pre-1992 Regime benefits grow with earnings (with no fund build-up), in the new Regime benefits grow with prices but the stock of SS taxes builds up. The behavior of the implicit tax between ages 57 and 65 is not as smooth as one would expect, given the emphasis placed by the Reform on producing an "actuarially fair system" and given that the simulation is based on constant growth rates. This may be explained by the calibration of the actuarial adjustment factor which is based on slightly different life table from the one used in this study and by the use of a different discount factor. In fact, the actuarial adjustments of the benefits which, under the new regime, apply at the different retirement ages was calibrated by Government Actuaries in order to achieve actuarial fairness across retirement ages for an individual who is 62 in 1996 and by assuming a real discount rate of $1.5 \%{ }^{54}$.

Finally, it is interesting to compare the base case with a counterfactual case where the actual earnings profile and actual income taxes have been used to produce a "realistic case".

Earnings are computed by taking medians from the given year-of-birth cohort of employees by calendar year. To follow this cohort back through time (i.e. before 1977) I used the growth rate of gross earnings, at current prices, for employees in the industrial sector. The age-earnings profile of the "typical actual worker" does not show an appreciable decline until the last available years: the stable growth in earnings for this group is explained both by the fact that we are following a true 
cohort of full-time male employees through time and by the fact that my definition of this cohort covers a wide age band. This implies that part-time work should be excluded from the sample by definition and that sample numerosity only becomes a problem for the last few years, when many members of the cohort have retired ${ }^{55}$. Hence it is only from age 60 (year 1990) that I have replaced actual earnings with their projection, obtained by letting earnings increase at the same growth rate as nominal wages in the industrial sector. For this case, I provide information at age 61 (in Table 5) and the implicit tax profile (Figure 26). It is clear that the results for the "actual earnings" profile are totally dominated by changes in earnings growth rates and income taxes. The highest disincentive to supply labor for an extra year is for those of age 57,60 and 63 ; after age 67 there is a steady decline in the implicit tax. While the peak at age 60 can again be explained by, amongst other things, full eligibility, the spike at age 57 is partly due to a decline in the earnings growth rate immediately followed by a sharp increase (the former affects the numerator while the latter affects the denominator). This is also reflected in a relatively low replacement rate for age 57 . This early spike is a particularly interesting feature of the system as it happens to coincide almost exactly with a peak in the male hazard rate out of labor force.

\section{Part iv: Conclusions}

The Italian SS System is characterized by strong incentives to early retirement. These have certainly had an impact on individual intertemporal decisions, particularly those concerning labor supply. Both time series data and micro data provide support for the view that there is a causality relation between the increased generosity of the SS system and its eligibility criteria, and the timing of retirement. Moreover, the simulation exercise carried out in this study shows that these incentives differ across groups of the population according to such characteristics as individual earnings profiles and work experience. The tax on additional work implied by foregone Social Security wealth is almost 
invariably large and it usually peaks at the ages when the empirical evidence shows the highest detachment rates from the labor force. For example, the male hazard shown in Figure 18 and the distribution of actual retirement ages (Figure 21) suggest that there are three typical ages for leaving the labor force: a first peak is observed at ages 55 then a significant peak at age 60 (corresponding to normal retirement age in the private sector) whilst the third exit from the labor force occurs around age 65 . This is in line with the incentives provided by the SS system as measured by the implicit tax/subsidy. In fact, the tax/subsidy profile (Table l) suggests that the system encourages workers to leave the labor force at all ages, and certainly to retire no later than age 60 . The existence of these incentives in the SS Program is even more evident in the tax/subsidy profile computed under "realistic assumptions" with regard to the earnings profile and the income tax system. (Figure 27). This exercise points out that not only is the SS benefit formula actuarially unfair, but it is also totally dominated by the behavior of wages and prices immediately before the year chosen to retire As a result, the median worker of this exercise would find it very costly to postpone retirement after age 57. This suggests that a simple cost/benefit analysis calculation might have induced many to take advantage of early retirement, which in Italy has been widely available with no acturial penalty. The SS reforms of 1992 and 1995, aimed at reducing benefit outlays, have affected worker's behavior in many respects. There is a direct effect on savings, related to the susbtantial reduction in household pension wealth due to reduced benefit levels and restricted eligibility criteria. While the effects on labor supply decisions are harder to gauge, the econometric evidence presented in Appendix II suggests that the 1992 reform was regarded by many as a breaking-point, after which the SS system could no longer be as generous as in the past. Hence, many reacted to the reform by bringing forward their expected retirement age (particularly young people in the private sector). 


\section{Appendix I: Data Sources}

Historical data:

(a) Labor force participation by age and sex, (Figures 1-2)

This is based on ISTAT Annuario del lavoro e dell'emigrazione, (1958-1980), and Supplemento al Bollettino Mensile, several issues, plus Rilevazione delle Forze di Lavoro, Collana di Informazione, 1986-1994. The jump in the series in 1976, also discussed in Casavola-Sestito (1994), was produced by a change in the definition of both unemployment and employment. After that year, these two terms covered people actively seeking for work even if not previously in employment and people who did not regard themselves as employed but who worked during the survey week

(b) Share of workers.

(1) ISTAT: Annuario del lavoro (several issues). ISTAT: Rilevazione delle Forze di Lavoro, in Supplemento al Bollettino Mensile di Statistica (1975-1985) e Collana di Informazione (1986-1995). (2) Ministero del Tesoro e della Programmazione Economica: Relazione sulla Situazione Economica del Paese (several issues)

(3)For the insured population: INPS, Notizie Statistiche (several issues).

(c) Benefit Recipiency.

The figures based on historical data for benefit receipts are drawn from:

ISTAT, Statistiche dei trattamenti pensionistici in Collana di Informazione (1985-1994) and

ISTAT, Supplemento al Bollettino Mensile di Statistica (1975-1984).

INPS, Notizie Statistiche, 1977-1980. 
However, some more details can be found in CENSIS-CER "Rapporto sulla Situazione Sociale del Paese". The Treasury has published some special reports on projections for future pension outlays: Ministero del Tesoro, Ragioneria General dello Stato: Tendenze Demografiche e Spesa Pensionistica (1996) and Sanità, Scuola e Pensioni (1997)

\section{Contemporaneous data:}

All figures tabulated by the author are drawn from the Bank of Italy Survey 1989-1993 (see below).

\section{Studying Retirement in Italy.}

There are two main sources available at a micro level.

(1) Cross sectional Data provided by the Bank of Italy at regular intervals. This is a nation-wide survey which collects detailed information on Italian households concerning their saving/consumption decisions, earnings of each member of the family and demographic variables. I have used several cross-sections of the Survey: the waves available since 1984 (i.e. 1984, 1985 , 1986, 1987, 1989, 1991 and 1993); plus the waves that are part of the "Bank of Italy Historical Archive" (annually from 1977 to 1983). The two sets of samples differ in many respects: the former (i. e. more recent waves) have a larger number of observations (around 8000 as opposed to 4000 or less for previous years), but there is less detailed information on working status (e.g. the age at which the individual started working is missing) and, most importantly, age is recorded in 10 years/15 years bands which are kept fixed over the years. In this study I have used only the 19891991-1993 surveys, however I have carried out comparisons with the other available source (2). To this end, I constructed year-of-birth cohorts for both sources, which I kept fixed throughout the study.

I assigned individuals to different year-of-birth cohorts on the basis of the information on their age and the year of the survey. For all the observations where age was recorded in intervals (surveys 
of the years 1977-1983), I randomly assigned individuals to year-of-birth cohorts by assuming a uniform distribution within the age interval. Each age band may contain up to three cohorts.

In order to cope with the scarcity of observations resulting for some cells and given the restriction imposed by the recording of age before 1984, I defined cohorts over year-of-birth bands as in table A3. Besides the characteristics of those already retired, there are some retrospective questions posed to both retirees and workers (e.g. age at which they started work). However, a full work history cannot be constructed. There are also questions about expected retirement age and, in just one survey, expected SS benefit.

(2) The Data Base of the INPS Administration-Archive O1/M

This is an unbalanced panel running for 20 years (1974-1994) which records information about workers on the basis of a form sent yearly to the INPS Admiristration by employers. The information available concerns age, sex, occupation, wage and changes of job characteristics, but no information on education, or household structure is available. I constructed cohort gross earnings profiles for the simulation on the basis of this sample according to the following bands.

\section{Table A3 : Cohorts Definition}

$\begin{array}{ll}\text { year of birth } \\ \text { cohort } 1 & \text { before } 1911 \\ \text { cohort } 2 & \text { between } 1912 \text { and } 1926 \\ \text { cohort } 3 & \text { between } 1927 \text { and } 1936 \\ \text { cohort } 4 & \text { between } 1937 \text { and } 1946 \\ \text { cohort } 5 & \text { between } 1947 \text { and } 1956 \\ \text { cohort } 6 & \text { between } 1957 \text { and } 1959 \\ \text { cohort } 7 & \text { between } 1960 \text { and } 1963 \\ \text { cohort } 8 & \text { after } 1963\end{array}$




\section{Appendix II: The Effects of SS on Retirement - Survey of the Literature and Econometric Estimates.}

In this section I intend to give a brief review of the literature on incentives within the SS Program affecting individuals' behavior and then move on to some new empirical evidence which tries to directly measure behavioral responses to changes in SS provisions.

Existing Literature

While a great deal of research has been carried out both on the effects of the Reforms and on the relationship between saving behavior and SS wealth, very little attention has been devoted to the effects of SS security arrangements on labor supply. There are a few notable exceptions: in particular, Geroldi (1993), Peracchi and Rossi (1996) and Padoa Schioppa Kostoris (1996). The work carried out by Peracchi and Rossi tries to assess the overall impact of the 1995 Reform and stresses, amongst other aspects, how there are some distinct patterns in the time series data clearly generated by the increasing generosity of the SS system. In particular, the authors report some of the evidence produced by Geroldi to note that labor force participation in Italy is lower than in other countries and this is particularly so for the age group 55-59 (immediately prior to the normal retirement age). The authors also point out that the existence of the early retirement option is a very likely explanation of the fact that the average employment rate for the age group 50-57 falls with 
each year of age. The results presented in this study (Part I and Part III) confirm these facts. A more direct question is raised by the work of Padoa Schioppa Kostoris (1996), who evaluates the potential financial gains fron the 1995-reform under different scenarios. To this end, the author estinates potential quits originating from early retirement by setting up a simulation model in which the gains for a representative individual from postponing retirement are computed. The author shows that the possibility of working while retired provides, under certain conditions, a large incentive to retire early. Another relevant approach to assessing the importance of the labor supply incentives of SS security is to turn attention away from the "median worker" to other cases. A very detailed study by Rostagno (1996) shows that incomplete earnings histories may play a crucial role in evaluating the effects of the reforms and that these cases may be much more common then previously thought. This might help to explain some features of the hazard rates out of the labor force shown in this study (Part II), because while many retire well before the normal retirement age there is still action in the data after age 60

An important test of the effects of changes in the institutional setting is the analysis of the behavioral responses of individuals and households. There is a very stimulating empirical literature on the effects of the SS system on the saving patterns of Italian households. After the early papers which estimated a very low degree of substitutability between pension wealth and private wealth (Brugiavini, 1991 and Jappelli, 1994) on households micro data, a number of contributions have challenged that finding. Rossi and Visco (1994 and 1995) argue that much of the decline in the Italian saving rate in the 1970 's was due to the increased generosity of the SS system over those years and time series estimates suggest that about one third of Italian accumulated capital stock may have been lost because of this exceptional growth. More recently Attanasio and Brugiavini (1995) have adopted a "natural experiment" approach in using micro data to evaluate the differential impact of the 1992-reform on the saving behavior of households. In particular, the authors distinguish 
between groups of the population which are likely to be affected in different ways by the reform and then look at the mean variation (between the post-reform and the pre-reform value) in savings across these groups. It emerges that between 1991 and 1993 groups which were most affected by the reform in terms of benefit cuts or tighter eligibility rules also tended to save more.

\section{Redistributional Effects of the SS System and Econometric Estimates of Changes in Expected}

\section{Retirement Age.}

One distinct feature of the Italian SS System is the difference existing in the arrangements of the different funds. I have already discussed how the Public Sector, as opposed to Private Sector, Employees Fund was privileged in many respects by the pre-1992 legislation, particularly because of the early retirement option (more generous for the Public Sector) and because of the benefit computation formula (of a pure final salary type in the Public Sector). Castellino (1994) estimates that a large stock of resources were redistributed across generations and across funds because of these different features. One way to look at how these differences affect labor supply decisions is to contrast the hazard rate of Public Sector Employees and Private Sector employees as I have done in Part II (Figures $18 \mathrm{a}$ and I8b). In the private sector, three relevant peaks were pointed out: age 56 (early retirement) age 60 (normal retirement) and age 64 (possibly incomplete earnings history). In the public sector there is also evidence of early retirement between ages 55 and $6 \mathrm{I}$, but then virtually every worker has retired by age 65 (normal retirement age).

Turning to the econometric evidence I present some estimates of changes in expected retirement ages drawn from the Bank of Italy panel of household level data. The methodology adopted is a "difference-in-difference" estimator and draws heavily on the work by Attanasio and Brugiavini 
(1995) described above. In particular, the basic identifying assumption is that the 1992-reform is the only relevant change (as far as differential labor supply decisions are concerned) and therefore I exploit the reform to measure behavioral responses before and after the event. The first difference is the time difference and the second difference is that between groups. Groups in the population are assumed to be exogenously determined and, given the availability of panel data, I can control for individual's characteristics throughout (Venti and Wise, 1995). Hence membership of a group can be interpreted as an instrument (control). I allocate individuals to groups according to the characteristics observed at the beginning of the sample (year 1989) and discard those who later cross groups, particularly if they change employment status and type of occupation. A careful selection of the sample is crucial to this methodology, because of the identification issues described above. This left me with approximately 1500 men and 700 women.

Given that the panel is partly rotating - i.e. some households are replaced after two years there are at least two data points for each individual, which allowed me to compute differences in the expected retirement age. I selected six groups, three according to occupation: (i) employee in the private sector (ii) employee in the public sector and (iii) other occupations; and two according to experience: (1) less than 15 years' SS tax payments in 1993, (2) more than 15 years' tax payments in 1993. This is because the 1992 reform relies on a pro rata method (described earlier) which leaves the rules to be adopted for the latter group almost unchanged, while it greatly affects the eligibility criteria and benefit calculation for the former group. However, in constructing the variable "experience" I had to rely on information regarding the age at which work started, which may be a noisy measure. A slight different selection criteria based on year-of-birth cohorts provided almost identical results in the estimates. It is worth recalling at this stage that the Amato reform of 1992 has gradually postponed the normal retirement age but has not tackled the early retirement option, apart from restricting eligibility requirements in the public sector ${ }^{56}$. 
Table 6 presents mean expected retirement age for some groups of the population. While the figures are a suggestive of a reduction occurring between year 1991 and year 1993 it is hard to place any statistical significance on this finding

Tables 7 and 8 show the econometric estimates. In table 7 the regression is carried out for males, the dependent variable is the change (in years) in expected retirement age, the explanatory variables are group dummies which take value 1 if the individual belongs to that group and zero otherwise. In this case, OLS estimates automatically deliver an efficient estimator of mean changes in the dependent variable. In fact, variations in sample numerosity across groups suggest that it is possible to improve on simple arithmetic means.

The results of table 7 give the baseline specification. Expected retirement age seems to have increased between 1989 and 1995, particularly for young individuals working in the private sector. However, the results of table 8 suggest that the reforms have had an impact on expected retirement age: in 1993 young individuals working both in the private sector and in the public sector tended to bring forward their expected retirement age. This is in line with the common belief that, while postponing normal retirement age (in the private sector), the 1992-reform has mainly affected younger workers. In particular, young workers in the private sector tended to bring forward retirement by approximately 2.5 years and there is evidence of a significant difference in the behavior of private sector and public sector employees.

\section{Interpretation of results}

It is hard to provide a clearcut interpretation of the above results, particularly because the event "retirement" may be quite far in the future for many workers in the sample and the expected 
retirement age could be a noisy variable. The 1992 reform did not remove the early retirement option, hence it would still be possible, both in the private sector and in the public sector, to bring forward retirement, while the reform did postpone the statutory retirement age. Young workers have been greatly affected by the 1992 reform as their SS wealth has been reduced by a considerable amount. The implicit tax profile, corresponding to the 1992 reform (see Fig.24), shows that the implicit tax on work is still positive and high over the life cycle, hence providing an incentive to retire early. What seems to emerge (also from table 6) is that before the reform many thought of their retirement age as the normal retirement age, while the reform has focused the attention of workers on this issue. The 1992 reform also made it clear that the system could no longer be as generous in the past, and, given the incentive system discussed in this paper, on average workers want to get out of the program as soon as they can. 


\section{FOOT NOTES}

In 1990 estimates wcre: (i) an average of 1.3 children per woman of child bearing age and (ii) life expectancy at birth of 73.6 years for men and 80.2 for women. Source: Treasury Special Report (Ministero del Tesoro. Ragioneria Generalc dello Stato). The Italian Central Statistical Office has more recently (1996) cstimatcd: (i) an average of 1.18 children per woman and a life expectancy at birth of 75.3 for men and 81.7 for women

- This ratio is given by old people to people of working age. The ratio based on the actual labor force figures (appearing as the denomina1or) may be misleading as labor force series show a jump in 1977 duc to a change in the Labor Force Survey questionnaire.

3 Source: M. Livi Bacci (1995) and ISTAT (1996). The difference between the serics of the two graphs A4 and A5 are due both to the difference in age groups (age 60 in the former casc and 65 in the latter) and to the difference in estimation timing. In fact the ISTAT figures updates the dependency rate forecast starting from year 1996

4 Sourcc: Treasury Annual Report (Relazione Generale sulla Situazione Econonica del Paese), 1996.

s. Source: L. Beltrametti (1996).

"In 1993 households held, on average, 349 million Italian Lira in private wealth and 382 million Italian Lira in pension wealth, corresponding, on average, to nine times and tell times the after-tax household income of that ycar. Source: my own calculations based on Bank of Italy cross section data. US\$ 1 is equivalent to 1500 Italian Lira.

The choice of age groups is constrained by data availability. However thesc age-groups are consistent, for men, with the SS configuration which used to set the normal retirement age at 60 .

There is a noticeable jump of all the series in Fig.2 (but also in Fig.1, though less sharp) in the ycar 1977. This is due to a change in the definition of the labor force occurring in that year, which is described in more detail in Appendix 1.

The choice of this widc age group is determined by the availability of data on DI benefits recipients. In fact DI benefits are not distinguished by age for every SS fund. It is possible to infer from the National Institute for SS-INPS data (which is just a subset of the SS program, mainly excluding the public sector) that tot many DI benefits are paid out before the age of 30 , hence making this age the natural cutoff point. Alternatively I could have shown, for the INPS fund alone, the share of DI receipients age 50 over the population age 50 ; however this provides a misleading picture as in some years there was a disproportionate number of DI benefits paid out to those self-employed in agriculture. 
E.g. sonı pcople may clainı a survivor benefit and an old-age pension. Unfortunately, I could not distinguish in this picture. between males and females, because of lack of data.

1: In Section II I explain how DI benefits played the role of unemployment/poverty safety net until 1984, when a law was passed by Parliament. greatly limiting eligibility and increasing the frequency and quality of screcning. To get a general picture it could be added that, in 1993, DI benefits paid by the INPS Adninistration (i.e. cxcluding the public sector) covered approximately $7 \%$ of the resident population.

12. I also have the SS Data (INPS Archive) in panel forn over 20 years, which is also described in Appendix I. However, this latter data set only covers private sector employees and it is an unbalanced panel: in order to provide a general description of the labor market I therefore optcd for the Bank of Italy data. This also allowed ine to present sone interesting conparisons between private sector and public sector enployces pursucd further in Appendix II.

13 Therc is a discrepancy between the line representing disability insurance recipients derived from this data source and the one derived from official statistics (shown in Fig.4). First it should be noticed that Fig.4 refers to the share of the population of age $30+$ (both mates and females) receiving DI benefits. Furthermore. aggregate data counts the number of benefits and not the number of recipients. I have attempted the same calculation on nicro data in producing Fig. 10: however, not every income earner reports her/his second or third pension even if they receive it and they do not always report receiving a DI benefit if they work. Finally, as I explain in Appendix 1, the Bank of Italy Data. which is a very rich data sourcc. tends to slightly oversample wealthy households probably underestinating the number of DI. In any case. if I cumulate the share of DI benefit receipicnts fron age 30 onward I obtain approximately the same result.

14 For the "retired" curve I only consider individuals receiving an old agc SS benefit or an early retirement SS benefit, excluding all other SS benefits, e.g. the "basic pension" (an income maintenance benefit).

15. Because I an cxcluding non-work related SS benefits (as explained in notc 13 above) the share of women receiving some benefits would be much higher (approximately 90\%) at later ages, when women beconce more likely to receive a surviyor benefit or a basic pension.

16. Any sort of SS benefit, even if not main source of income.

$1 . \quad$ See note 15 above.

18 I am not describing the self-employed INPS Fund, although this had an interesting evolution and is becoming of increasing importance.

19 I.e. an unfunded method of financing. 
explicitly (through special provisions which are part of the INPS Administration. c.g. income maintenance provisions to the needy and very old) or implicitly through disability benefits. Though these income maintenance provisions are not included in this study, they have certainly contributed to inflate the INPS budget and are relevant in cxplaining the aggrcgate data

21 I an referring to The Public Sector Employees Fund as one entity, but there are two major groups: Central Government Einployees and INPDAP (other Civil Servants e.g. local Government Employees, teachers in primary education etc..): this latter group was formerly known as the Treasury Fund.

$\therefore \quad$ Source: INPS, Le Pensioni domani, 1993.

23 There is no split between what is paid for old-agc benefits vis-à-vis the other benefits

24 US $\$ 1$ is equivalent to 1500 Italian Lira. From now on I use Lit, in place of Italian Lira.

Retirement is non-mandatory, but individuals who intend to work beyond the normal retirement age are not protected by the law. However, before the 1992 Reform a worker could postpone retirement (up to age 65 in the private sector) if tlis would allow him to complete 40 years' tax payments. The 1992 Reform encouraged workers to postponte retirement (until age 65 ) even if 40 years' contributions had been completed by providing a slightly higher return in the benefit computation formula. Claiming and receiving a pension are often separate events. The delays in paying different types of bencfits vary: in most cases, benefits are received one month later than the date of claim (the latter usually coincides witl the worker's birthday)

26. However it should be added that normal retirenent age for the public sector is (in the pre-1995 legislation) 65 for both sexcs.

:? Allowance is made for special cases: e.g., maternity leave.

is This is an index provided by the Central Statistical Office (ISTAT) in which weights applicd to prices are taken from a large sample of the Italian population based on a sampling frame of blue-collar and white-collar cmployees (Indice dei prezzi al consumo per le famiglie di operai e impicgati).

29 Indexation to nominal wage started, for INPS-FPLD, in 1975: the legislation has changed several times in the last few decades tending to extend this feature to more groups of the working population. The timing of indexation has also changed several times: during the $70 \mathrm{~s}$ it was done quarterly.

30. This ratio can be computed only since 1975. Therefore in Figure A7 I have also shown again the ratio of DI benefits over total benefits for this sub-period (provided in Figure A6 for a longer spell) in order to draw a comparison. 
I have already described under the heading "SS tax" how this additional payroll tax mainly gocs to the National Hcalth Scrvice to provide health insurance for retirees.

32 Income tax is paid on the TFR only above a given minimun Icvel. This tax-exempt level changes over time.

3.3 Hence the bencfit is: $(33 \%)^{*}$ (adjustment factor)*(present value of SS taxes)

3.1 For example. for someone retiring at age 62 in 1995 bencfits in the transitional period were based on two regines as follows. A weighted average of final salaries was computed by distinguishing two conponents: for a portion the average of the last five years' real earnings and for a portion the last six years' real carnings (plus a further six months). This average was the pensionable earnings measure. To this, a return of $2 \%$ per year (up to a maximum of 40 years) was applied, provided pensionable earnings were below a given limit: a reduced rate applied to earnings above the limit.

3: It should be recalled that although retirement is non-mandatory there is virtually no possibility of working beyond age 65

it An alternative case is presented in which the post-1995 legislation (i.e. after the most recent reform of the Italian Social Security System) is analyzed at the steady state.

The pro rata mcthod corresponds to a benefit computation where the pre-1992 legislation applies to the fraction of ycars for which the worker has been contributing under the old regime and the post-1992 legislation applies to the remaining fraction. Hence, for our cohor, the effect of the new legislation is only felt for at most $6 / 40$ ) of the computational period. The 1995 Reform also entails a similar pro rata method starting in year 1996 for the transitional period: this would be even less relevant to the results of the base case simulation.

38 As explained in Part 11. inflation is measured by the consumer price index, while real wage growth should be measured by increases in contractual minimum wages. In all the simulations I have adopted a $1.5 \%$ real wage growth and a $3.5 \%$ price growth. In the counterfactual, where actual earnings are used, I have adoptcd real earnings growth in the industrial sector up to 1995 and carnings growth equal to GDP growth afterwards.

39. It should be noted that the Italian tax system is progressive. highly non-linear and subject to marked changes over the years: hence in general it would be inappropriate to simply extrapolate incone taxes and rebates from one year to the next. In practice. since I am assuming constant growth rates and a tax system which grows with the economy in all relevant simulations, the after-income-tax benefits could be computed starting from real benefits as well 
SS taxes in Italy are particularly high (see Part II) and have also changed over the years.

$42 \quad$ As explained in the previous section, special allowance is made for a dependent wife only in thosc cases where the pension is topped up to a minimum level and the retiree is allowed to receive earnings at a higher level than in a "single-household" casc. In this exercise I have ignored the fact that a pension to survivors exists both during the worker's active life and during retirement. The present simulation only accounts for the wife of the retiree claiming benefits

However. as I explained in Part II, these rules would vary across different occupational groups within the private sector.

4. The underestimation is generated by the difference in the compounded rates based on $r l=1.5 \%+(0.75)^{*}(3.5 \%)$ in each year, as opposed to $r 2=((1.015) *(1.035)-1)$ in each ycar.

45 Strictly speaking this is not a tax as the employer retains part of gross wage from his employees which is not paid to any SS fund. However I call it TFR-tax for simplicity.

to $\quad$ Notice that I anl ignoring throughout the exercise an additional $0.8 \%$ SS tax paid by the cmployee as this does not have any corresponding benefit (see Part II).

4. Although I am showing a computation carried out in one step, the actual computation in the simulation requires two separate steps, first taking out the SS tax and then income taxes which are highly non-linear.

18 Source: Ow1 calculation on INPS (Istituto nazionalc della Previdenza Socialc), OIM Workers Archive.

41) In particular with the Bank of Italy cross sectional survey. See Data Appendix for details

"In particular, I have used a $1.5 \%$ annual rate both for real earnings growth and real GDP growth and a $3.5 \%$ rate for annual inflation. Since these growth rates had been chosen for future projections, in order to obtain stcady earnings I also used the same rates in retrospective extrapolation - even if this resulted in gross underestimation of true growth figures. Government Actuaries have actually run future projections on the effects of the SS reforin by making use of a number of different scenarios. The motivation for the choice of parameters in this exercise is twofold: on the one hand, adopting the same real growth rate both for GDP and earnings gives a simple benchmark; on the other hand, there is evidence that in the last 20 years there has not been a marked difference, on average, between the two rates (see also Rostagno, 1996b).

'Having completed 40 years' contributions to the system the retiree receives a first benefit of $80 \%$ of pensionable earnings (i.e. a fraction of $2 \%$ for each year of contribution).

5? For the median worker of the base case the TFR benefit at retirement is roughly $23 \%$ of total net SSW 
3 While the 10 th and 90 th percentile were almost untouched by the roof and floor of the SS system, the 5th and 95th percentile almost invanably hit these barriers: while these may be extreme cases, they are useful in describing how these upper and ninimum level operate.

This calibration procedure is designed so that an individual of age 62 in 1996 is indifferent between the prereform and the post-reform regimes.

55 The Data Appendix provides a graphical representation of age-earnings profile for various cohorts of the sample

5i The normal retirement age gradually moves from 60 to 65 for men. The early retirement option is available. but public sector employees need 35 years contributions to become eligible in place of the previous 20 years $(15$ for married women). In the public sector normal retirement age has been 65 throughout. 


\section{References}

Attanasio, Orazio P. and Agar Brugiavini. 1996. “L'Effetto della Riforma Amato sul Risparmio delle Famiglie Italiane," Nota di lavoro, 96.05.

Banca d'Italia. 1995. "La Riforma del Sistema Pensionistico," Note del Bollettino Economico, 25, 4-19.

Beltrametti, Luca. 1993. "Una Stima della Ricchezza Pensionistica per 1'Italia (1951-1991)," Rivista di scienze sociali, 1, 3-15.

Beltrametti, Luca. 1995. “On Pension Liabilities in Italy," Ricerche Economiche, 49, 405-428.

Beltrametti, Luca. 1996. Il debito pensionistico in Italia, Il Mulino.

Brandolini, Andrea and Luigi Cannari. 1994. "Metodological Appendix: The Bank of Italy's Survey of Household Income and Wealth," in Ando, L. Guiso and I. Visco eds., Saving and the Accumulation of Wealth. Essay on Italian Household and Governement Saving Behavior Cambridge University Press, Cambridge, UK

Brugiavini, Agar. 1987. "Empirical Evidence on Wealth Accumulation and the Effects of Pension Wealth: an Application to Italian Cross-Section Data," Financial market group, discussion paper, 20. London School of Economics.

Camera dei Deputati, Servizio Bilancio dello Stato. 1991. "I Modelli di Previsione della Spesa Previdenziale dell'INPS e della Ragioneria Generale dello Stato," Servizio Studi, 10 
Camera dei Deputati - XI Commissione. 1994. Indagine Conoscitiva sulla Situazione e sulle Prospettive del Sistema Previdenziale, Allegati tecnici, Roma.

Camera dei Deputati, Servizio Bilancio dello Stato. 1996. "Gli Effetti Finanziari di Medio-Lungo Periodo della Riforma del Sistema Pensionistico Obbligatorio (Legge 8 agosto 1995, n. 335)," Documenti e ricerche, 2.

Casavola, P., and Paolo Sestito. 1994. "L'Indagine ISTAT sulle Forze del Lavoro", Lavoro e Relazioni Industriali, 1.

Castellino, Onorato. 1976. Il Labirinto delle Pensioni, Il Mulino, Bologna.

Castellino, Onorato. 1994. "La Riforma del Sistema Previdenziale Ovvero il Rapporto che non fu Scritto," Moneta e credito, 188, 515-540.

Castellino, Onorato. 1995. "Redistribution Between and Within Generations in the Italian Social Security System," Ricerche Economiche, 49 (4), 317-327

Cozzolino, Maria, and Fiorella Padoa Schioppa Kostoris. 1995. "Contribution-Based Vs. EarningsRelated Retirement Pension System: Some Policy Proposal for Italy," Ricerche Economiche, $49,375-403$.

Di Vezza, Luigi, 1990. La giungla delle liquidazioni, Roma, edizioni Lavoro. 
Gazzetta Ufficiale della Repubblica Italiana. 1992. Legge 23 ottobre 1992, n.421, Delega al Governo per la Razionalizzazione e la Revisione delle Discipline in Materia di Previdenza.

Feldstein, Martin. 1974. "Social Security Induced Retirement and Aggregate Capital Accumulation", Journal of Political Economy, 82, 905-926.

Franco, Daniele, and Giancarlo Morcaldo. 1990. "The Italian Pension System: Development and Effects on Income Distribution and Poverty," Labour, 4 (3), 133-159; and Labour, 4 (2), 105-128.

Geroldi, Gianni. 1993. "Eta' Legale ed Eta' Effettiva di Pensionamento," in INPS ed. Le Pensioni Domani. Primo Rapporto sulla Previdenza in Italia, 385-442, Il Mulino, Bologna.

Gronchi, Sandro. 1990. "Limiti e Contraddizioni del Nuovo Regime di Perequazione Salariale delle Pensioni" in Felice Roberto Pizzuti and Guido Maria Rey eds., 11 Sistema Pensionistico un Riesame, Il Mulino, Bologna

Heckman, James J., and R. Robb. 1985. "Alternative Methods for Evaluating the Impact of Interventions," in Heckman and Singer, eds., Longitudinal Analysis of Labour Market Data Econometric Society Monograph, 10, Cambridge University Press.

INPS. 1993. Le Pensioni Domani, Il Mulino, Bologna. 
Istituto Poligrafico e Zecca dello Stato. 1988. "Origini, Funzioni e Linee di Riforma di alcuni Istituti del Sistema Pensionistico Italiano," in D. Franco and G. Morcaldo, La Sicurezza Sociale e il suo Finanziamento, Rapporto ‘88.

Jappelli, Tullio. 1995. Does Social Security Reduce Wealth Accumulation? Evidence from Italian Survey Data, Ricerche Economiche, Vol 49, n. 1, pp. 1-32.

Livi Bacci, Massimo. 1995. "Evoluzione Demografica e Sistema Pensionistico,” Economia italiana, January-April.

Livi Bacci, Massimo. 1995. "Popolazione, Trasferimenti e generazioni," in O. Castellino ed., Le Pensioni Difficili. La Previdenza Sociale in Italia tra Crisi e Riforme, Il Mulino, Bologna.

Lucifora, Claudio, and Fulvio Rappelli. 1995. "Evoluzione delle Retribuzioni nel Ciclo di Vita: un'Analisi su Dati Longitudinali”, Lavoro e Relazioni Industriali, Rivista di Economia Applicata, 3, 77-116.

Ministero del Tesoro - Ragioneria Generale dello Stato. 1989. Metodi per la Previsione a Lungo Termine degli Squilibri Previdenziali, Istituto poligrafico e Zecca dello Stato, Roma.

Ministero del Tesoro - Ragioneria Generale dello Stato. I991. FPLD: una Proiezione al 2025, Roma.

Ministero del Tesoro - Ragioneria Generale dello Stato. 1996. Tendenze Demografiche e Spesa Pensionistica: alcuni Possibili Scenari, Roma. 
Ministero del Tesoro - Ragioneria Generale dello Stato. 1997. Sanità, Scuola e Pensioni, Roma.

Padoa Schioppa Kostoris, Fiorella. 1996. "La Riforma Italiana delle Pensioni di Anzianità e Vecchiaia del 1995 e gli Effetti di Finanza Pubblica," Ispe, Documenti di lavoro, 37/96.

Peracchi, Franco, and Nicola Rossi. 1995. "Nonostante Tutto, è una Riforma”, in F. Giavazzi, A. Penati e G. Tabellini eds., Frontiere della politica economica, Milano, Il Sole 24 Ore.

Peracchi, Franco, Nicola Rossi and Alessandro Venturini. 1995. "La Riforma Pensionistica," Terzo rapporto CNEL

Revelli, Riccardo. 1995. "Potenzialita' degli Archivi INPS ai Fini della Stima degli Aggregati dei Conti Economici Territoriali," in ISTAT ed., Quaderni di ricerca, 1, 137-184.

Rossi, Nicola, and Ignazio Visco. 1992. "Private Saving and the Governement Deficit in Italy (19511990)," Temi di Discussione- Banca d'Italia -, 178

Rossi, Nicola, Andrea Sorgato and Gianni Toniolo. 1993. "I Conti Economici degli Italiani: una Ricostruzione Statistica, (1890-1990)," Rivista di storia economica, x, l-21.

Rossi, Nicola and Ignazio Visco. 1995, "National Saving and Social Security in Italy," Ricerche Economiche, 49, 329-356. 
Rossi, Nicola, and Ignazio Visco. 1994. "Private Saving and Governement Deficit" in A. Ando, L. Guiso Luigi, and Ignazio Visco eds, Saving and the Accumulation of Wealth. Essay on Italian Household and Government Saving Behaviour. Cambridge University Press, Cambridge, UK

Rostagno, Massimo. 1996. Il Percorso della Riforma: 1992-1995. Nuovi Indicatori di Consistenza e di Sostenibilità per il Fondo Pensioni Lavoratori Dipendenti, (Banca d'Italia).

Venti, Steven F. and David A. Wise. 1995. "Individual response to a retirement saving program: results from U.S. panel data", Ricerche Economiche, 49, 235-254.

Zaghini, Enrico. 1988. "L'indicizzazione delle Pensioni nei Modelli Econometrici Annuali," Note Economiche, 2 .

Banca d'Italia. "I Bilanci delle Famiglie Italiane nelgli Anni 1977-1993," Supplementi al Bollettino Statistico (Note Metodologiche ed Informazioni Statistiche), Various Issues.

CENSIS. Rapporto sulla Situazione Sociale del Paese, Various issues.

INPS. 1994. Banche Dati Statistiche. Archivio 01/M, Roma

INPS. 1970. Notizie statistiche. Raccolta di studi su AGO, Roma.

ISTAT. Annuario Statistico Italiano, Various Issues. 
ISTAT. "Statistiche della Previdenza, della Sanità e della Assistenza Sociale," Annuario, Various Issues

ISTAT. Rilevazione Nazionale Forze Lavoro, anni 1986-1994, Collana di Informazione

ISTAT. Statistiche del Lavoro, Various Issues.

ISTAT. Annuario del Lavoro e dell'Emigrazione, issues 1958-1980.

ISTAT. Supplemento al Bollettino Mensile di Statistica, issues 1981-1985.

ISTAT. Supplemento Straordinario al Bollettino Mensile di Statistica.

ISTAT. Statistiche dei Trattamenti Pensionistici al 31/12/XX, Various Issues

ISTAT $\underline{\text { I Conti Economici degli Italiani. }}$

ISTAT. 1993. Rapporto Annuale, La situazione Economica del Paese.

Legge 08/08/1995 n. 335. Riforma del Sistema Pensionistico Obbligatorio e Complementare

Ministero del Tesoro. Relazione Generale sulla Situazione Economica del Paese, vol. III, Various Issues, Roma. 
Table A1

Number Of Pensions and Number of Workers for some Major S.S. Funds, 1993

\begin{tabular}{lrrr} 
& \multicolumn{1}{l}{$\begin{array}{l}\text { Pensions } \\
\text { (thousand) }\end{array}$} & \multicolumn{1}{l}{$\begin{array}{l}\text { Workers } \\
\text { (thousand) }\end{array}$} & \multicolumn{1}{l}{ Ratio } \\
& 14814 & 16345 & 0.91 \\
& 10141 & 11250 & 0.90 \\
& 3634 & 4347 & 0.84 \\
& 2038 & 893 & 2.28 \\
& 816 & 1798 & 0.45 \\
& 780 & 1655 & 0.47 \\
agriculture & 314 & 748 & 0.42 \\
corts\&crafts & & & \\
commerce & 2171 & 3776 & 0.57 \\
& 284 & 969 & 0.29 \\
& & &
\end{tabular}

INPS - Total

\begin{tabular}{|c|c|c|c|}
\hline & $\begin{array}{l}\text { Pensions } \\
\text { (thousand) }\end{array}$ & $\begin{array}{l}\text { Workers } \\
\text { (thousand) }\end{array}$ & Ratio \\
\hline & 14814 & 16345 & 0.91 \\
\hline & 10141 & 11250 & 0.90 \\
\hline & 3634 & 4347 & 0.84 \\
\hline agriculture & 2038 & 893 & 2.28 \\
\hline arts\&crafts & 816 & 1798 & 0.45 \\
\hline commerce & 780 & 1655 & 0.47 \\
\hline & 314 & 748 & 0.42 \\
\hline & 2171 & 3776 & 0.57 \\
\hline & 284 & 969 & 0.29 \\
\hline
\end{tabular}

Private Sector Employecs- FPLD

Sclf-cmployed

agriculture

arts\&crafts

commerce

Other INPS

Public Sector Employees

Others 
Table A2

Some key features of the pre-1992-Regime, the post-1992-Regime and the post-1995-Regime (having completed the transition)

\begin{tabular}{|c|c|c|c|}
\hline & pre-1992 & post-1992 & post-1995 \\
\hline \multirow[t]{2}{*}{ normal retirement age } & $60($ men $)$ & 65 (men) & $57-65(\mathrm{men})$ \\
\hline & 55(women) & 60)(women) & 57-65 (women) \\
\hline transitional period & & 2032 & 2035 \\
\hline Pensionable earnings & $\begin{array}{l}\text { average of final five years' } \\
\text { real earnings (converted to } \\
\text { rcal values through price } \\
\text { index) }\end{array}$ & $\begin{array}{c}\text { carcer average earnings } \\
\text { (converted to real values } \\
\text { through price index }+1 \% \text { ) }\end{array}$ & not applicable \\
\hline pension benefit & $\begin{array}{c}2 \% \text { (pensionable } \\
\text { earnings)* }(t), \\
\text { where " } t \text { " is the number of } \\
\text { years in the system (at most } \\
40 \text { years) }\end{array}$ & $\begin{array}{c}2 \% \text { (pensionable } \\
\text { earnings)* }(t), \\
\text { where " } t \text { " is the nuinber of } \\
\text { years in the system (at most } \\
40 \text { years) }\end{array}$ & $\begin{array}{l}\text { annuity based on stock of } \\
\text { SS payroll tax. Past taxes } \\
\text { converted to ral values } \\
\text { through nominal GDP } \\
\text { growth rate }\end{array}$ \\
\hline indexation of pension & $\begin{array}{l}\text { cost of living plus real } \\
\text { earnings growth }\end{array}$ & cost of living & cost of living \\
\hline pension to survivor & $\begin{array}{c}60 \% \text { to spousc } \\
20 \% \text { to cach child } \\
40 \% \text { to each child (if no } \\
\text { spouse) }\end{array}$ & Saune & $\begin{array}{c}\text { same but } 70 \% \text { to lone child } \\
+ \text { means-test }\end{array}$ \\
\hline $\begin{array}{c}\text { years of contrihutions for } \\
\text { eligibility }\end{array}$ & 15 & 20 & 5 \\
\hline early retirement provision & $\begin{array}{c}\text { any age if } 35 \text { years' SS } \\
\text { taxes }\end{array}$ & $\begin{array}{c}\text { any age if } 35 \text { years' SS } \\
\text { taxes }\end{array}$ & flexible within the window \\
\hline
\end{tabular}




\section{Table A3}

\section{Eligibility Criteria for Retirement and Early Retirement}

\section{Pre-1992 Regime}

\begin{tabular}{lllllll} 
& \multicolumn{2}{c}{ Private Sector } & \multicolumn{2}{c}{ Public Sector } & \multicolumn{2}{c}{ Self Employed } \\
& M & F & M & F & M & F \\
& & & & & & 60 \\
Old age benefit (age) & 60 & 55 & 65 & 65 & 65 & 35 \\
$\begin{array}{l}\text { Early retirement } \\
\text { (years of tax payments) }\end{array}$ & 35 & 35 & 20 & 15 & 35 &
\end{tabular}

\section{Post-1992 Regime}

\begin{tabular}{lllllll} 
& \multicolumn{2}{c}{ Private Sector } & \multicolumn{2}{c}{ Public Sector } & \multicolumn{2}{c}{ Self Employed } \\
& M & F & M & F & M & F \\
& & & & & & 60 \\
Old age benefit (age) & 65 & 60 & 65 & 65 & 65 & 60 \\
$\begin{array}{l}\text { Early retirement } \\
\text { (years of tax payments) }\end{array}$ & 35 & 35 & 35 & 35 & 35 & 35
\end{tabular}

Post-1995 Regime

Private Sector

$\mathbf{M}$

$\mathbf{F}$

Old age benefit (age)

$57-65$

$57-65$

Public Sector

Self Employed

$\mathbf{M}$

$\mathbf{F}$

$\mathbf{M}$

F

57-65

57-65

57-65

57-65 
Table 1: Base Case Incentive Calculations

\begin{tabular}{cccccc}
\hline \hline Last Year of Work & Replacement Rate & SSW & Accrual & Accrual Rate & Tax/Subsidy \\
\cline { 2 - 6 } 54 & -- & 285353 & 0 & 0 & 0 \\
$\mathbf{5 5}$ & $\mathbf{0 . 7 2 6}$ & $\mathbf{2 8 0 4 7 7}$ & $\mathbf{- 4 8 7 6}$ & $\mathbf{- 0 . 0 1 7}$ & $\mathbf{0 . 2 4 5}$ \\
56 & 0.744 & 274486 & -5990 & -0.021 & 0.308 \\
57 & 0.761 & 268066 & -6420 & -0.023 & 0.338 \\
58 & 0.780 & 261160 & -6907 & -0.026 & 0.372 \\
59 & 0.798 & 253918 & -7242 & -0.028 & 0.401 \\
60 & 0.799 & 241677 & -12241 & -0.048 & 0.697 \\
61 & 0.804 & 229536 & -12141 & -0.050 & 0.711 \\
62 & 0.805 & 217643 & -11893 & -0.052 & 0.718 \\
63 & 0.805 & 205963 & -11680 & -0.054 & 0.729 \\
64 & 0.809 & 194396 & -11568 & -0.056 & 0.746 \\
65 & 0.809 & 183099 & -11296 & -0.058 & 0.756 \\
66 & 0.809 & 172011 & -11088 & -0.061 & 0.772 \\
67 & 0.809 & 161167 & -10844 & -0.063 & 0.787 \\
68 & 0.809 & 150577 & -10590 & -0.066 & 0.803 \\
69 & 0.809 & 140269 & -10308 & -0.068 & 0.818 \\
\hline \hline
\end{tabular}

Table 2: Incentive Calculations - Single Worker

\begin{tabular}{cccccc}
\hline \hline Last Year of Work & Replacement Rate & SSW & Accrual & Accrual Rate & Tax/Subsidy \\
\cline { 2 - 6 } 54 & -- & 236380 & 0 & 0 & 0 \\
$\mathbf{5 5}$ & $\mathbf{0 . 7 3 5}$ & $\mathbf{2 3 0 9 9 7}$ & $\mathbf{- 5 3 8 3}$ & $\mathbf{- 0 . 0 2 3}$ & $\mathbf{0 . 2 8 2}$ \\
56 & 0.736 & 225293 & -5704 & -0.025 & 0.301 \\
57 & 0.754 & 219247 & -6045 & -0.027 & 0.326 \\
58 & 0.773 & 212808 & -6439 & -0.029 & 0.356 \\
59 & 0.791 & 206140 & -6668 & -0.031 & 0.378 \\
60 & 0.793 & 195449 & -10691 & -0.052 & 0.623 \\
61 & 0.797 & 184917 & -10532 & -0.054 & 0.632 \\
62 & 0.799 & 174681 & -10237 & -0.055 & 0.633 \\
63 & 0.799 & 164705 & -9975 & -0.057 & 0.638 \\
64 & 0.803 & 154893 & -9812 & -0.060 & 0.648 \\
65 & 0.803 & 145393 & -9500 & -0.061 & 0.651 \\
66 & 0.803 & 136142 & -9251 & -0.064 & 0.660 \\
67 & 0.803 & 127152 & -8991 & -0.066 & 0.668 \\
68 & 0.803 & 118427 & $-\mathbf{8 7 2 5}$ & -0.069 & 0.677 \\
69 & 0.803 & 109978 & $\mathbf{- 8 4 4 9}$ & -0.071 & 0.687 \\
\hline \hline
\end{tabular}


Table 3: Incentive Calculations - Incomplete Earnings History

\begin{tabular}{cccccc}
\hline \hline Last Year of Work & Replacement Rate & SSW & Accrual & Accrual Rate & Tax/Subsidy \\
\cline { 2 - 6 } 54 & -- & 249356 & 0 & 0 & 0 \\
$\mathbf{5 5}$ & $\mathbf{0 . 6 3 8}$ & $\mathbf{2 4 5 9 8 8}$ & $\mathbf{- 3 3 6 8}$ & $\mathbf{- 0 . 0 1 4}$ & $\mathbf{0 . 1 6 9}$ \\
56 & 0.656 & 241570 & -4418 & -0.018 & 0.227 \\
57 & 0.674 & 236698 & -4871 & -0.020 & 0.257 \\
58 & 0.692 & 231316 & -5382 & -0.023 & 0.290 \\
59 & 0.710 & 225575 & -5741 & -0.025 & 0.318 \\
60 & 0.729 & 219396 & -6179 & -0.027 & 0.352 \\
61 & 0.751 & 212772 & -6624 & -0.030 & 0.388 \\
62 & 0.770 & 205864 & -6908 & -0.032 & 0.417 \\
63 & 0.788 & 198653 & -7210 & -0.035 & 0.450 \\
64 & 0.809 & 191057 & -7596 & -0.038 & 0.490 \\
65 & 0.809 & 179911 & -11147 & -0.058 & 0.746 \\
66 & 0.809 & 168972 & -10939 & -0.061 & 0.762 \\
67 & 0.809 & 158276 & -10696 & -0.063 & 0.776 \\
68 & 0.809 & 147834 & -10442 & -0.066 & 0.792 \\
69 & 0.809 & 137674 & -10161 & -0.069 & 0.807 \\
\hline \hline
\end{tabular}

Table 4: Incentive Calculations - Post 1995 Regime

\begin{tabular}{cccccc}
\hline \hline Last Year of Work & Replacement Rate & SSW & Accrual & Accrual Rate & Tax/Subsidy \\
\cline { 2 - 6 } 54 & -- & 159881 & 0 & 0 & 0 \\
55 & -- & 156914 & -2968 & -0.019 & 0.149 \\
56 & -- & 153398 & -3516 & -0.022 & 0.181 \\
$\mathbf{5 7}$ & $\mathbf{0 . 4 6 3}$ & $\mathbf{1 5 2 5 5 7}$ & $\mathbf{- 8 4 2}$ & $\mathbf{- 0 . 0 0 5}$ & $\mathbf{0 . 0 4 4}$ \\
58 & 0.482 & 151386 & -1170 & -0.008 & 0.063 \\
59 & 0.502 & 150151 & -1235 & -0.008 & 0.068 \\
60 & 0.523 & 149496 & -655 & -0.004 & 0.037 \\
61 & 0.547 & 148423 & -1073 & -0.007 & 0.063 \\
62 & 0.570 & 146543 & -1881 & -0.013 & 0114 \\
63 & 0.593 & 144000 & -2543 & -0.017 & 0.159 \\
64 & 0.622 & 140868 & -3132 & -0.022 & 0.202 \\
$\mathbf{6 5}$ & $\mathbf{0 . 6 2 8}$ & $\mathbf{1 3 4 4 2 0}$ & $\mathbf{- 6 4 4 8}$ & $\mathbf{- 0 . 0 4 6}$ & $\mathbf{0 . 4 3 2}$ \\
66 & 0.634 & 127868 & -6553 & -0.049 & 0.456 \\
67 & 0.640 & 121318 & -6549 & -0.051 & 0.475 \\
68 & 0.646 & 114879 & -6439 & -0.053 & 0.488 \\
69 & 0.652 & 108342 & -6537 & -0.057 & 0.519 \\
\hline \hline
\end{tabular}


Table 5: Incentive Calculations - Summary of Other Cases, Last Year of Work is Age 61

\begin{tabular}{cccccc}
\hline \hline Case & Replacement Rate & SSW & Accrual & Accrual Rate & Tax/Subsidy \\
\cline { 2 - 6 } Base Case & 0.804 & 229536 & -12141 & -0.050 & 0.711 \\
Single Worker & 0.797 & 184917 & -10532 & -0.054 & 0.632 \\
Incomplete History & 0.751 & 212772 & -6624 & -0.030 & 0.388 \\
$5^{\text {th }}$ Percentile & 1.357 & 87029 & -4382 & -0.048 & 1.135 \\
$95^{\text {th }}$ Percentile & 0.580 & 408138 & -15660 & -0.037 & 0.390 \\
Post 1995 Regime & 0.547 & 148423 & -1073 & -0.007 & 0.063 \\
Actual Earnings & 0.840 & 165975 & -9613 & -0.055 & 0.648 \\
\hline \hline
\end{tabular}

Table 6

Mean expected retirement age

Panel data 1989-1995

\begin{tabular}{|c|cccc|}
\hline Group & $\mathbf{1 9 8 9}$ & $\mathbf{1 9 9 1}$ & $\mathbf{1 9 9 3}$ & $\mathbf{1 9 9 5}$ \\
\hline males young (1959-1974) & 59.19 & 60.06 & 59.89 & 61.14 \\
males old (1922-1958) & 60.24 & 60.68 & 59.94 & 60.07 \\
females young (1959-1974) & 56.58 & 57.23 & 56.74 & 58.40 \\
females old (1922-1958) & 57.30 & 57.93 & 57.90 & 59.17 \\
\hline
\end{tabular}


Table 7

Yearly changes in expected male retirement age

Panel data 1989-1995. Baseline Regression: groups defined by age

\begin{tabular}{cccc} 
Occupation & Generation & $\Delta$ years & S. E. \\
\hline Private Sector Employee & 1 & 0.957 & 0.358 \\
Private Sector Employee & 2 & 0.197 & 0.194 \\
Public Sector Employee & 1 & 0.644 & 0.673 \\
Public Sector Employee & 2 & 0.756 & 0.297 \\
Others & 1 & -0.050 & 0.586 \\
Others & 2 & 0.494 & 0.268 \\
\hline \hline
\end{tabular}

Generation $=1$ if years of tax payments in 1993 is $<15$

$=2$ if years of tax payments in 1993 is $\geq 15$

Hypothesis Tests:

(1) Private Sector Empolyees of Gencration I = Public Sector Empolyees of Generation I

(2) Private Sector Empolyecs of Generation 2 = Public Secior Empolyees of Generation 2

\begin{tabular}{ccc}
\hline \hline $\mathrm{H}_{0}$ & $\mathrm{~F}$ & Prob $>\mathrm{F}$ \\
\hline$(1)$ & 0.17 & 0.680 \\
$(2)$ & 2.49 & 0.115 \\
\hline \hline
\end{tabular}


Table 8

Yearly changes in expected male retirement age

Panel data 1989-1995

Groups defined by age

\begin{tabular}{cccc}
\hline \hline Occupation & Generation & $\Delta$ years & S. E. \\
\hline Private Sector Employee & 1 & 1.387 & 0.453 \\
Private Sector Employee & 2 & 0.254 & 0.253 \\
Public Sector Employee & 1 & 0.792 & 0.831 \\
Public Sector Employee & 2 & 1.129 & 0.371 \\
Others & 1 & -0.483 & 0.774 \\
Others & 2 & 0.762 & 0.305 \\
Private Sector Employee in Year 1993 & 1 & $-2.570^{*}$ & 0.910 \\
Private Sector Employee in Year 1993 & 2 & -0.567 & 0.469 \\
Public Sector Employee in Year 1993 & 1 & 0.480 & 1.671 \\
Public Sector Employee in Year 1993 & 2 & -0.854 & 0.749 \\
Others in Year 1993 & 1 & 0.963 & 1.444 \\
Others in Year 1993 & 2 & -1.295 & 0.777 \\
Private Sector Employee in Year 1995 & 1 & 0.753 & 0.887 \\
Private Sector Employee in Year 1995 & 2 & 0.442 & 0.527 \\
Public Sector Employee in Year 1995 & 1 & -1.792 & 1.805 \\
Public Sector Employee in Year 1995 & 2 & -1.434 & 0.845 \\
Others in Year 1995 & 1 & 1.283 & 1.466 \\
Others in Year 1995 & 2 & -0.217 & 0.866 \\
\hline \hline
\end{tabular}

Number of obs. $=1896$

Generation $=1$ if years of tax payments in 1993 is $<15$

$=2$ if years of tax payments in 1993 is $\geq 15$

Hypothesis Tests:

(1) Private Sector Empolyecs of Generation I = Public Sector Empolyees of Generation I

(2) Private Sector Empolyees of Generation $2=$ Public Sector Empolyees of Generation 2

(3) Private Sector Empolyees in Year 1993 of Generation I = Public Sector Empolyees in Year 1993 of Generalion I

(4) Private Sector Empolyees in Year 1993 of Generation 2 = Public Sector Empolyees in Year 1993 of Generation 2

(5) Private Sector Empolyees in Year 1995 of Generation I = Public Sector Empolyees in Year 1995 of Generation 1

(6) Private Sector Empolyees in Year 1995 of Generation 2 = Public Sector Empolyces in Year 1995 of Gencration 2 


\begin{tabular}{ccc}
\hline \hline $\mathrm{H}_{0}$ & $\mathbf{F}$ & Prob > F \\
\hline$(1)$ & 0.36 & 0.530 \\
$(2)$ & 3.79 & 0.050 \\
$(3)$ & 2.57 & 0.109 \\
$(4)$ & 0.11 & 0.745 \\
$(5)$ & 1.63 & 0.200 \\
$(6)$ & 3.54 & 0.061 \\
\hline \hline
\end{tabular}




\section{List of Figures Legends}

Figure 1. Share of the populations age $65+$

Figure 2. Dependency ratio - old

Figure 3. Dependency ratio - old and young

Figure 4. Projected Demographic Trends

Share of Population 65+ over Working Age Population

Figure 5. Share of Disability Insurance Benefit Receipts - FPLD (Private Sector Employees)

Figure 6. Share of Disability Insurance Benefit Receipts - FPLD (Private Sector Employees)

Figure 7. Share of Disability Insurance Benefit Receipts as a fraction of total Social Security and DI Benefits - FPLD (Private Sector Employees)

Figure 8. Historical Trends in the Labor Force Participation of Older Men

Figure 9 Historical Trends in the Labor Force Participation of Older Women

Figure 10. Social Security and Disability Insurance Benefit Receipients - Age 30+

Figure 11. Social Security Replacement Rate Over Time- FPLD (Private Sector Employees)

Figure 12. Participation Rates by Age and Sex

Figure 13. Distribution of Activities of Men by Age

Figure 14. Distribution of Activities of Women by Age

Figure 15. Public Income Recipiency for Men

Figure 16. Share Receiving Pension

Figure 17. Distribution of Family Income by Source

Figure 18. Hazard Rate Out of Labor Force for Men

Figure 18a. Hazard Rate Out of Labor Force - Private Sector Employees

Figure 18b. Hazard Rate Out of Labor Force - Public Sector Employees

Figure 19. Hazard Rate Out of Labor Force for Women

Figure 20. Retirement Age - All 
Figure 21. Retirement Age for Men

Figure 22. Retirement Age for Women

Figure 23. Tax/Subsidy Rate Across Earnings Profiles

After SS Tax - Constant Earnings/Tax Growth

Figure 24. Tax/Subsidy Rate Across Regimes

After SS Tax Figures- Constant Earnings/Tax Growth

Figure 25. Tax/Subsidy Rate Across Regimes

After SS Tax Figures- Constant Earnings/Tax Growth

Figure 26. Tax/Subsidy Rate Across Growth Rates

After SS Tax Figures- Actual Earnings/Tax Growth

Figure 27. Tax/Subsidy Rate Against Hazard

Private Sector Employees- Actual Earnings/Tax Growth 


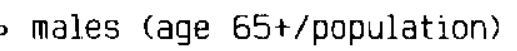

$\Delta$ females (age $65+/$ population)

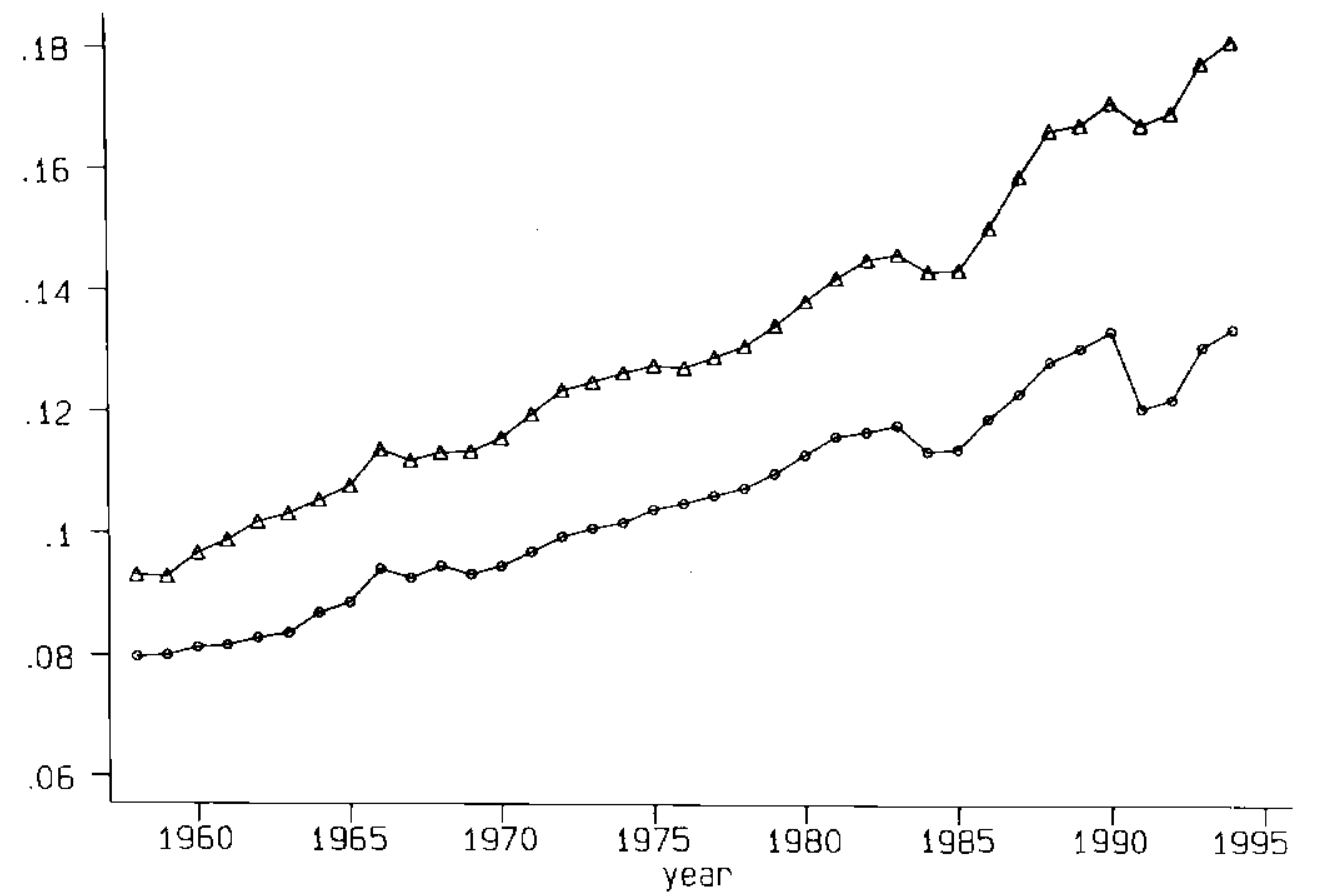

Figure 1: Share of the population age $65+$ 
- males (age 65t/age 14-65) $\Delta$ females (age 65t/age 14-65)

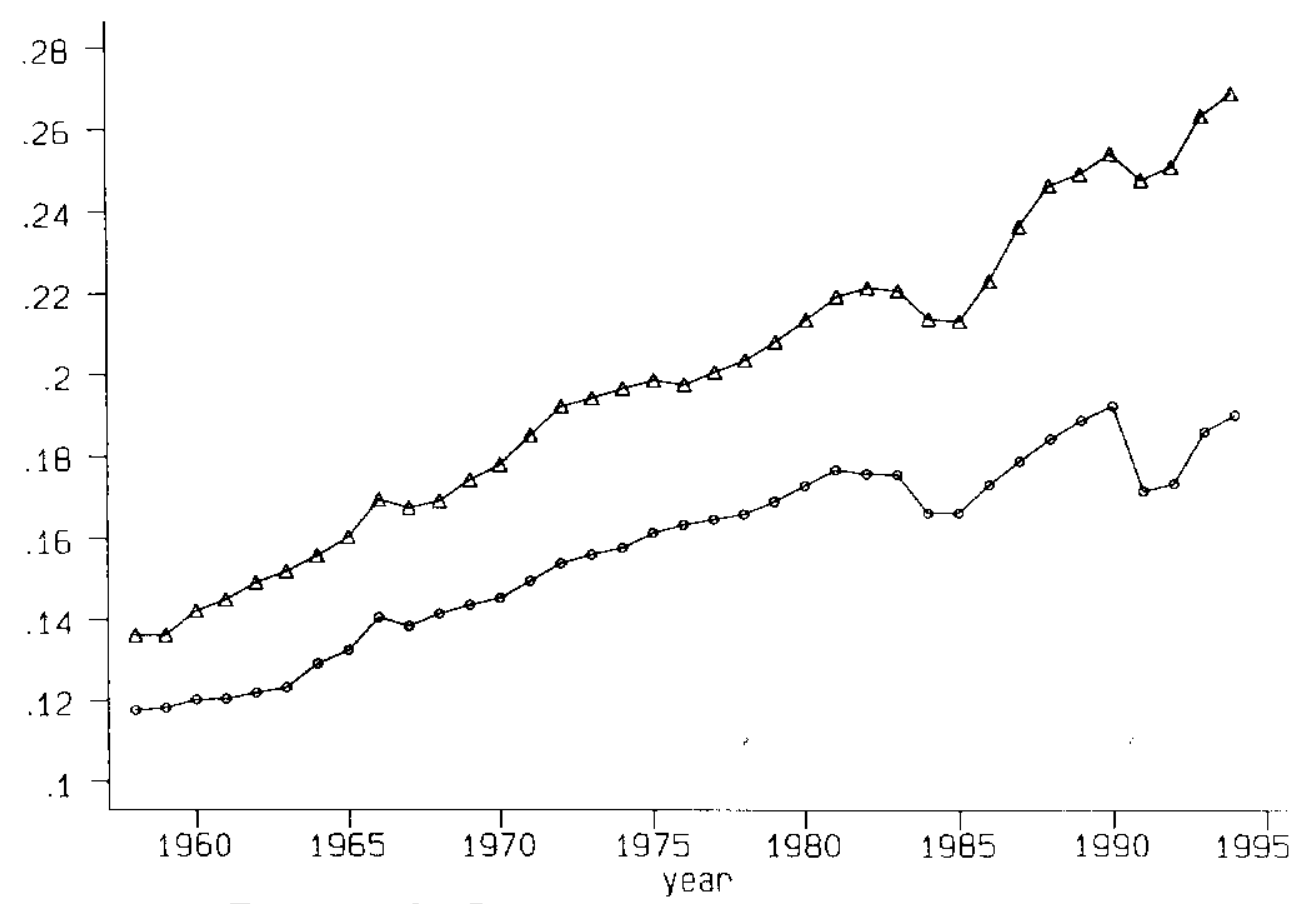

Figure 2: Dependency Ratio - Old 
- males (oldtyoung/age 14-65) a females (oldtyoung/age 14-65)

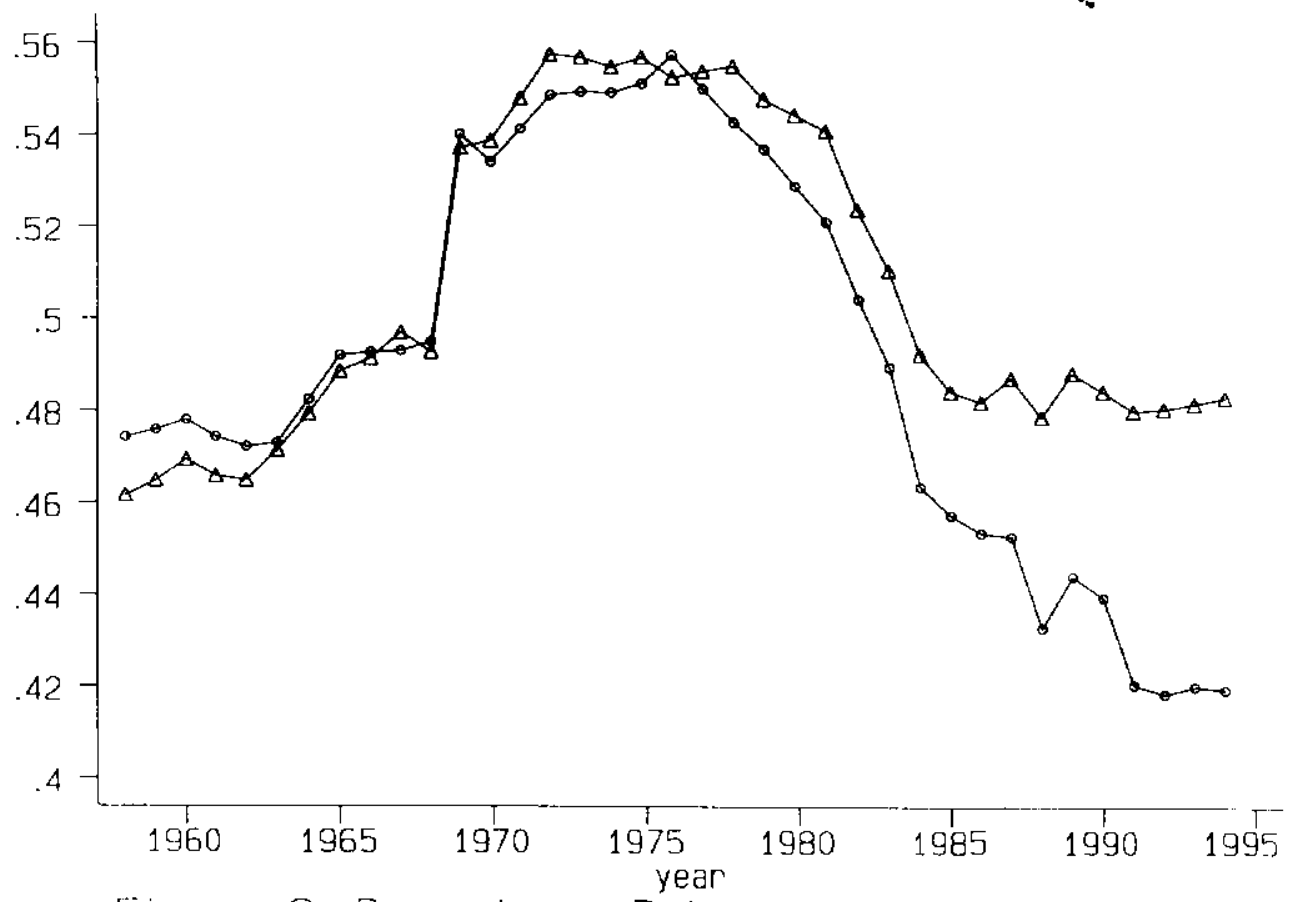

Figure 3: Dependency Ratio - old \& Young 


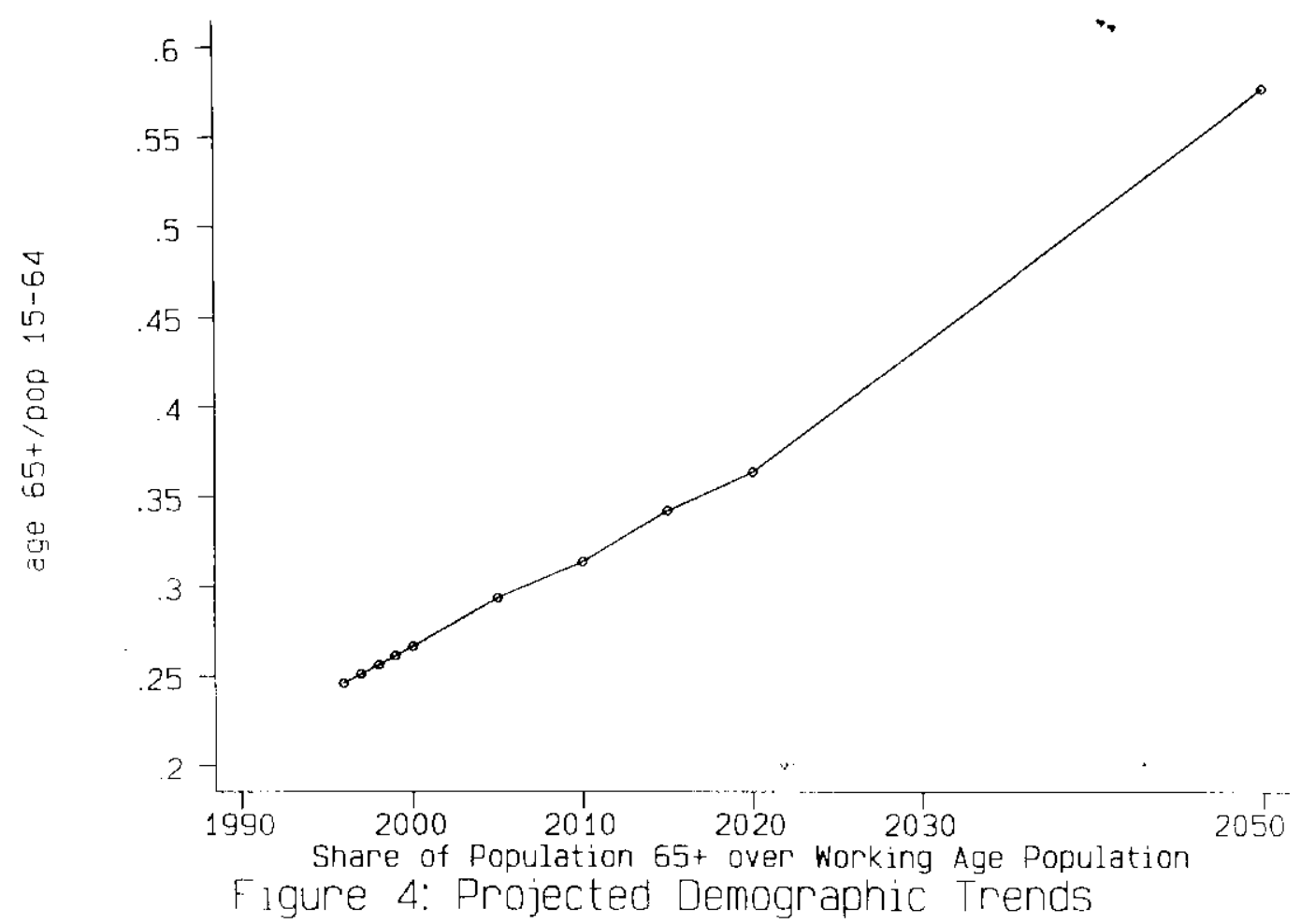




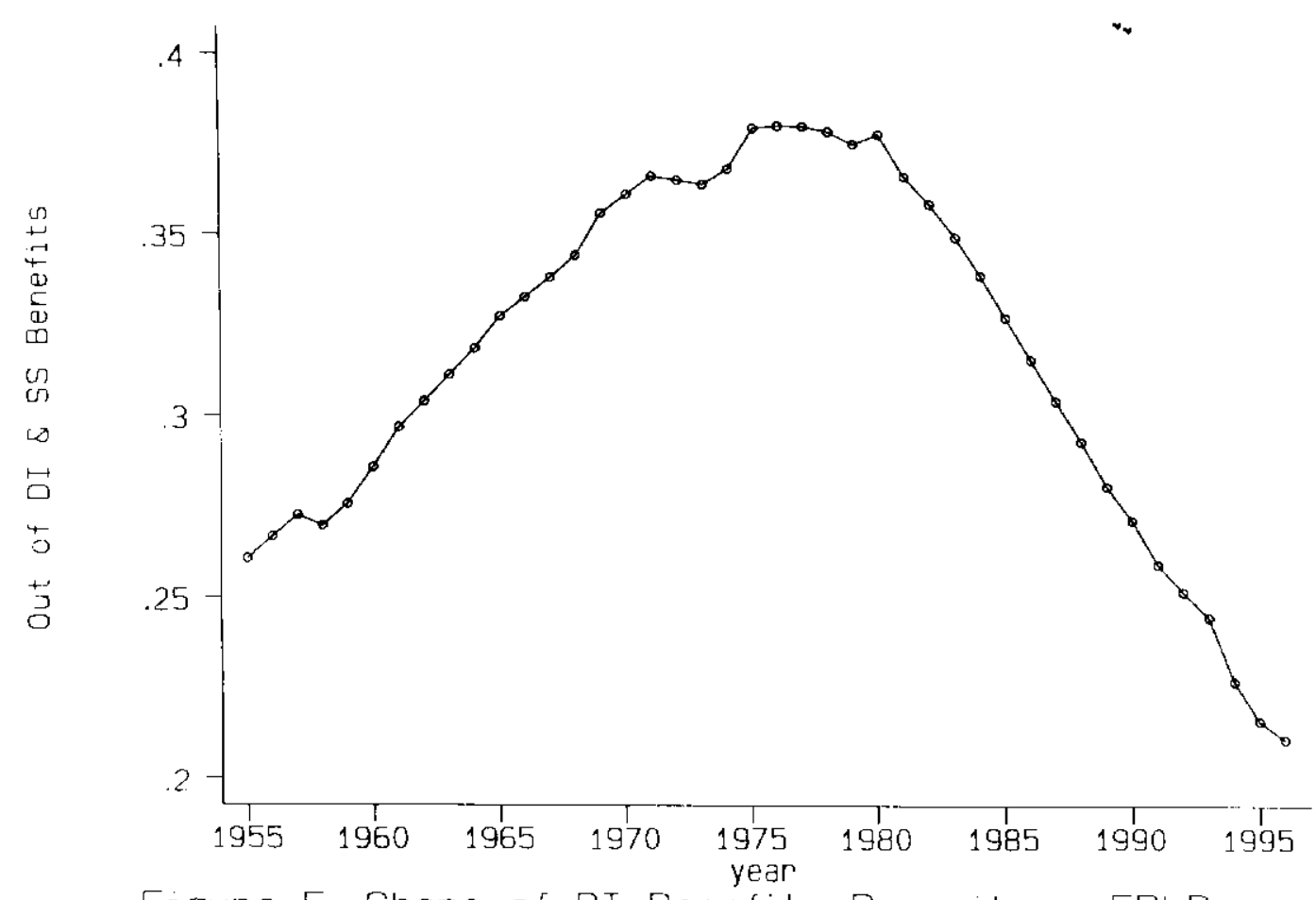

Figure 5. Share of DI Benefits Recepits - FPLD 


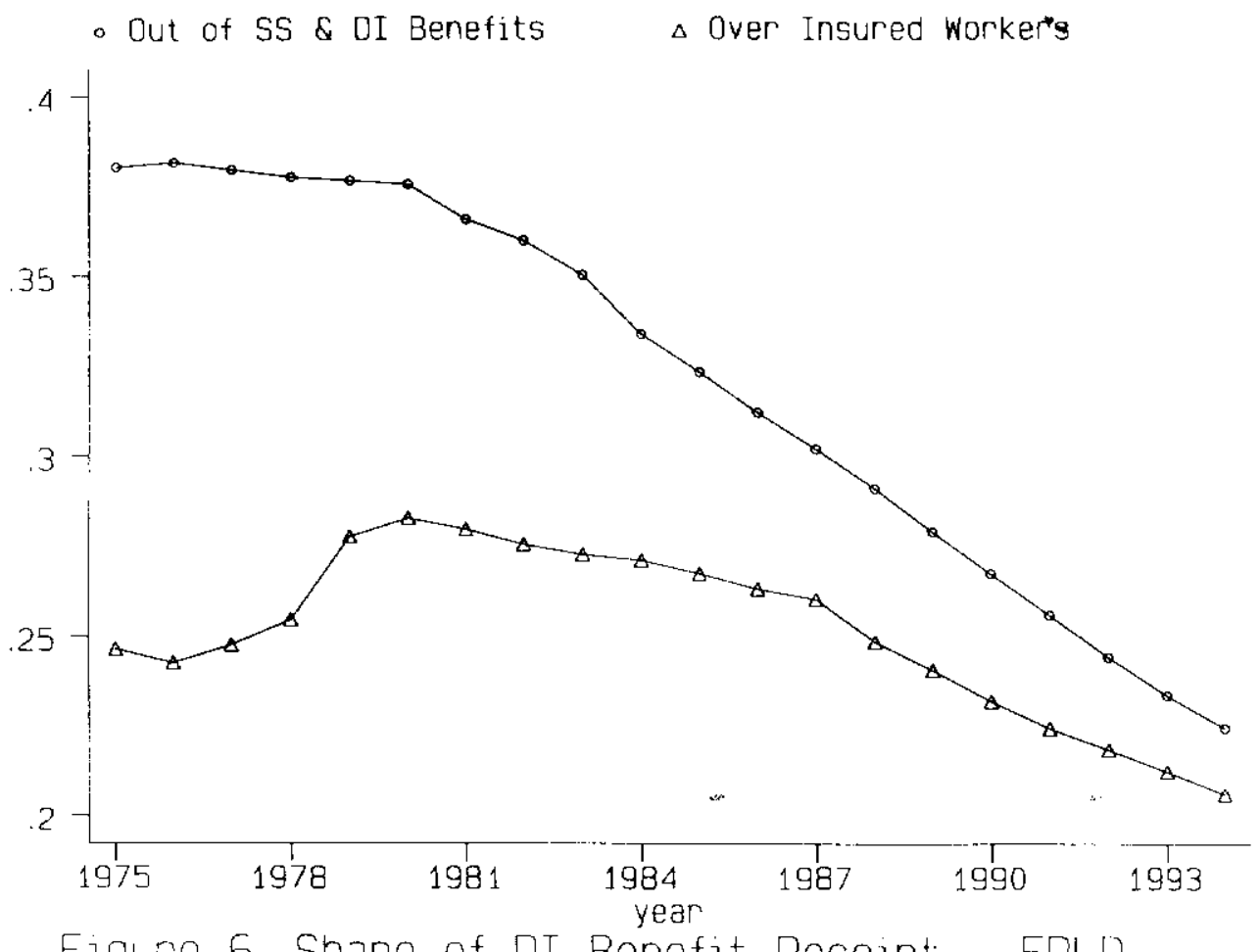

Figure 6. Share of DI Benefit Receipt -- FPLD 


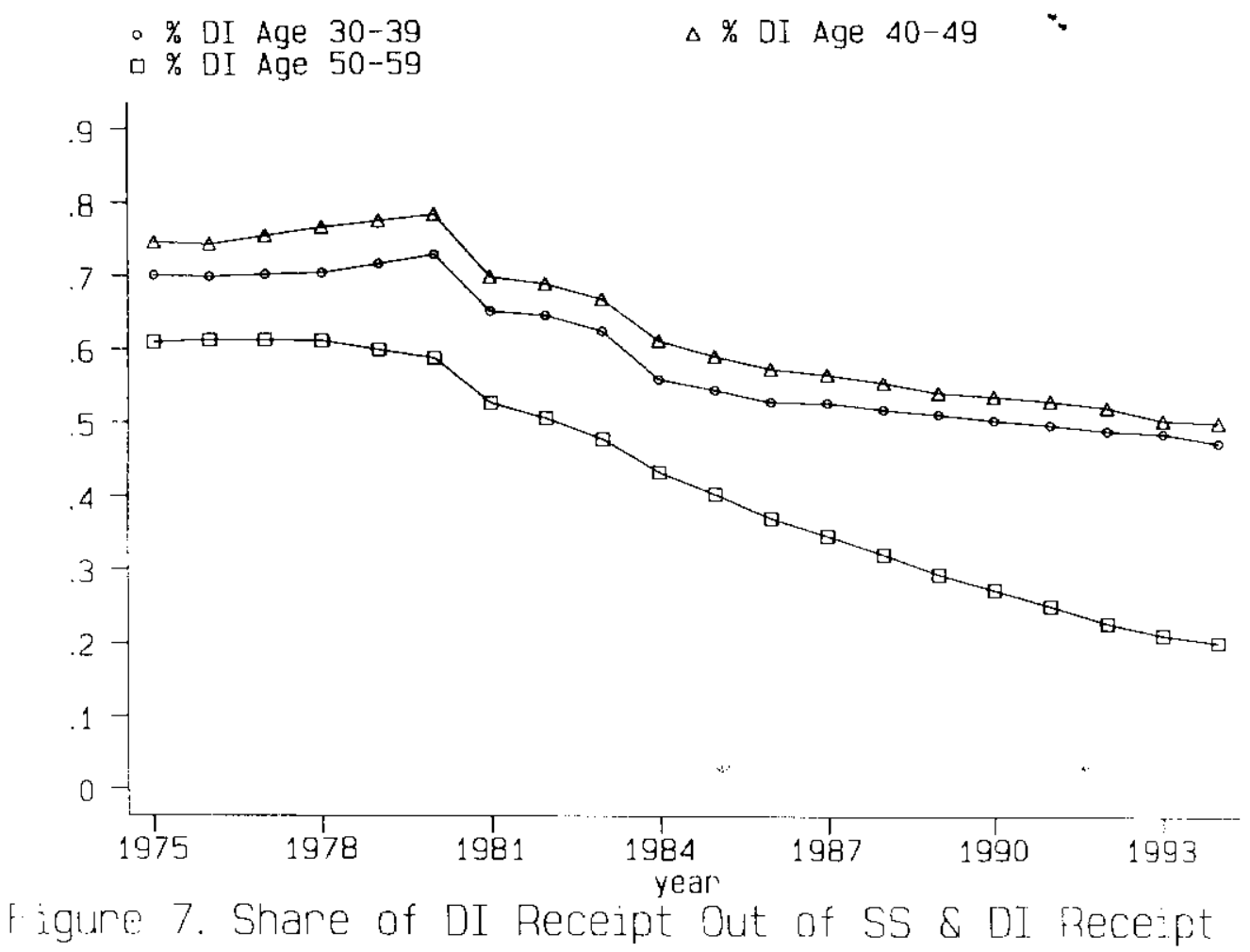


- 40-50 men

- 60-65 men

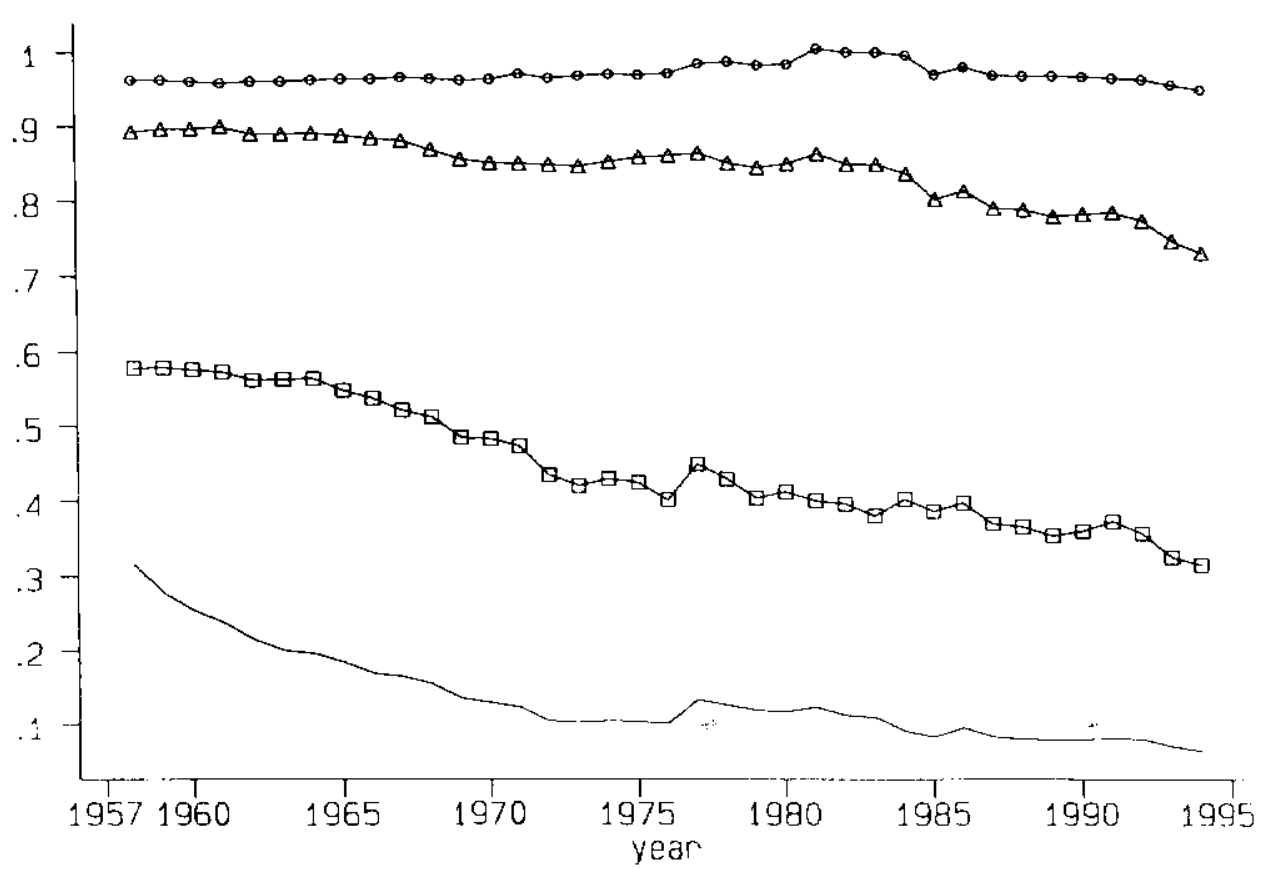

Figure 8. Historical Trends in LFP of Older Men 
- 40-50 women

ㄷ 60-65 women

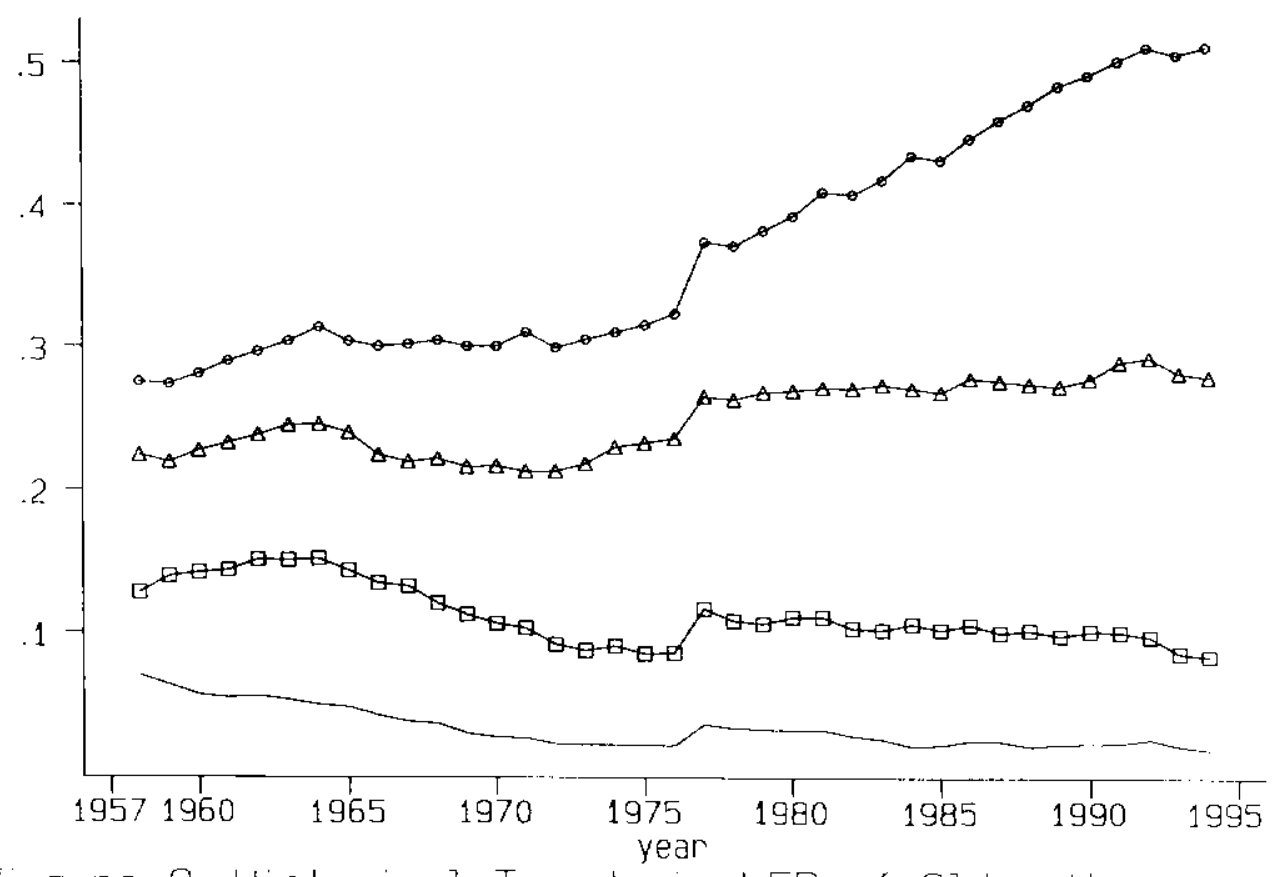

Figure 9. Historical Trends in LFP of Older Women 
- 3S venefits/pop $30+$

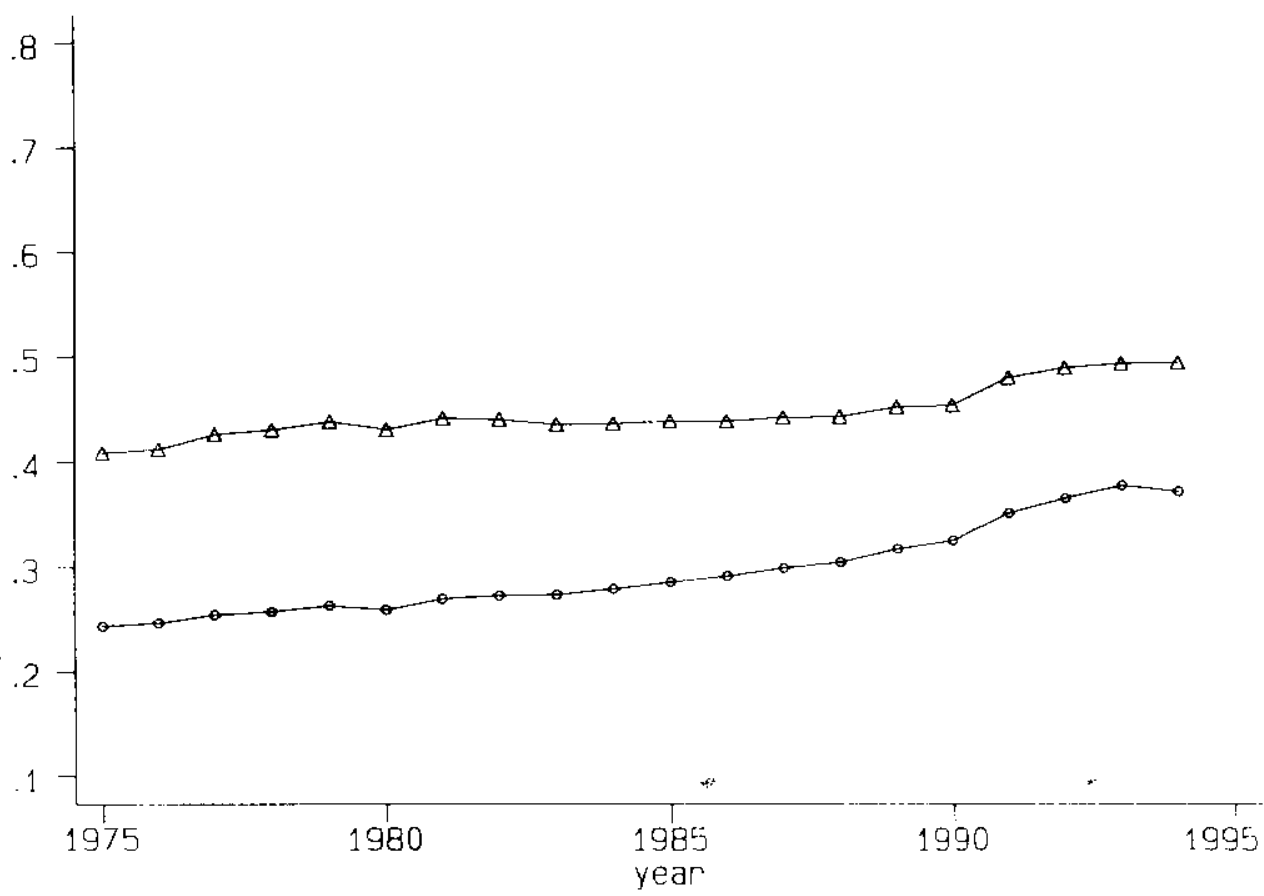

Figure 10. SS and DI Benefit Receipients - Age 30+ 


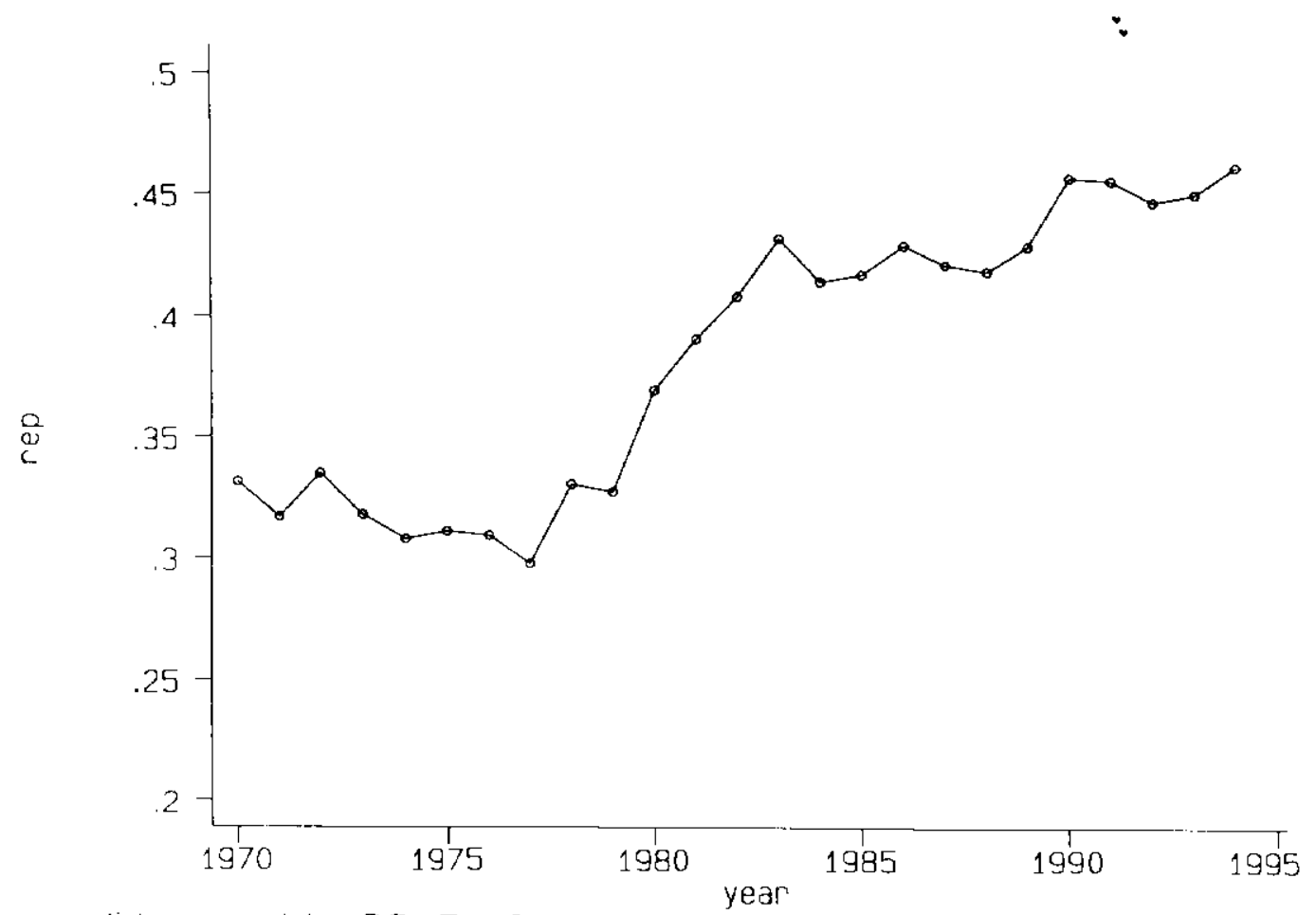

Figure 11. SS Replacement Rate Over Time - FPLO 


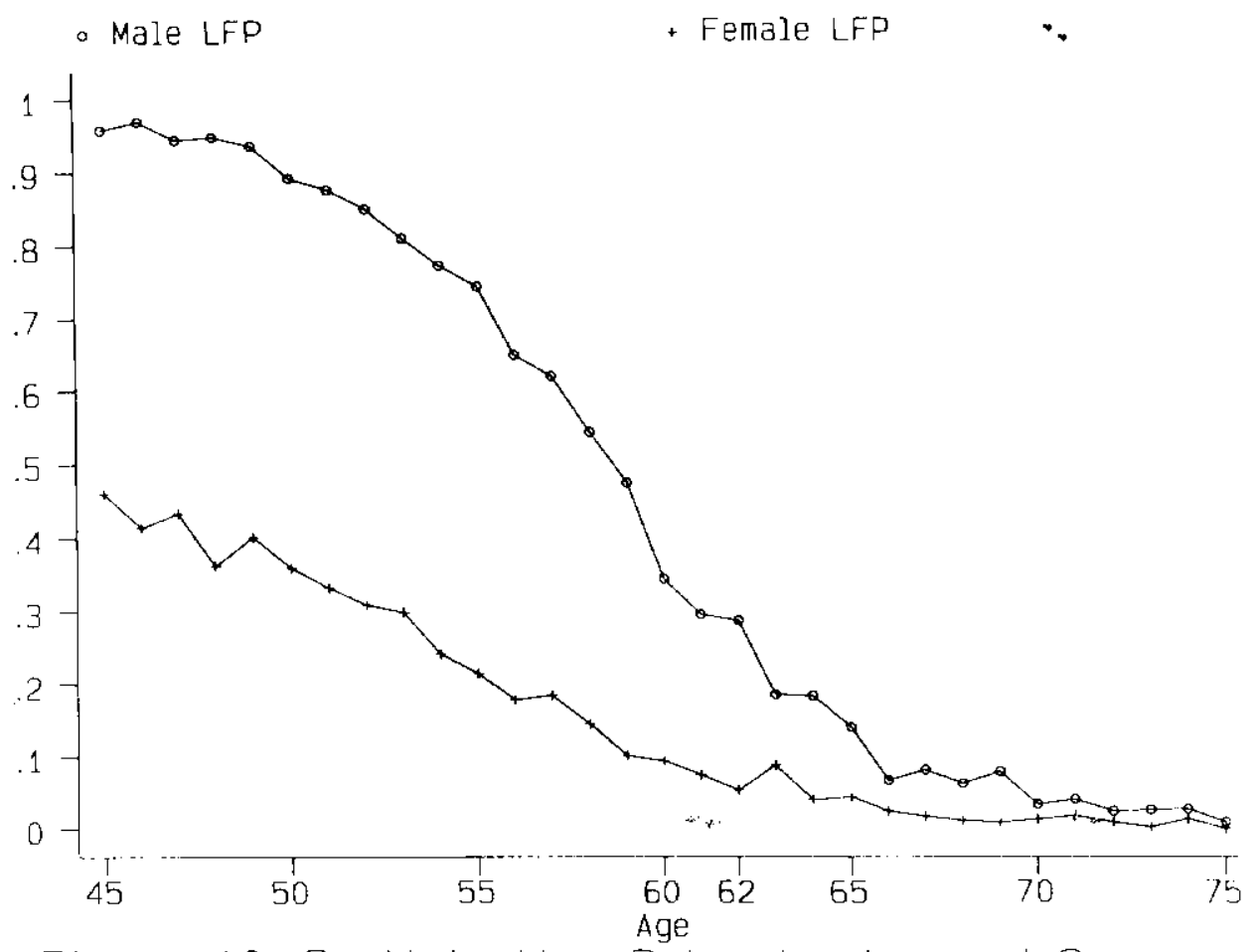

Figure 12: Participation Rates by Age and Sex 


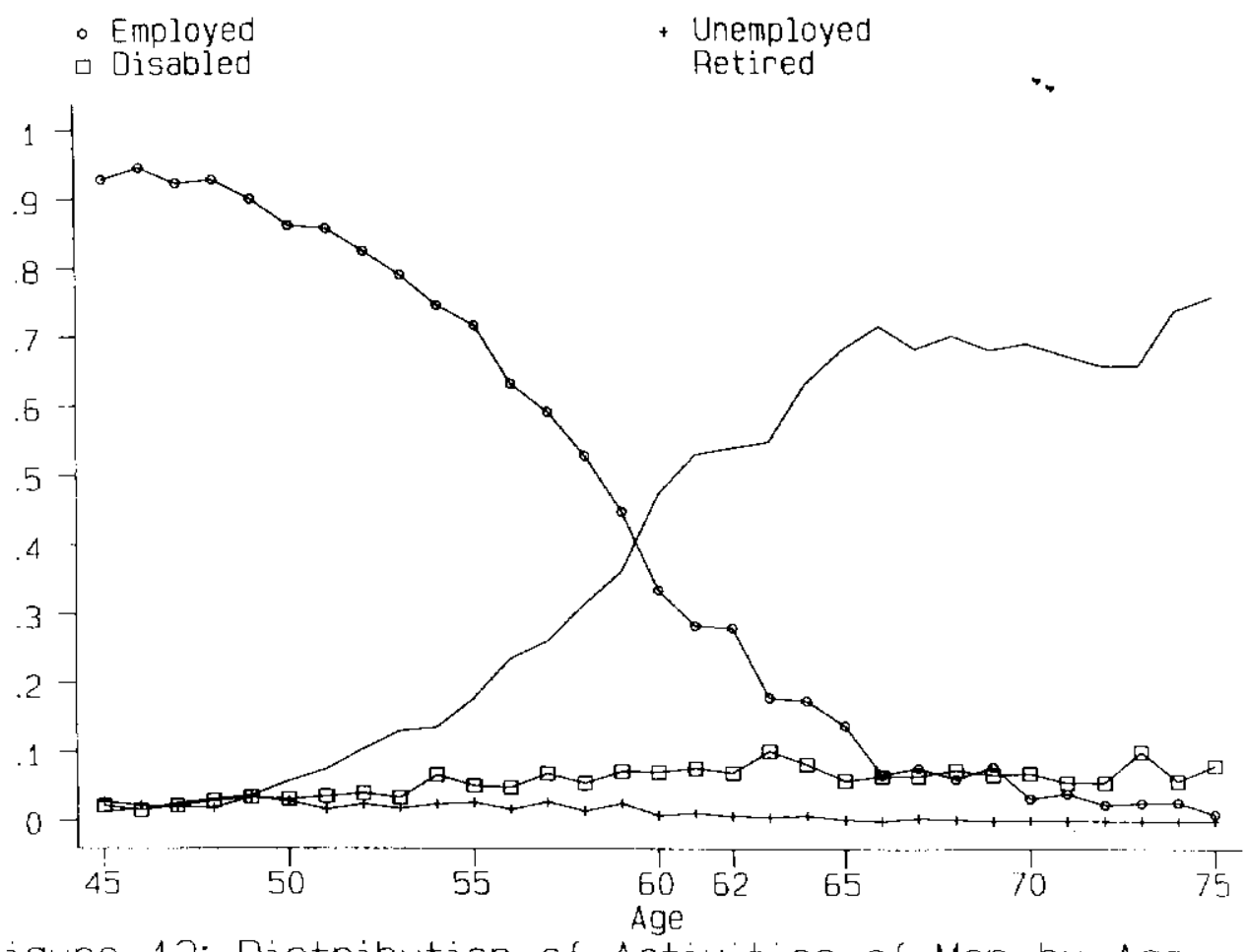

Figure 13: Distribution of Activities of Men by Age 


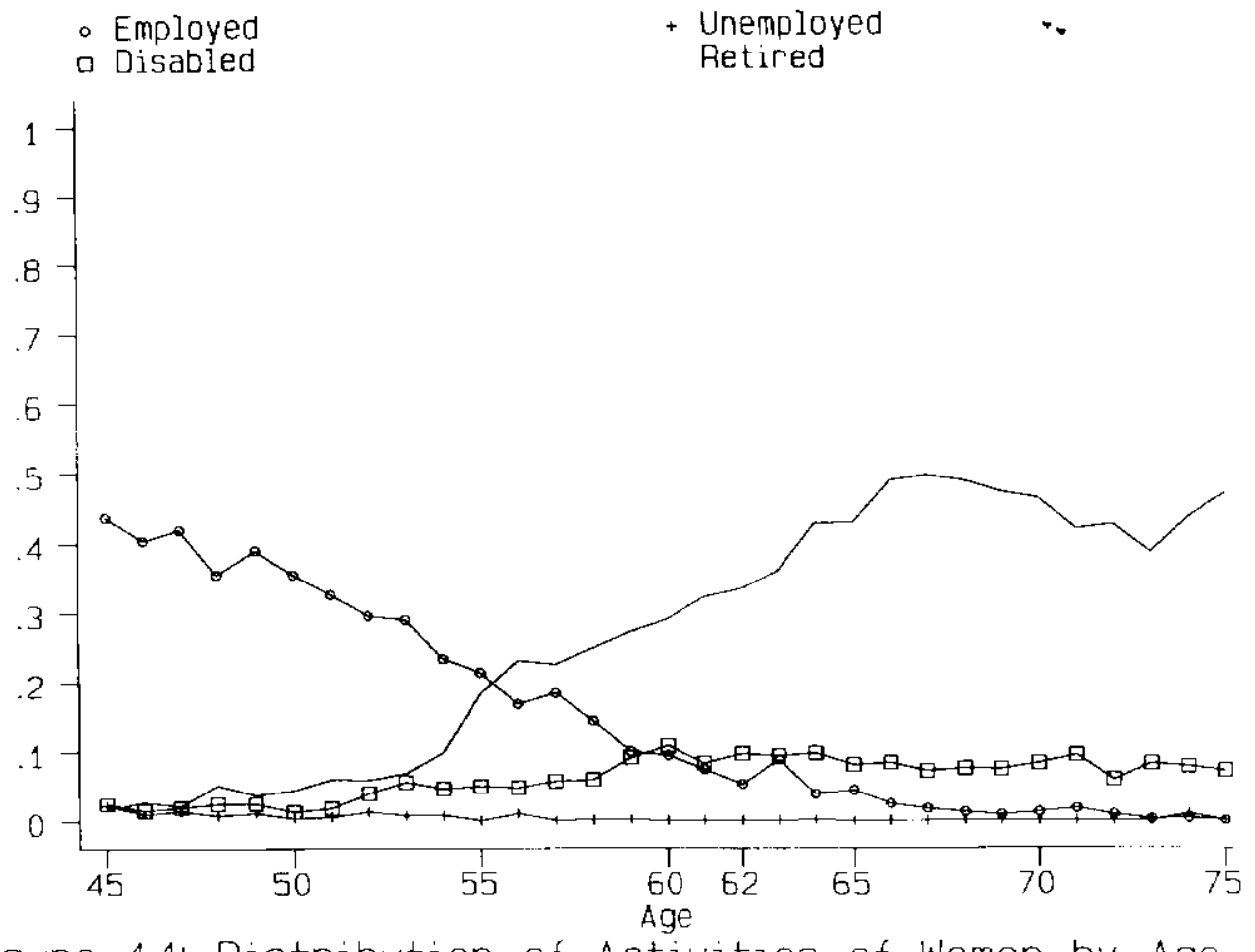

Figure 14: Distribution of Activities of Women by Age 


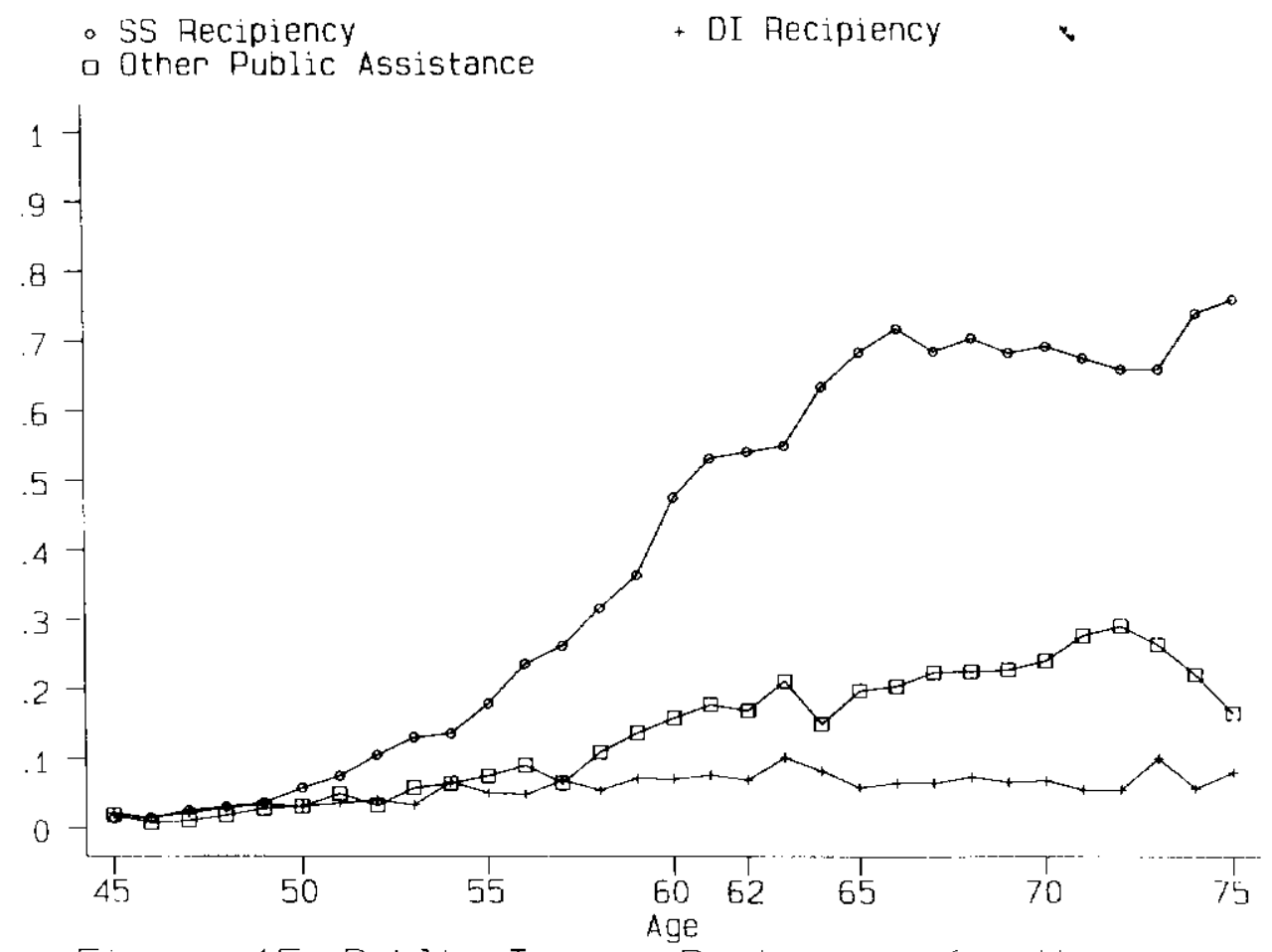

Figure 15: Public Income Recipiency for Men 


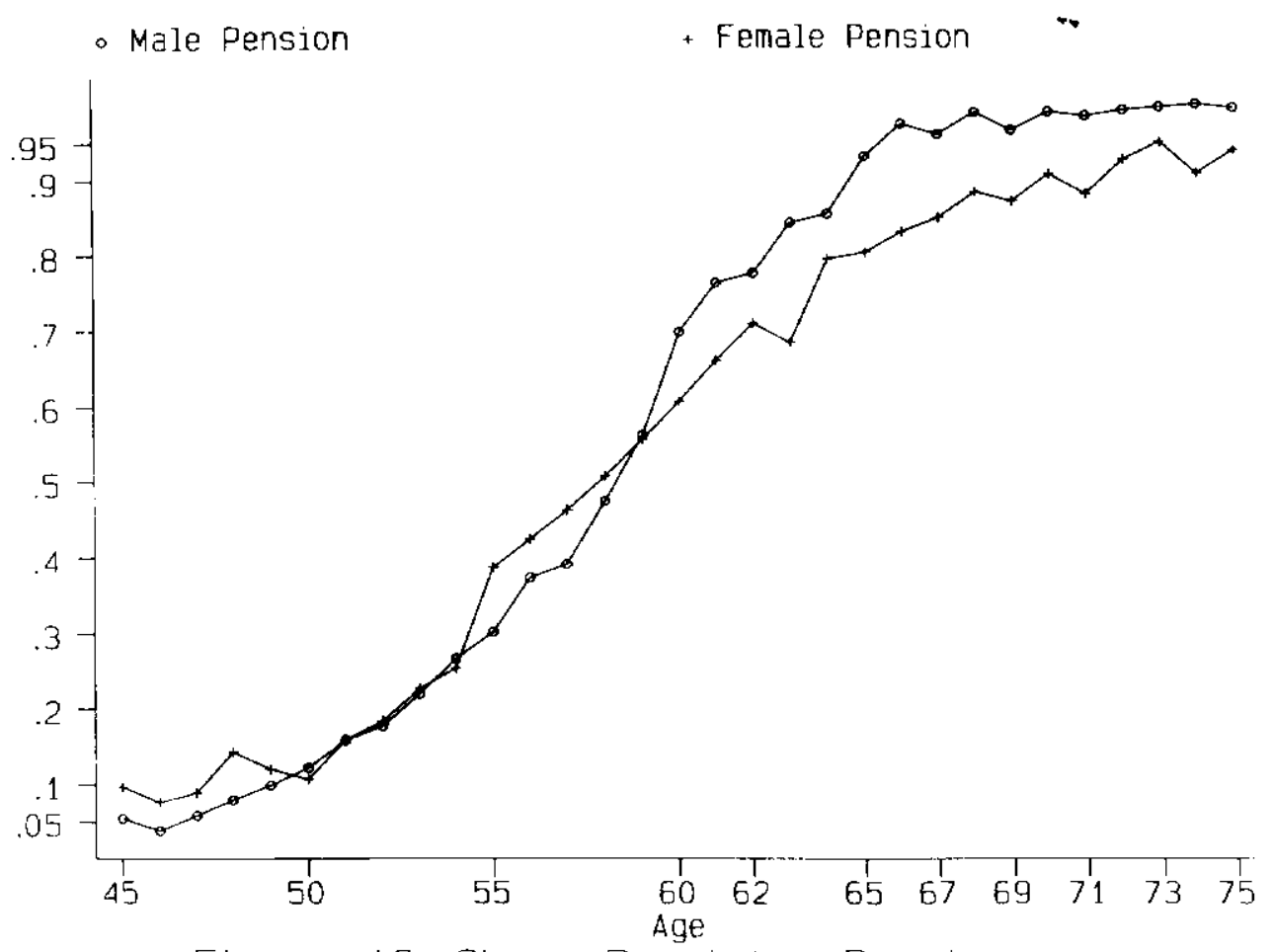

Figure 16: Share Receiving Pension 
- Earnings

- Public Assistance Income

+ Capital Income -.

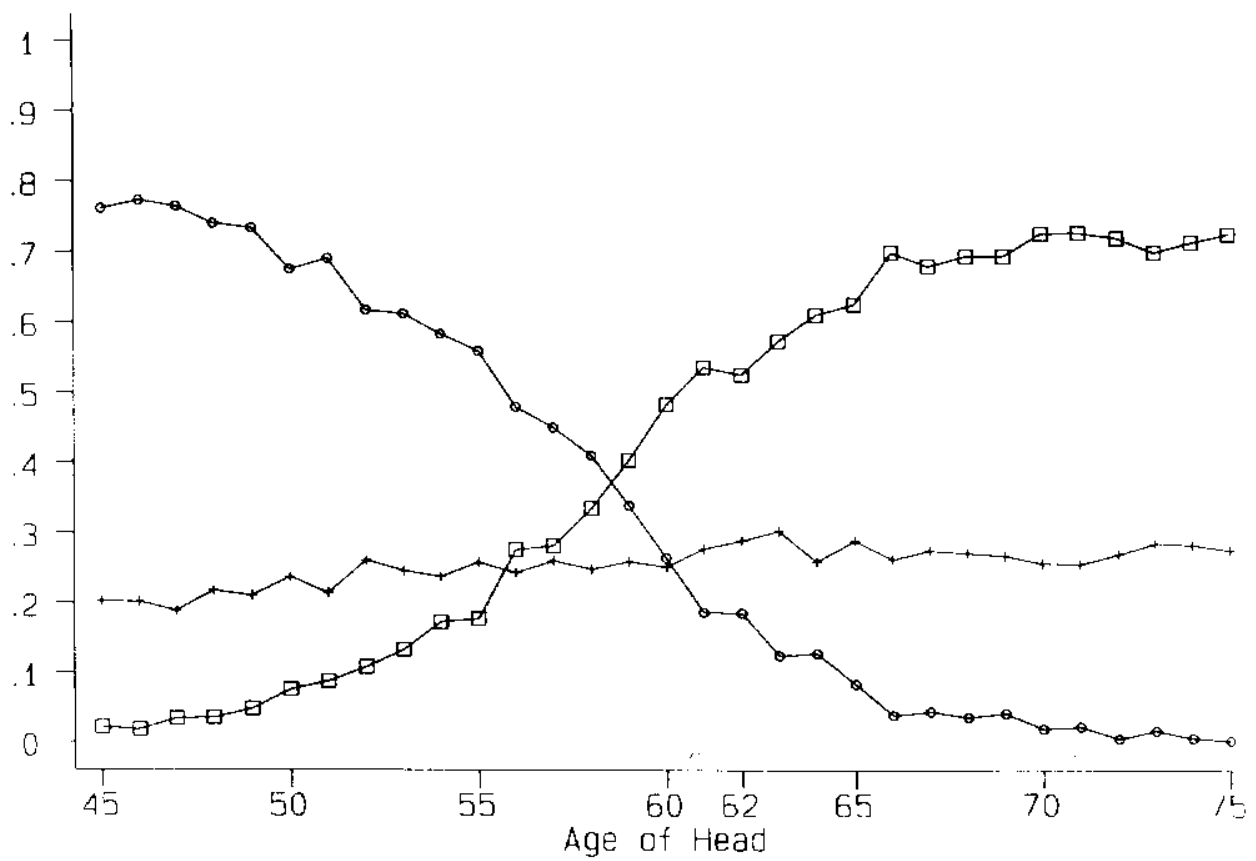

Figure 17: Distribution of Family Income by Source 


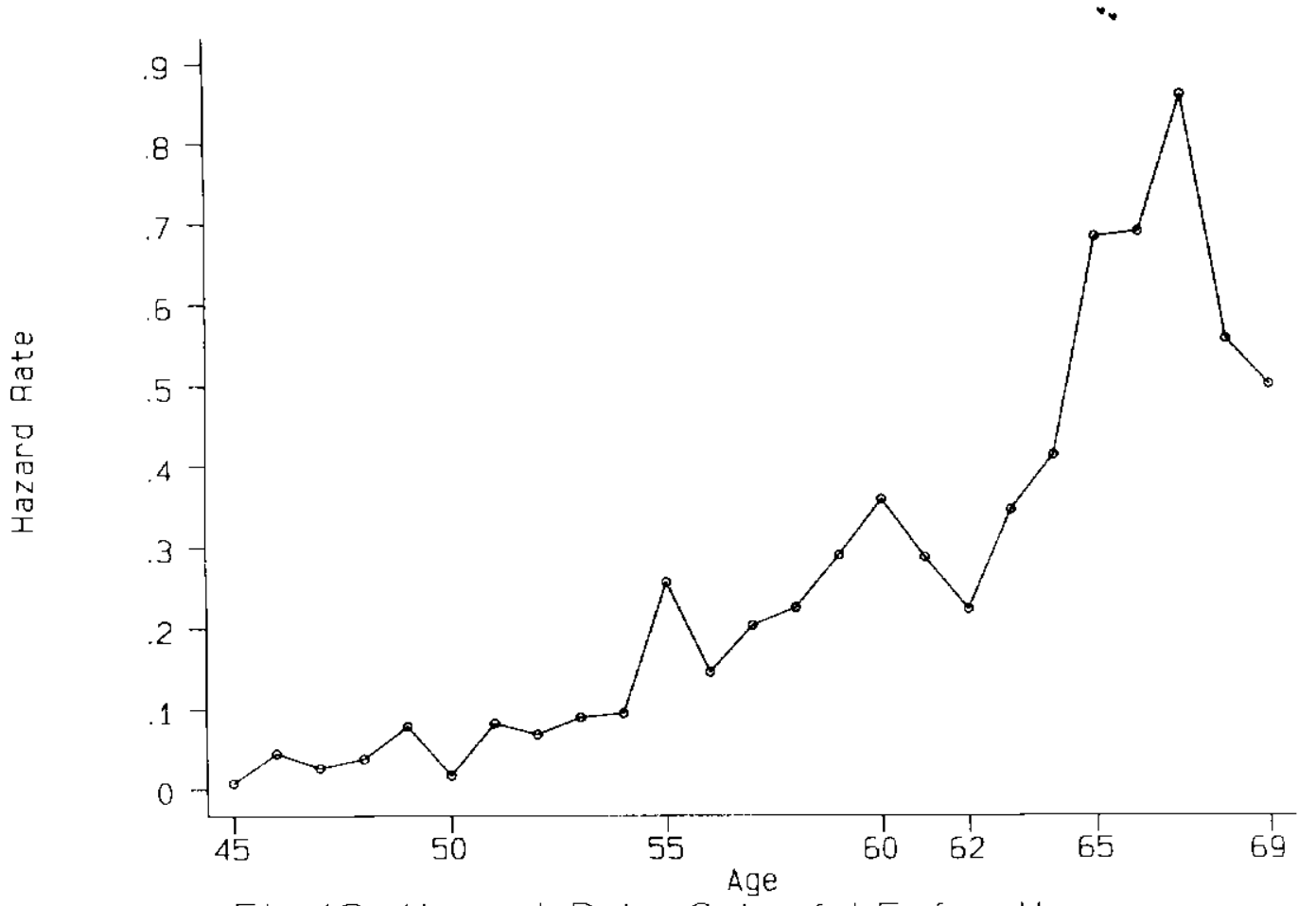

Fig.18: Hazard Rate Out of LF for Men 


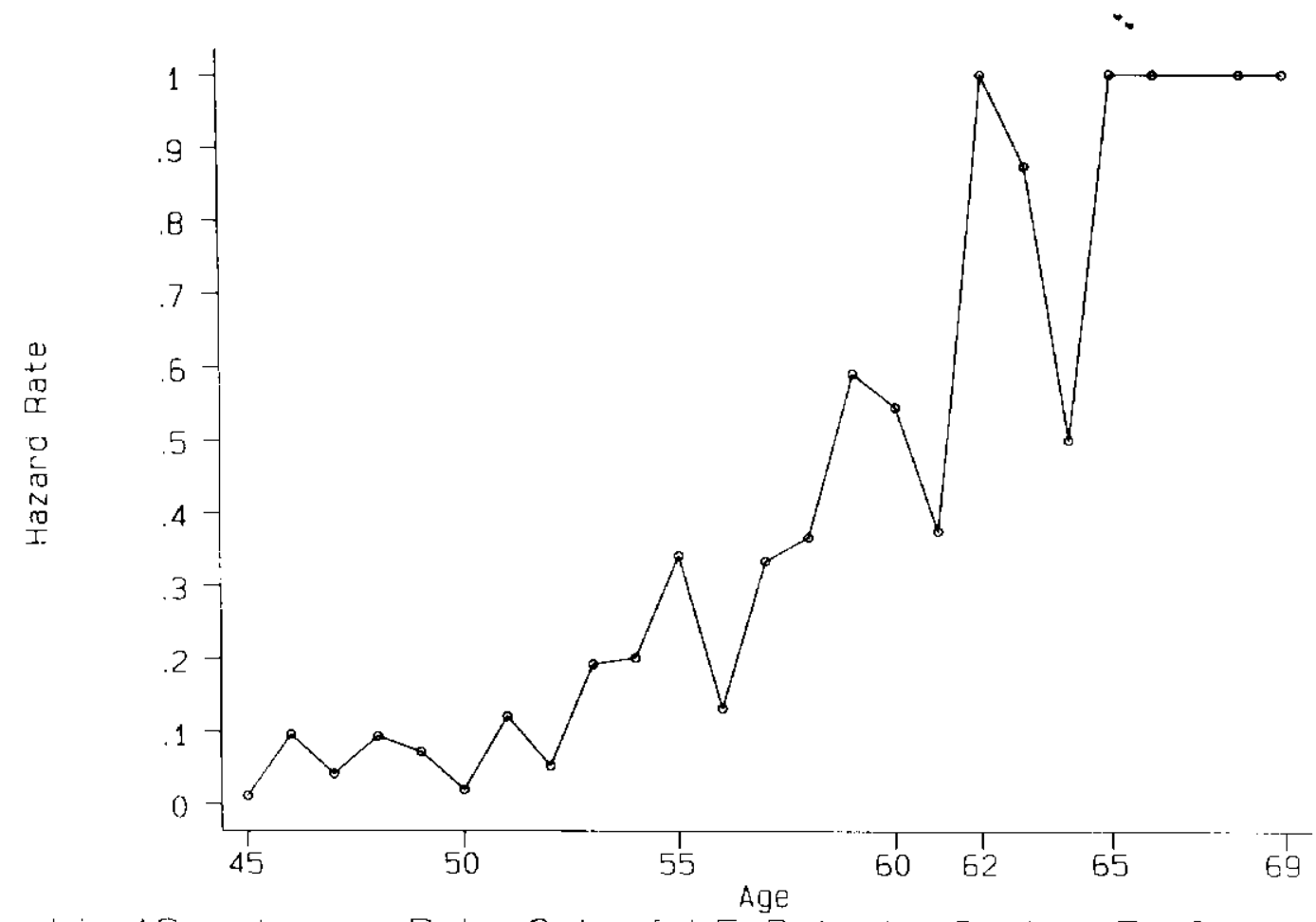

I ¿g.18a: Hazard Rate Out of LF-Private Sector Employee 


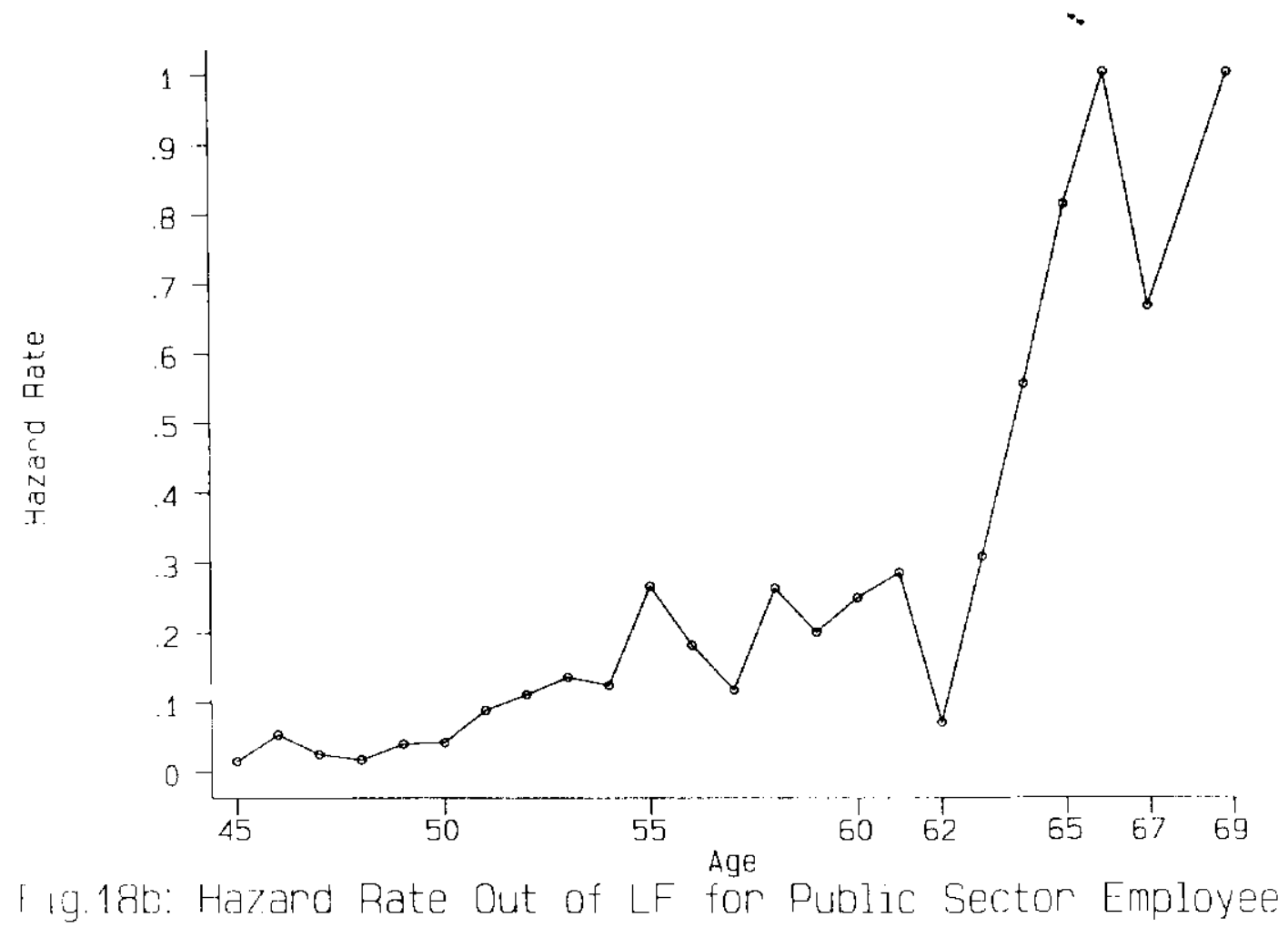




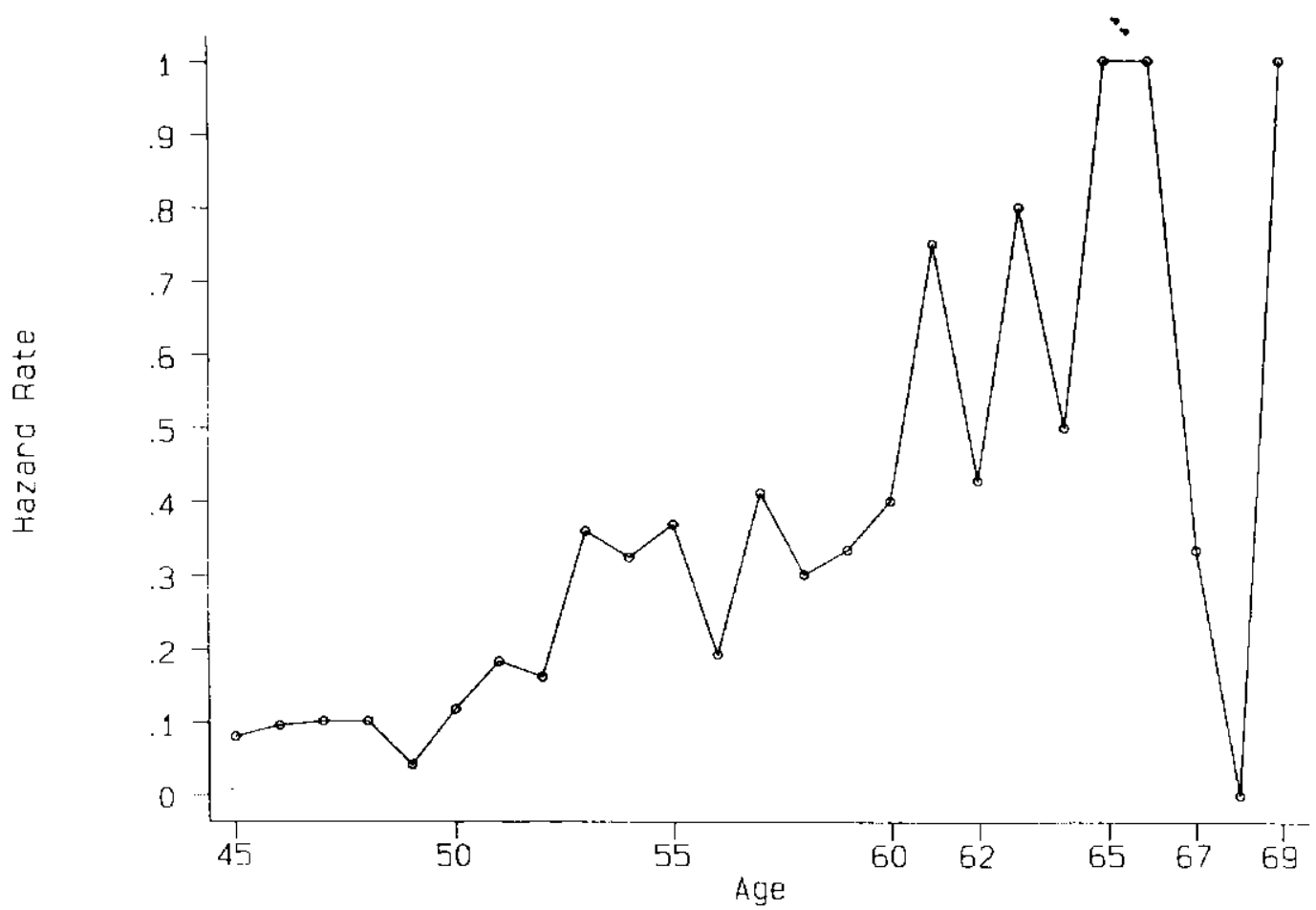

Fig.19: Hazard Rate Out of LF for women 


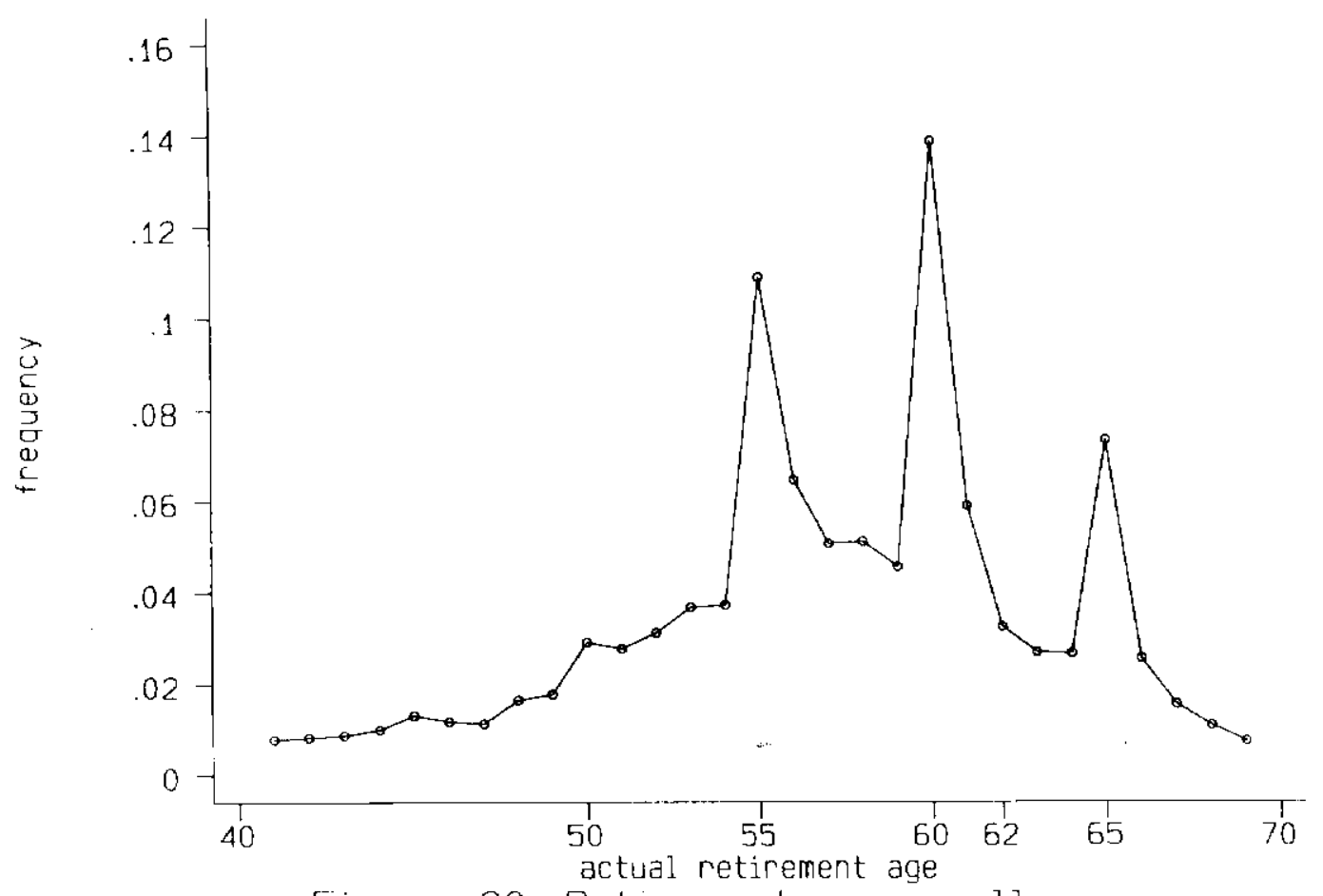

Figure 20: Retirement age - all 


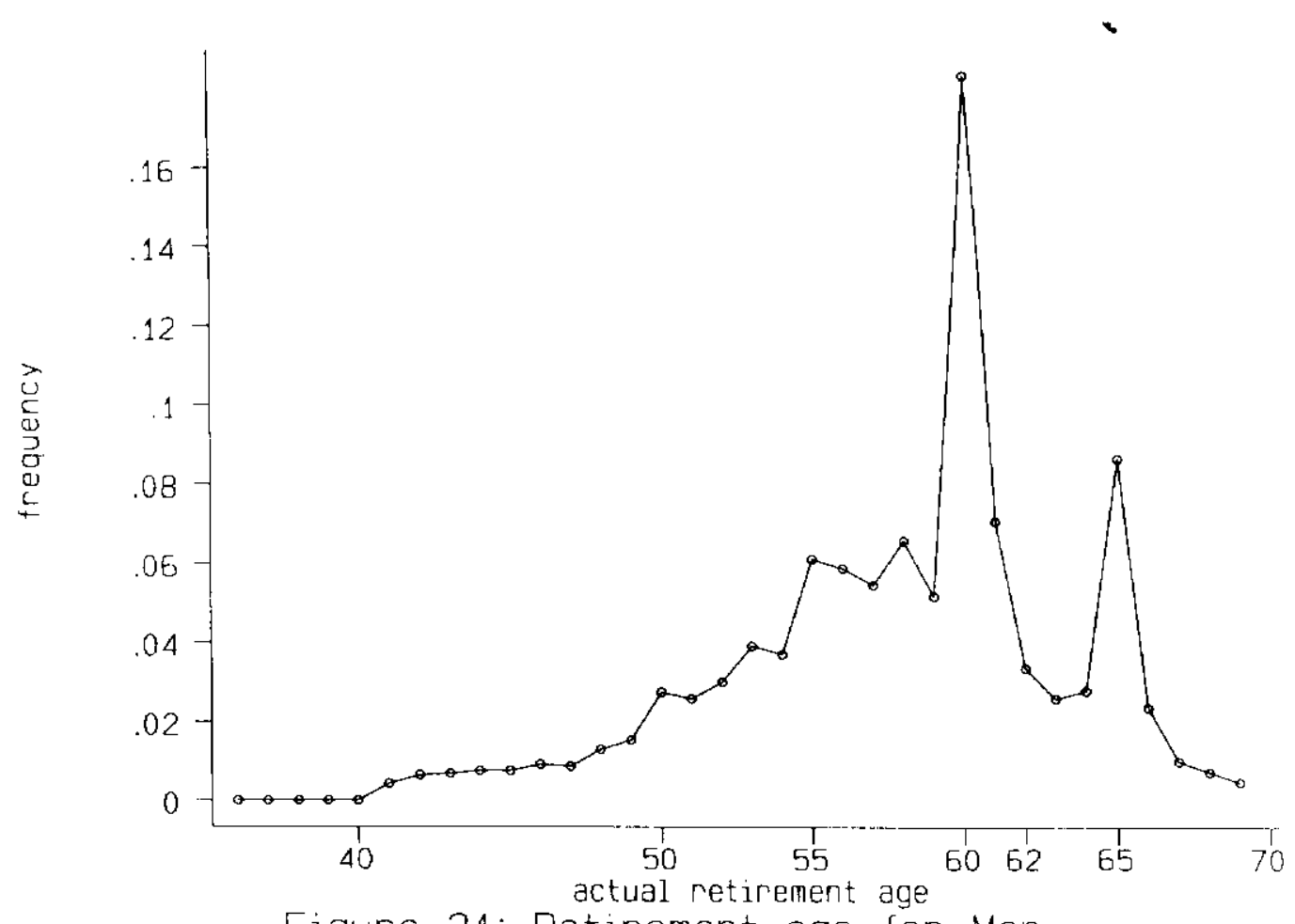

Figure 21: Retirement age for Men 


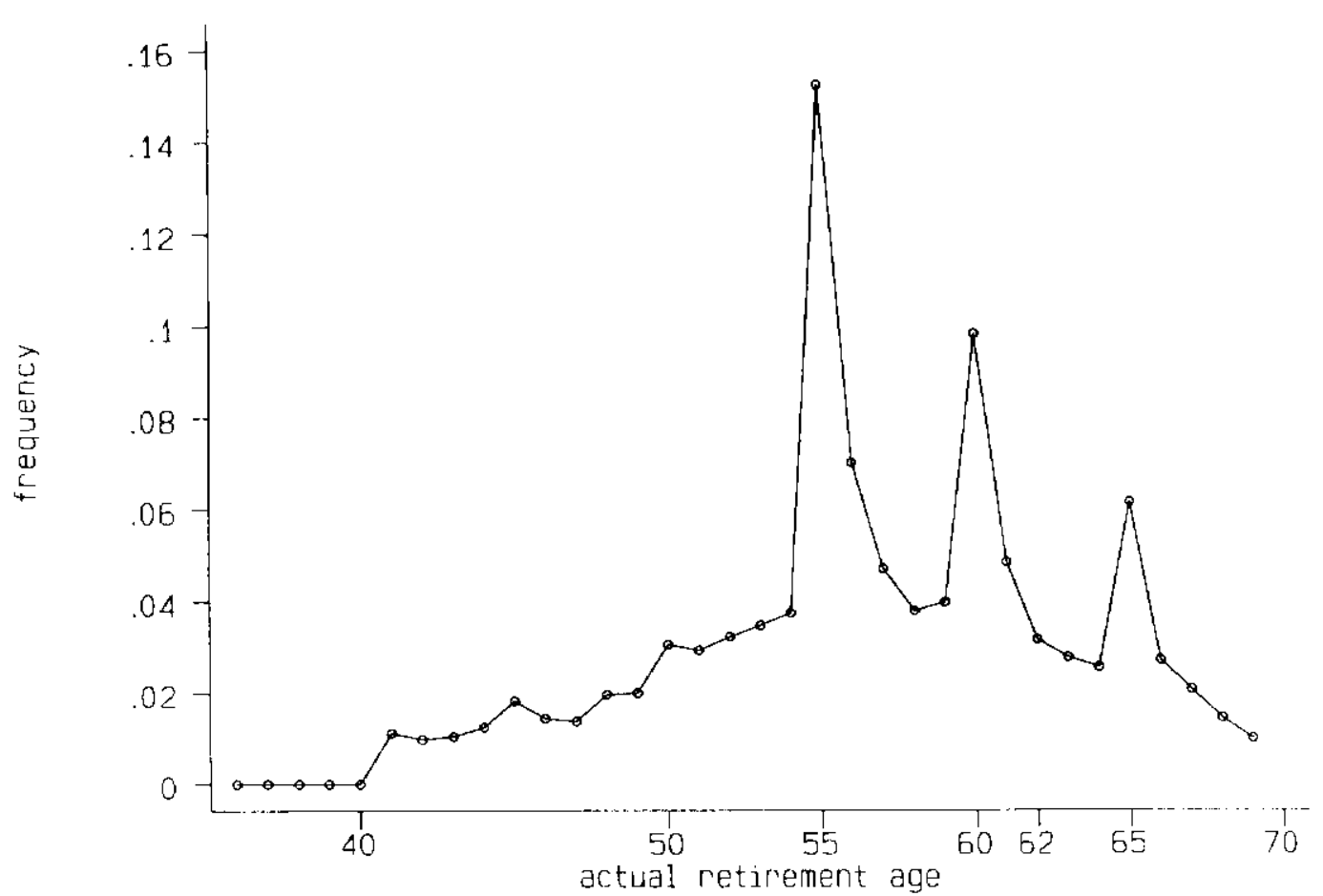

Figure 22: Retirement age for women 


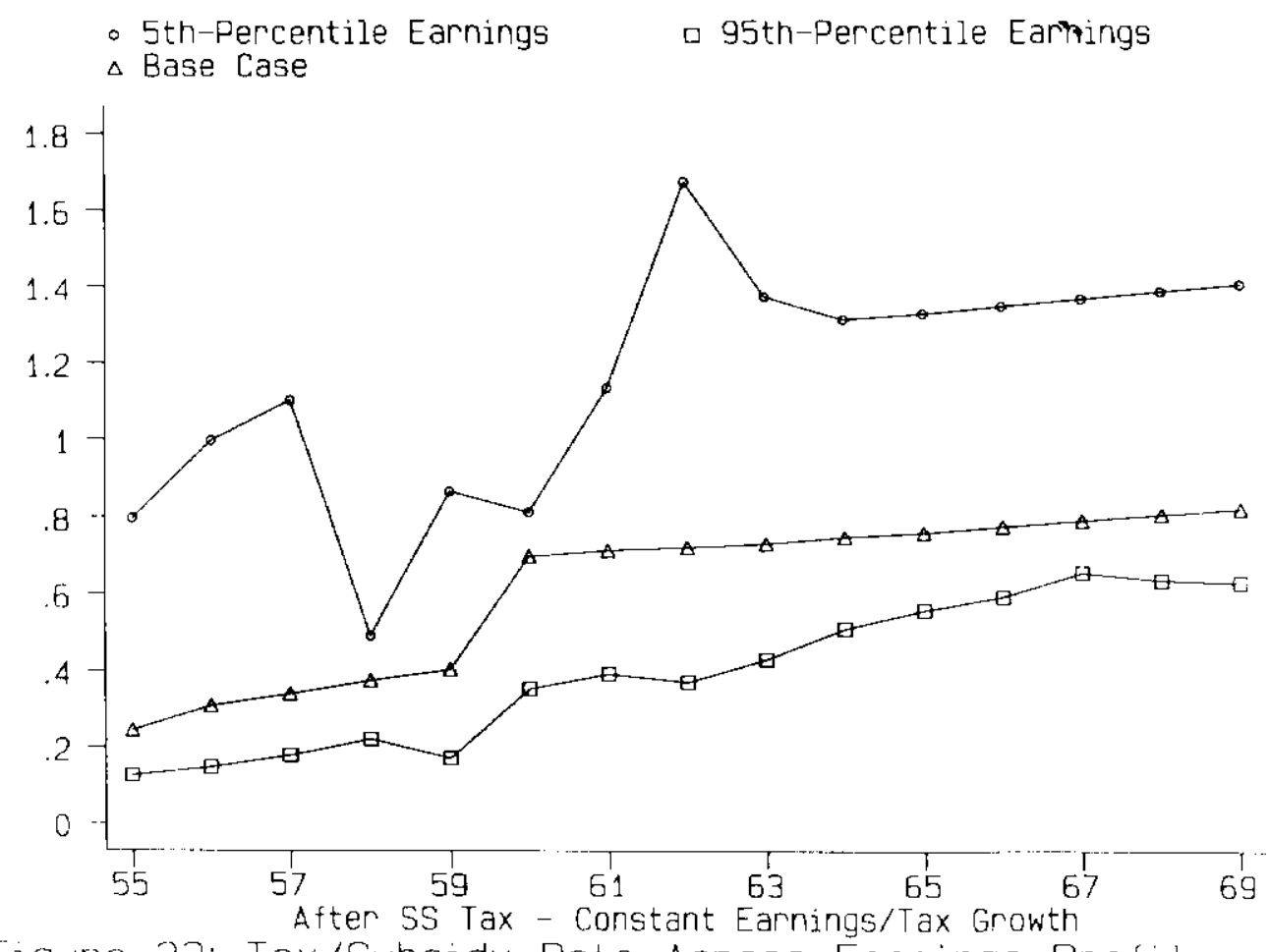

Figure 23: Tax/Subsidy Rate Across Earnings Profiles 


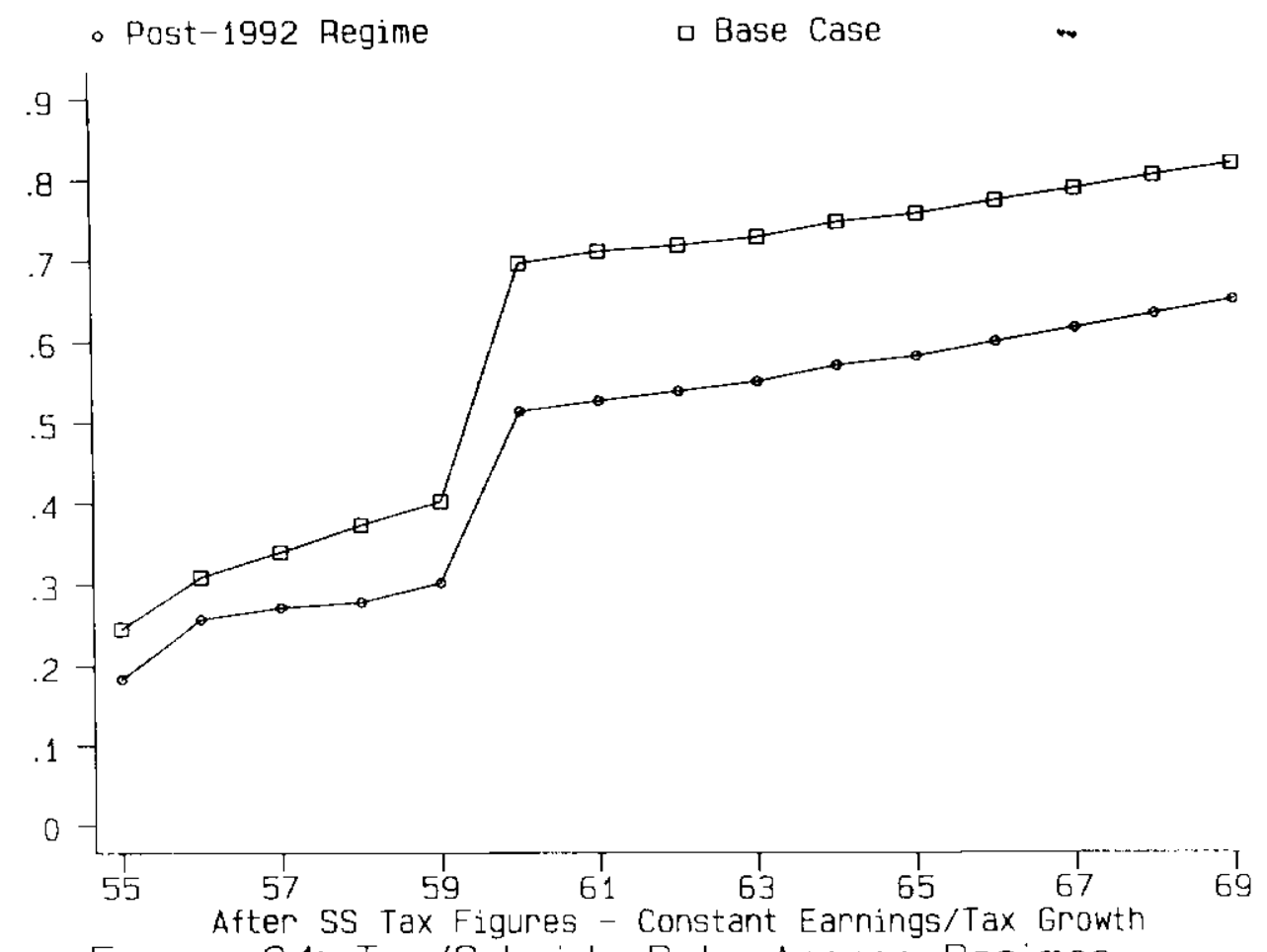

Figure 24: Tax/Subsidy Rate Across Regimes 


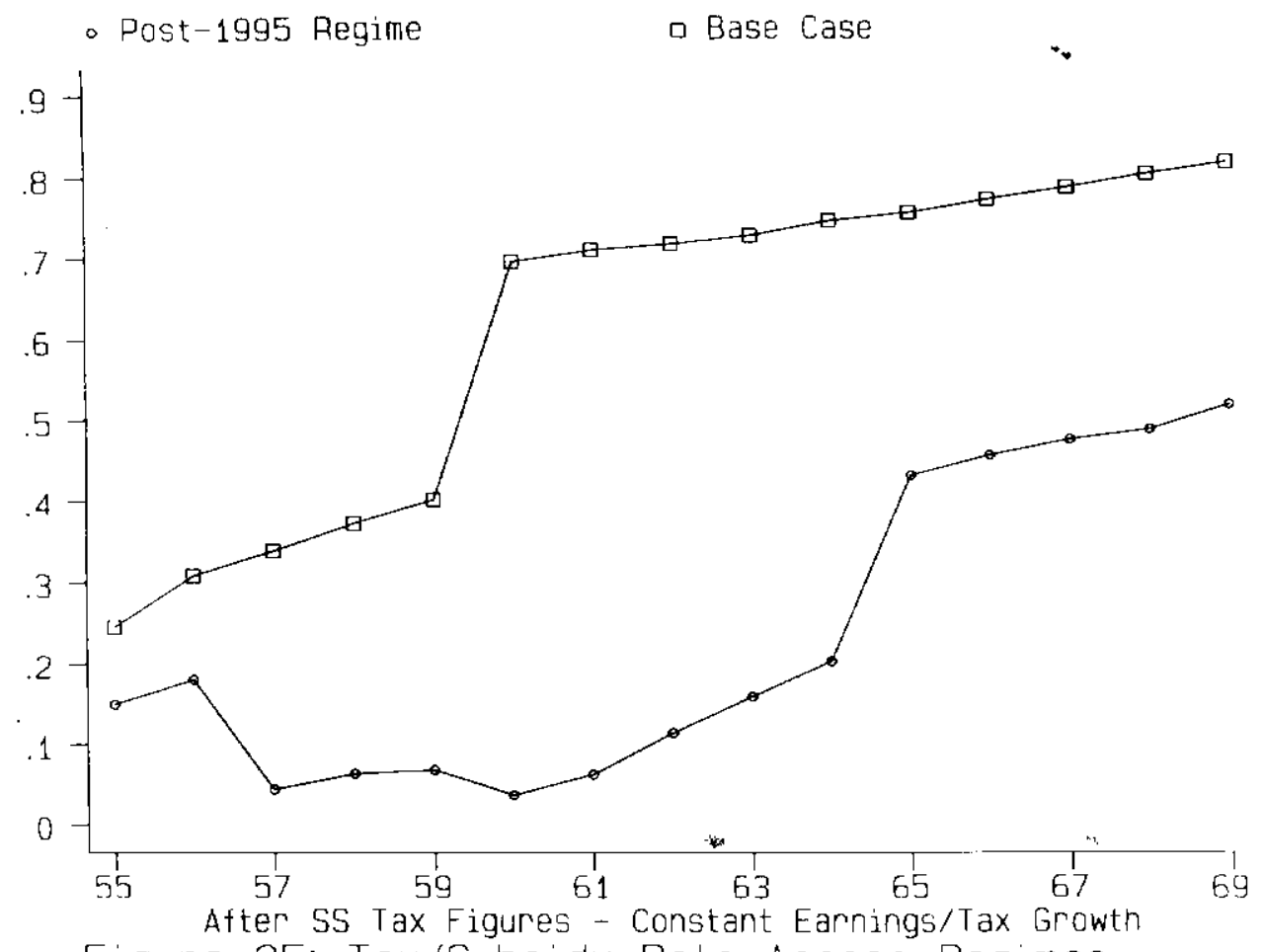

Figure 25: Tax/Subsidy Rate Across Regimes 
- Base Case

- Actual Growth Rates

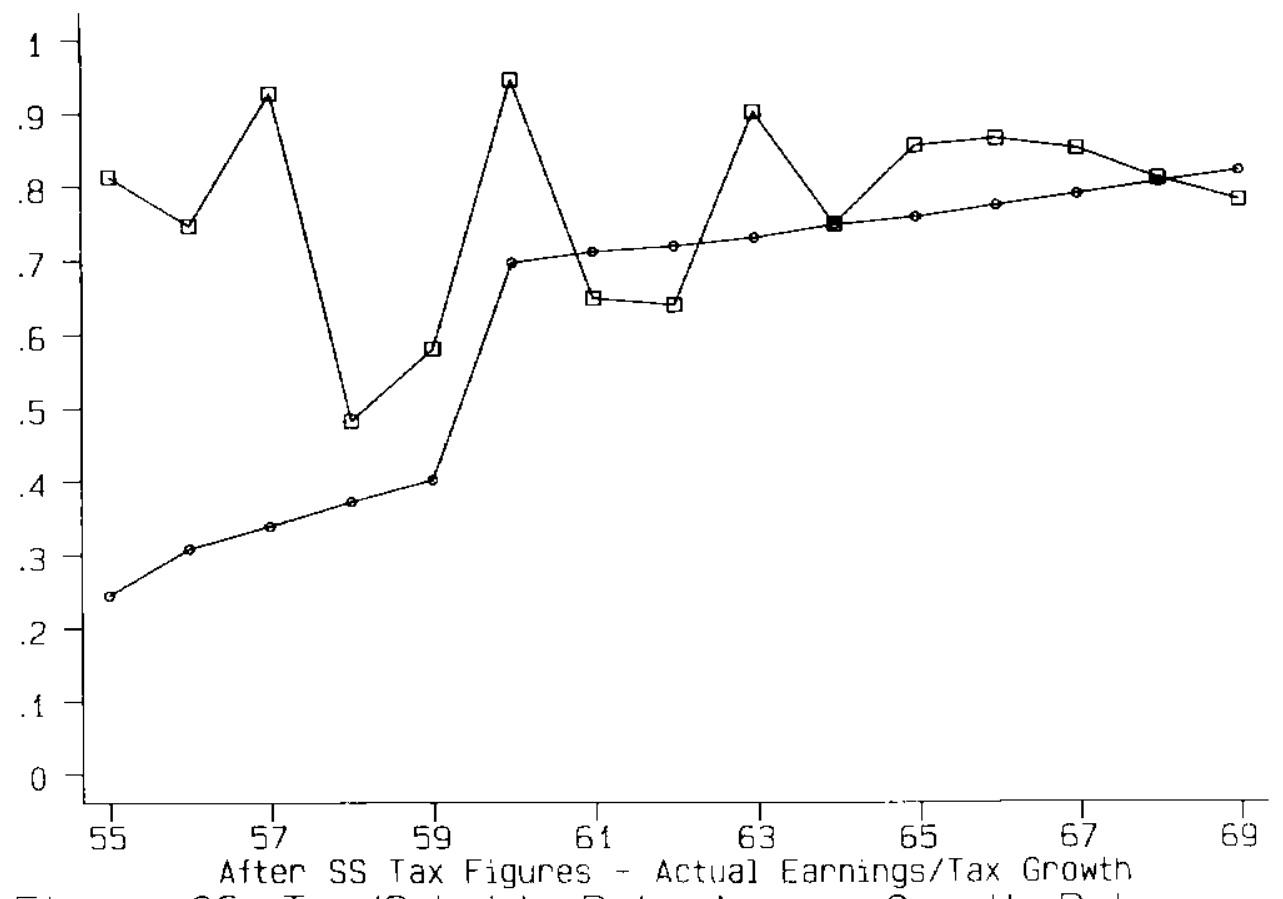

Figure 26: Tax/Subsidy Rate Across Growth Rates 
- Imp. Tax Private Sector

a hazard out of LF $\bullet$

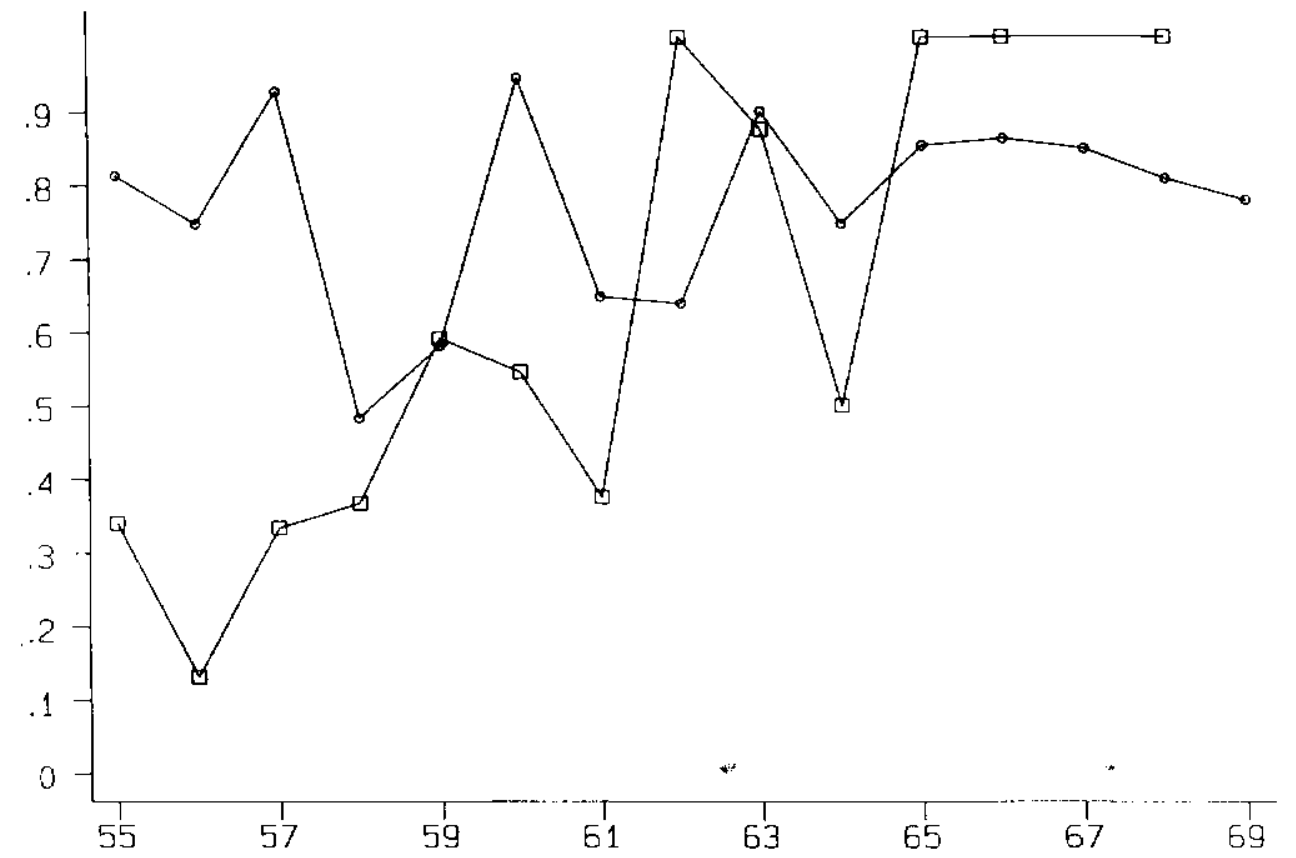

Private Sector - Actual Earnings/Tax Growth

Figure 27: Tax/Subsidy Rate Against Hazard 